Ideologies of computer scientists and technologists (Correctness beyond reason)

Camille Akmut 



\title{
Social conditions of outstanding contributions to computer science : a prosopography of Turing Award laureates (1966-2016)
}

Draft $^{1}$

\author{
Camille Akmut
}

\begin{abstract}
The Turing Award, commonly described as computer science's highest award and equivalent of the Nobel prize in that discipline, has now been awarded for half a century. In the following, we describe the social regularities that underlie and the conditions that embed these high achievements in computer science innovation.

We find, contrary to a meritocratic ideal of one's only abilities determining success or recognition within sciences, that several characteristics of scientists, exogenous and non-exogenous alike to their scientific work and identities, are of overbearing or disproportionate importance in defining academic acknowledgement. We find in particular that nationality or birth place, gender and one's network have a big role in making Turing Award laureates. As do social origins, with a significant portion of Turing Award winners coming primarily from middle- and upper-class family backgrounds, especially households with significant cultural capital (i.e. one or both parents hold an advanced degree or are engaged in an academic profession). Reviewing the data before us, we were also unable to ignore the non-participation of visible minorities and non-white computer scientists to the body of Turing Award recipients.

In short, place of birth, nationality, gender, social background, "race" and networks play a role in making Turing Award laureates. This paper also explores the ways in which a social history or sociology of computer science and the wider technology sector may unfold in the future, by discussing theoretical implications, methods and sources.
\end{abstract}

Keywords : computer science, history, sociology, gender, science, technology, ACM, Turing.

\footnotetext{
${ }^{1}$ A draft entitled "Social conditions of outstanding contributions in computer science : a statistical analysis of 50 years of Turing award recipients (1966-2016)" was presented in December 2017 at the German Center for Higher Education and Science Research in Berlin.
} 


\section{Introduction : A belated history of computer science}

It is a fact that traditionally, and today still, the history of science is mostly devoted to the study of the canonical scientific disciplines : mathematics, physics and astronomy, chemistry and biology.

Here, obscure scribes struggle with various number systems in the Mesopotamia of the 20th century BCE, but no word of Diffie, Merkle or Stroustrup whose contributions are at the heart of much of modern finance, commerce, technology and communication, the very ones that affect us, in the here and now of the 21st century.

Yet it is also a fact that there are very few other sciences that have as direct an impact on our lives and hold the potential of fundamentally transforming them as computer science does. Specifically very few who hold as much potential, both in good and bad, to simultaneously uproot, control and threaten them and likewise extend, preserve, document and transmit them.

Few other scientific enterprises permeate our lives and those of those we hold dear, down to their most intimate aspects, as that emerging discipline ${ }^{12345678}$. Who we are, how we think, how we communicate, and very likely in the future how we look, how we feel, how we see are just a few of these transformations. It is long overdue that the history of science abandons its cozy canon.

And, because computer science is a novel discipline, so is necessarily the

\footnotetext{
${ }^{1}$ Brin, Sergey and Page, Larry. 1998. "The anatomy of a large-scale hypertextual Web search engine" Computer Networks and ISDN Systems 30(1-7) : 107-117.

${ }^{2}$ Greenwald, Glenn and MacAskill, Ewen. 2013. "NSA Prism program taps in to user data of Apple, Google and others" The Guardian 07/06/2013.

${ }^{3}$ Sankar, Pooja. "Pooja Sankar: Building the Piazza Collaboration System" Computer $46(3): 6-7$.

${ }^{4}$ Hill, Phil. 2016. "Popular Discussion Platform Piazza Getting Pushback For Selling Student Data" e-Literate 10/11/2016.

${ }^{5} \mathrm{Li}$, Yanhong. 2002. "Toward a qualitative search engine" Internet Computing 2(4) : 24-29.

${ }^{6}$ Wildau, Gabriel. 2016. "Baidu probed after student death sparks outrage over online ads" Financial Times 03/05/2018.

${ }^{7}$ Hern, Alex. 2018. "Facebook logged SMS texts and phone calls without explicitly notifying users" The Guardian 29/03/2018.

${ }^{8}$ Ahmed, Maha. 2018. "Aided by Palantir, the LAPD Uses Predictive Policing to Monitor Specific People and Neighborhoods" The Intercept 11/05/2018.
} 
history of computer science ${ }^{9}$; but, better premature than belated.

There is a huge need for a science that looks at computer science, not from the internal point of view of computer science itself, which is concerned primarily with the technical aspects of the discipline e.g. the mathematical-electrical conditions of computer operations understood momentarily as central processing unit, arithmetic logic unit and control unit, and memory and input-output channels $^{1011}$, but from the external point of view of the history or the sociology of science ; one ideally that would make strange the technology we take for granted, familiar the unbeknown and alternatively exciting and revolting what is anticipated. This is meant as such a contribution.

It assumes that history is a worthwhile enterprise, and the social sciences in general, only in so far as they help us better understand ourselves, who we are, where we come from, the world we live in (currently), our current place inside of it, what is (currently), what was and what could be (including once more).

Brecht famously said that because things were the way they are, things will not stay the way they are. But, speaking on the responsibility of historians, perhaps it is to Marx that we should turn to when historians of science confuse their fascination for numbers, and their intellectual work, for their research objects, thus becoming little more than the lackeys of numbers that the German 40 economist from Trier once described.

In many ways, when looking at the state of the history of computer science and its applications we can say with little fear that we miss even the most basic of information when it comes to who, outside of a simple procedural history of computer science as a succession of big names, decides what is deemed significant enough to be brought to the attention of the wider public, what it is categorized as worthy of being financed or otherwise pursued and supported academically.

\footnotetext{
${ }^{9}$ We write specifically the history of computer science and not computing, the former we understand to mean in the strictest sense the academic discipline, the latter the much broader history of the attempts to create machines for purposes of automatic computation

${ }^{10}$ This description is based on a simplified Von Neumann architecture.

11 "The term "computer" is not well defined, and its meaning will change with new developments" (Newell, Perlis and Simon 1967).
} 
Who are the people who make the computing technology that we use? Specifically, who are those who have an above-average influence on its design and direction? And, further : what are the interests of those who make these decisions, their social characteristics, and so forth?

And, because premature in the case of the history of computer science and computer remains better in most instances than belated, we can answer : presumably 1 . white 2 . male 3 . heterosexual 4 . middle- or upper-class 5 . from a Western country 6. from the USA 7. from the coastal regions within the United States 8. educated at a handful of major universities.

And, because we know very little, on a fundamental level, there is a need for research that answers even the most basic of questions, before grand theories can be thought of as important.

We find ourselves in the same position as computer pioneers during the second half of the 20th century such as Forsythe or Gaurn who concluded that the domain was so new and vast, hence experimental research, though often considered inferior to theory and a detriment to a budding science, should precede general theories.

The topic of this paper will be on the social conditions of outstanding contributions in computer science and it is based on an analysis of half a century

E.g. Heidegger and the letters he wrote about his Jewish colleagues, the opportunism of Carl Schmitt, that only rivalled Heidegger's during the Nazi period, Sartre and the phone call he made to the Nobel foundation inquiring about the money after having declined it, Michel Foucault and what he did with the personal correspondence of his roommates and the questions on positivism he could not answer (so he made up something else instead), the college essays that Derrida submitted multiple times, the disdain held by Wittgenstein for academics, whom he must have considered barely more than sheeps, the narrowmindedness of Semmelweis' colleagues, Rousseau whose pedagogy stood in stark contrast with his own neglect of his children, the young woman that Rembrandt had locked up in a crazy house because he did care to uphold his promise anymore, Max Planck's opinions on women and women scientists in particular, the historian of science at Uppsala who rejected Foucault's doctoral thesis, but whose name is now only remembered in connection with that event, the colleague of Dover at Oxford he hated so much he could have killed by his own dmission, the Lacour and Green study that never was but still made it in Science, the University of Chicago's department of economics' apparent lack of any common sense or moral compass in admitting a former Goldman Sachs trader who had boasted of swindling "widows and orphans" during the subprime morgage crisis to its $\mathrm{PhD}$ program, etc..

${ }^{12}$ To break with the myth of the intellectual once and for all, one would be well advised to read the biographies and autobiographies of any number of scientists or academics or artists. 
of Turing awards.

\section{Research directions and methods}

The analysis of outstanding performances, in academia and elsewhere, presents a particular challenge to social sciences in so far as these high-achievers, either by own conception or through common sense notions by mainstream entertainment, journalism, popular science or idealistic scholarship, tend to appear as not bound by the same rules as common lives, the same passions, the same appetites, the faults, the malice, even the pettiness ${ }^{12}$.

In what is arguably computer science's most famous book, The Art of Computer Programming, one can find such notions. Indeed its author, Donald Knuth, tells us that he wrote the series for "the one person in 50 who has this strange way of thinking that makes a programmer" ${ }^{13}$. In turn, those who find themselves to be among that number, should be highly supportive of such arguments in the process of being elected amongst the lucky few.

In another of computer science's revered works, Structure and Interpretation of Computer Programs, one learns against expectations from the very beginning that computer science : is not a science, is not about computers and is according to its authors, Sussman and Abelson of MIT, closer to magic.

But, the aim of such a work is not purely for bravado. While demystifying such notable careers may be one of its effects, it can be and it is encouraged to be read as a way to make appear closer and more attainable, at least more reasonable and realistic, the important, useful and far reaching innovations due to Turing Award winners, in the areas of programming languages, databases, electronic circuits and AI to cite just a few.

Starting this research, we had tried to apply classic research questions from the history or sociology of education, of which here are some below.

Is an education at a prestigious college a requirement for great achievements

\footnotetext{
${ }^{13}$ Knuth 1997b.
} 
such as the kind recognized the Turing Award? More precisely, does such an affiliation predict the potential for these accomplishments and if so to which degree? Further : is the study of computer science as a degree necessary to make contributions within that field? If not, is a degree in a science subject necessary? Is precocity an indication of future greatness?

While these are worthwhile objects of research, they were not what we found to be the most interesting relationships between winners and the Turing award. We did however answer them : we found most of what could have been expected from a research on international scientific prizes, like the Nobel, namely that recipients were much more likely to have been schooled at institutions located on the coastal areas of the United States, in the prime educational regions and also computing centers of California and New England.

Intimately linked to questions of educational origins are those of social origins in the study of higher education. These we handle as well. They remain, no matter how out of fashion they may have fallen with certain researchers who believe themselves to be living in post-classes societies, which they can only conclude because they do, important.

while looking at the data and reviewing and analyzing it, we were drawn to different outlooks : coming rapidly to the conclusion that women, of which only 3 had won the Turing award since its creation, and none up until 2006, which is to say none for the first 40 years of its existence, were grossly underrepresented among Turing award winners in extents we had rarely met before, we moved to review the Turing Award from the perspective of the history of gender in science, largely a history of gender inequality and in large parts also exclusion for much of its time span.

We wanted to firstly establish these facts about the participation of women in computer science at its highest levels, but also to understand the situations of the few women who had made it this far and what had brought them to be recognized in their specific fields of study.

Reviewing the data still, we found that Turing Award laureates were bound by many personal relationships : some had been advised by former winners, 
some had studied under them, others had written articles with them, before being themselves awarded the prize, some even many of these things at the same time. And, so, a network analysis helped us visualize these links between Turing winners.

The lack of diversity in places of birth, nationality and ethnicity or "race" amongst Turing Award laureates, was impossible to ignore, with the great majority of them white, U.S. American and to some small degree European.

Finally, a comparison with a similar award soon appeared to be essential and proved very helpful. This helped objectify structures and relationships and unveil inherent qualities, and in turn distinguish those from statistical artifacts, by creating a variety of relevant reference points.

This research was structured in the following way : a prosopography paired with statistics and followed by conclusions as well as theories on the social regularities that preside over "genius" i.e. high-achievement in computer science.

\section{Data : or how this study was conducted}

Our primary source, for much of the statistical work, were the Turing Award

140 biographies provided by the $\mathrm{ACM}^{14}$.

They contain series of information, themselves already partially coded into categories, such as "Birth", "Education", "Experience" and "Honors and Awards". They provide indications as to date and place of birth, degrees obtained and where these were obtained from, places of employment, etc.

As such, they were perfectly suited for the type of study undertaken here, called prosopography or collective biography, though we did not keep with the categories provided and sometimes had to complete or extend what was found in the notices with other sources when information was lacking or non-existent. Unfortunately, not all laureates' biographies featured the same level or depth of 150 information.

\footnotetext{
${ }^{14}$ https : //amturing . acm.org
} 
Of prosopography, Lawrence Stone wrote (has written) that it "is the investigation of the common background characteristics of a group of actors in history by means of a collective study of their lives. The method employed is to establish a universe to be studied, and then ask a set of uniform questions - about birth and death, marriage and family, social origins (...), place of residence, education" 15 .

Historians of science accustomed to working in previous centuries or on more established societies, or, as in this case, disciplines, as well, can think of this collection as they do of the Biographical memoirs of Fellows of the Royal Society, which contain biographies for all deceased fellows of the society, with the exception that of the Turing Award biographies we lack sometimes mention of authors ${ }^{16}$, almost always a bibliography and the extent of the information provided does not come close to the on average 20 pages long memoirs.

We have also used other types of information on the ACM, partly produced by itself, as in the case of the Royal Society, partly derived from other scholars, often writing within ACM publications, such as compositions of prize juries and leading committees.

A standout publication that we have relied on in addition to the aforementioned was the biographical dictionary Computer Pioneers by J.A.N. Lee ${ }^{17}$. Of much help were also the oral histories conducted by the Computer History Museum and the British Library with individual Turing laureates. In some cases, we used less conventional sources, such as when we relied on the curriculum

Series for the History of Computing", jointly with Tomash Publishers of Los Angeles and San Francisco, such as Babbage's Calculating Engines: A Collection of Papers, as volume 2, The Papers of John Von Neumann, volume 12, and various other writings including by Turing Award laureates such as Maurice Wilkes or Donald Knuth.

${ }^{15}$ Stone 1971.

${ }^{16}$ No author is mentionned in the case of John Hopcroft for example.

${ }^{17}$ Lee 1995.

${ }^{18}$ The MIT Press has done perhaps more than any other publisher to promote publications on the history of computer science and its applications, including their various social implications, with series such as "History of Computing" and "Inside Technology" and publications like Abbate's Inventing the Internet and Recoding Gender. In those same collections, see also Hicks 2017 and Lecuyer 2006 on respectively the situation of pioneering female computer scientists in Britain and the early history of Silicon Valley. This is in addition to the collection of primary sources and original writings published in the "Charles Babbage Institute Reprint 
vitae uploaded by Turing Award laureates to the internet. Many monographs published by the MIT Press have also been of general use to us ${ }^{18}$.

This information was then aggregated and integrated into a database. The outcome of that process is a table with 64 entries, one for each Turing Award recipient, each in turn containing 39 columns, or the equivalent of about 2500 individual information.

This study comprises all Turing Award laureates from 1966 to and including 2016, from Alan Perlis to Tim Berners-Lee.

That being said, the data provided by the ACM was not always perfect. This we discuss separately in the following subsection.

\subsection{Problems with the data}

The problems were multifold. There were errors and inconsistencies or simply absence of information. We provide some examples below.

In what appears to be an indication of nationality, that of Iverson is listed as "United States" instead of Canada. In John Backus' Turing award biography "Université Henre Poincaré" is misspelled, it should read "Henri Poncaré" after the mathematician. Leonard Adleman's file mentions "Berkley" instead of "Berkeley". The information provided on Joseph Sifakis is at odds with that provided by Britannica ${ }^{19}$ where education is concerned and incomplete in any case.

In three cases, Rabin, Dahl and Naur, we have no information available on their undergraduate degree ; all three of whom were born outside of America. In these cases, we assume for undergraduate institution the university that granted their masters degree as a proxy (as in all three cases, information becomes available again at that level).

Kenneth Thompson's bachelor degree is listed as "EECS", for Electrical Engineering and Computer Science, and as having been obtained in 1965 by his Turing Award biography, though we are not certain this is possible or correct,

\footnotetext{
${ }^{19}$ Hosch 2015.
} 
considering that the Department of Electrical Engineering and Computer Sciences at Berkeley was only founded in 1973 while the Department of Computer Science which preceded it had only been or begin to be established in $1968^{20}$.

Leiden University is unusually referred to as "University of Leyden" in the biography of Edgar Dijkstra, and although this spelling, of the city and by extension its university, appears in several older English publications ${ }^{21}$, it seems rare.

Sometimes euphemisms are used, such as in the case of the biography of Antony Hoare whose parents, we learn, "were involved in the business of what was then the British Empire" to mean that his father was a colonial civil servant and his mother the daughter of a tea planter.

In the most extreme of cases, we found errors up to and including in the citations of the laureates themselves : facilitate is spelled "facilitiate" in Wilkinson's, while the rather uncommon "subsequentially" is used in Newell's.

For them, we had to supplement information with other sources whenever necessary, which we list.

Sometimes, the data, correct, needed to be normalized. We record for instance the Carnegie Institute of Technology as CMU and the New York State College for Teachers as the State University of New York at Albany.

\section{The Turing Award and the ACM (1947-2018)}

The Turing Award was created in $1966^{22}$. In the ACM's own words, the Association for Computing Machinery, which oversees the award, the Turing Award is "computing's most prestigious honor" ${ }^{23}$. It "acknowledges individuals who have made lasting and major contributions to the field." ${ }^{24}$

\footnotetext{
20 "History - EECS at Berkeley". https://eecs.berkeley.edu/about/history

${ }^{21}$ E.g. publications by authors Cole and Jackson in volume 147 of Nature from 1941 and Dunin's "The University of Leyden, And America" in Paedagogica Historica, vol. 8, from 1968.

${ }^{22}$ Lee $1972: 488$.

23 "Turing Award 50". https://www.acm.org/turing-award-50

${ }^{24}$ Ibid.
} 
Turing awards are awarded once a year to one or many people. When an award is given to multiple people, this can be mean that it is either for collective work or for an innovation that has multiple, independent contributors ${ }^{25}$. It is presented each year in $\mathrm{June}^{26}$.

Each winner has a citation, in which is explained the reasons for the nomination hence the work accomplished by the laureate and for which the award is given. This citation can be collective if the award is.

The award is bound with a monetary prize. When it was established, the latter was of the amount of 1000 U.S. dollars ${ }^{27}$ or the equivalent of about 7,500 current dollars. That prize money is now 1,000,000 dollars and has been since 2014 when Google became the primary, and possibly sole sponsor ${ }^{28}$. It is unclear, beyond what we know of the philanthropy practices of big corporations like it or family dynasties ${ }^{29}$, what Google's interests are in investing into the prize. But, we noted that multiple Turing award winners work or had worked for Google : Ken Thompson, where he was one of the creators of the Go programming language ${ }^{30}$ and Vint Cerf, who is currently "vice president and Chief Internet Evangelist" according to his corporate page ${ }^{31}$, for example.

The Turing Award was able to establish itself as the top prize for computer scientists fairly quickly. Donald Knuth has referred to it as "the ultimate honor in our field" 32 . An early example of this, considering that the prize itself is relatively new when compared to other similar but more established awards, is further given by a necrology of Herbert Simon published in Science in 2001, where the author, Turing award laureate Edward Feigenbaum, writes : "Before

\footnotetext{
${ }^{25}$ See the nominations in the year 2002 and 2007 respectively.

26 "Call for Nominations, ACM A.M. Turing Award". https://amturing.acm.org/call_ for_nominations.cfm

${ }^{27}$ Revens 1972 : 488.

${ }^{28}$ Communications of the ACM 2014.

${ }^{29}$ In recent months, the Guardian and other newspapers such as The New Yorker reported extensively on these practices in the case of the Sackler family, Purdue Pharma and the drug OxyContin. See Dubb and Costello 2018. Many books have been written about Rockefeller philanthropy : Ettling 1981 or Siegmund-Schultze 2001 for example.

${ }^{30}$ Donovan and Kernighan 2015 : xi.

31 "Vinton G. Cerf - Google AI". https://ai.google/research/people/author32412

${ }^{32}$ Knuth 2003 : 9.
} 
his Nobel Prize, Simon had already won the A. M. Turing Award, the top accolade for computer science, prompting computer scientists to refer to him as "our Nobel Prize winner" 33 . ${ }^{34}$

But, to better understand the Turing Award we need to look at the ACM, which organizes and promotes and answer a series of questions : specifically, what is the ACM? Who leads it? What is the composition of the ACM Council? What is the composition of the jury of the Turing Award? What role do they play? This, we do in the following sections.

The Association for Computing Machinery is according to its own description "the world's largest computing society" 35 as well as the "world's largest educational and scientific society" 36 with over 100,000 members $^{37}$. It was founded in 1947 in New York City as the Eastern Association for Computing Machinery at a meeting at Columbia University ${ }^{38}$.

The notice for this meeting stated the purpose of the association to be : "to advance the science, development, construction, and application of the new machinery for computing, reasoning, and other handling of information." 39

In 1948 its name was changed to Association for Computing Machinery ${ }^{40}$.

It has had offices in New York City since about $1953^{41}$ and its headquarters are still located there ${ }^{42}$.

It is "governed by a Council consisting of 16 members" and with the exception of the chair of the Publications Board they are elected by the members of the ACM for two-year terms ${ }^{43}$.

\footnotetext{
${ }^{33}$ Feigenbaum 2001.

${ }^{34}$ Feigenbaum received the Turing Award in 1994, Simon in 1975.

35 "About the ACM Organization".

https://www.acm.org/about-acm/about-the-acm-organization

36 "ACM History". https://www.acm.org/about-acm/acm-history

37 "ACM at a Glance". https://www.acm.org/membership/acm-at-a-glance

${ }^{38}$ Revens 1972: 485.

${ }^{39}$ Revens $1972: 486$.

${ }^{40}$ Revens $1972: 485$.

${ }^{41}$ Revens 1972 : 487.

42 "Contact Information". https ://www . acm.org/about-acm/contact-us

43 "ACM History". https://www . acm.org/about-acm/acm-history
} 
The ACM also publishes multiple major computer science journals that are of much importance to the research and activities of computer scientists. Its oldest publications are the Journal of the ACM, first published in January 1954, Communications, January 1958, Computing Reviews, February 1960 and ACM Computing Surveys in March $1969^{44}$.

Arguably best known is the Communications of the ACM. One type of publication, perhaps one of its outstanding features, found in Communications are algorithms ${ }^{45}$. They generally appear with accompagnying implementations in the ALGOL programming language ${ }^{46}$ and are numbered in order of publication : e.g. Algorithm 32, Algorithm 33, etc.. A famous example is Algorithm 64, published in 1961 by Hoare, which defines the quicksort algorithm (a method of sorting arrays of items that is still widely taught and in wide use $)^{47}$.

Two other journals published by the ACM that are of significance for the discipline as a whole (as opposed to specialized publications that cover subfields) are the Journal of the ACM, its oldest publication, and the quarterly $A C M$ Computing Surveys, founded in 1969, which, as its name suggests, publishes survey articles.

The ACM also publishes various journals called Transactions that are each dedicated to an area of computer science such as the eponymous Computer Systems, Graphics, Networking (jointly with the IEEE), etc.

A history of the ACM would not be complete without mention of the other, big association for computer scientists, although its scope, as its name indicates, is different, and in some ways both broader and narrower ${ }^{48}$, the Institute of Electrical and Electronics Engineers. The IEEE was founded in 1963, which

\footnotetext{
${ }^{44}$ Cochran $1987: 867$.

${ }^{45}$ Knuth cites five important features of algorithms, besides being merely "a finite set of rules that gives a sequence of operations for solving a specific type of problem" : finiteness, definiteness, input, output and effectiveness. See Knuth 1997 : 4-6.

${ }^{46}$ ALGOL was designed by multiple Turing Award laureates : Backus, Perlis, Naur and McCarthy amongst others with further contributions by Wirth and Hoare (ALGOL W).

${ }^{47}$ Hoare 1961.

${ }^{48}$ This puts it into a similar space as the AIEE, American Institute of Electrical Engineers, or the IRE, Institute of Radio Engineers.
} 
is to say about 15 years after the ACM. It promotes itself as the "the world's

Table 1: ACM Turing and IEEE Computer Pioneer awards compared

\footnotetext{
${ }^{49}$ https: //www. ieee.org/

${ }^{50}$ See table below.

${ }^{51}$ And, in fact, an Ada Lovelace award (already) exists, established by the Association for Women in Computing. As does a Von Neumann award in the form of the John von Neumann Theory Prize, for contributions to operations research. It was first awarded in 1975(, which is to say within 10 years of the Turing Award creation.

${ }^{52}$ Bullynck et al. had already considered why Turing was chosen instead of someone else, they "speculate that Turing was preferred over von Neumann, because the latter was associated with hardware engineering rather than with theoretical foundations", drawing parallels to the uses of Gauss as a conceptual antithesis to computational approaches in mathematics, see Bullynck et al. 2015 : 38.

53 "IEEE Medal of Honor".

https ://www.ieee.org/about/awards/medals/medal-of-honor.html
} 


\begin{tabular}{|l|l|l|}
\hline Ivan Sutherland & 1985 & 1988 \\
\hline Alan Perlis & 1985 & 1966 \\
\hline John McCarthy & 1985 & 1971 \\
\hline Peter Naur & 1986 & 2005 \\
\hline Nicklaus E. Wirth & 1984 & 1987 \\
\hline John Cocke & 1989 & 1987 \\
\hline C.A.R. Hoare & 1990 & 1980 \\
\hline Robert W. Floyd & 1991 & 1978 \\
\hline Douglas C. Engelbart & 1992 & 1997 \\
\hline Ken L. Thompson & 1994 & 1983 \\
\hline Dennis M. Ritchie & 1994 & 1983 \\
\hline Butler Lampson & 1995 & 1992 \\
\hline Marvin Minsky & 1995 & 1969 \\
\hline Robert E. Kahn & 1996 & 2004 \\
\hline Edgar Frank Codd & 1996 & 1982 \\
\hline Frances (Fran) E. Allen & 2004 & 2006 \\
\hline Edward Feigenbaum & 2013 & 1994 \\
\hline Barbara Liskov & 2018 & 2008 \\
\hline
\end{tabular}

We registered 18 commonalities between recipients of both prizes, making up roughly one third and one fifth of each award's pool of winners respectively. We noted further that for its first ten awards, encompassing the first four years ot its existence, the IEEE seems to have made it a point to distinguish only computer scientists that had not been previously given the Turing $\operatorname{award}^{54}$; after which point, starting in 1985, it started awarding its prize to a series of widely celebrated figures such as Perlis, McCarthy and Naur. This gives insight into the strategies of a newly established prize and what happens when a prize seeks to reward the same accomplishments as a previous one, but has to deal

\footnotetext{
${ }^{54}$ See appendix.
} 
with the latter's own, already established legacy ; as opposed to the Turing award which for the most part had only had to deal with the challenges of being a new prize.

It is also noteworthy that in some instances IEEE's recognition preceded the 325 ACM's, such as in the case of Ivan Sutherland, Peter Naur and Robert Kahn. As the Computer Pioneer award was created 25 years after the Turing award, in some cases comparisons are not possible.

Another key difference between the two prizes is that the Computer Pioneer award is given in much higher frequency to multiple people : it has been awarded to 99 people so far ${ }^{55}$ including 19 awards in 1996 alone. Yet another difference when compared to the Turing Award is that in some years, no awards were given such as in 1983, 2005, 2007, 2010 and 2017.

Another prize that could be mentionned, and that may become of interest to future research is the Gödel Prize, who has for particularities when compared to the Turing Award that it is given by a European association, the EACTS 56 , jointly with the ACM, has for limitations theoretical computer science and a reward that is currently significantly lower, $5000 \$$.

\section{Educational origins of Turing winners}

As previously indicated, we wanted to know where the Turing laureates had studied.

Specific questions included : what proportion had attended the 3 or 4 universities that have crystallized as the main centers for computer science education and research at the end of the 20th century and the beginning of this century in the USA?

${ }_{45}$ Currently, they are commonly understood as being MIT, Berkeley and Stanford and although they all cover the entire spectrum, their areas of strength have

\footnotetext{
${ }^{55} \mathrm{At}$ the time of this writing, which is to say up to and including the 2018 laureates.

${ }^{56}$ European Association for Theoretical Computer Science.
} 
historically been, hence their reputation as a leading center for computer science founded on, among other things :

- MIT : Artificial Intelligence (AI Lab, founded by Minsky* and McCarthy*);

- Stanford : (Analysis of) Algorithms (Knuth*, Floyd*)

- Berkeley : Theory of Computing (Karp*).

We relied on the Shanghai Ranking, or Academic World Ranking of Universities, the oldest of its kind, having been published since 2003, to objectify these relations ${ }^{57}$.

Table 2: Shanghai Ranking of universities in computer science and engineering (2007-2017)

\begin{tabular}{|l|l|l|l|l|l|}
\hline Institution & CSEENG 2017 & CS 2009-15 & ENG 2010-16 & ENG 2008-09 & ENG 2007 \\
\hline MIT & 1 & 2 & 1 & 1 & 1 \\
\hline Stanford & 3 & 1 & 2 & 2 & 2 \\
\hline Berkeley & 2 & 3 & 3 & 4 & 5 \\
\hline
\end{tabular}

355 CS \& ENG : Computer Science \& Engineering.

CS : Computer Science.

ENG : Engineering/Technology and Computer Sciences.

Sources : see appendix for a (the full list of sources.

In trying to establish this for earlier periods, we also relied on Lecuyer's history of Silicon Valley between 1930 and 1970, where only two universities appear in the index, a fact which is not only attributable to the geographical limitation to San Francisco : Stanford (26 times) and MIT $(6)^{58}$.

To this group, one can add : CMU, which had been preceded by Carnie Institute of Technology, featured in fourth place or higher in various rankings,

\footnotetext{
${ }^{57}$ The Shanghai Ranking has been criticized for a variety of reasons, both theoretical and methodoligal. Two conflicting reviews that address it from the point of view of reproducability are present in Florian 2007 and Docampo 2013.

${ }^{58}$ Lecuyer 2006.
} 
We started by looking at where Turing award winners had obtained their undergraduate degrees. Next, we looked at the subject of their bachelor degrees.

Table 3: universities ranked by the number of Turing award winners (bachelor)

\begin{tabular}{|l|l|}
\hline Institution & Bachelor students $\mathrm{n}(\%)$ \\
\hline Berkeley & $6(9 \%)$ \\
\hline Cambridge & $4(6 \%)$ \\
\hline Carnegie Mellon University* & 4 \\
\hline Harvard & 4 \\
\hline California Institute of Technology & $3(4 \%)$ \\
\hline MIT & 3 \\
\hline Oxford & 3 \\
\hline University of Chicago & 3 \\
\hline Duke & 2 \\
\hline Stanford & 2 \\
\hline Technion & 2 \\
\hline- Total Ivy League** & $6(9 \%)$ \\
\hline
\end{tabular}


$\mathrm{n}=64^{59} \mathrm{t}=64$

* Previously, Carnegie Institute of Technology.

** Including Princeton (1) and Yale (1).

Almost one third, or $28 \%$, of all Turing award winners have gathered at a handful of universities for undergraduate studies : Berkeley, Cambridge, Carnegie Mellon University and Harvard.

Further, alf of all Turing award winners can be found in 10 institutions alone, all of which, with the exception of Cambridge and Oxford, are US colleges. Technion, in Israel, has had 2 laureates ex aequo with Duke and Stanford.

We also provide statistics for the share that Ivy League colleges have in Turing award winners at the bachelor level, less than 10\%, but this category, important as we know it to be in many other areas of society, has less significance in the case of computer science in the sense that it does not include multiple major centers of computer science such as notably Berkeley, where of all the most Turing award winners are found, MIT, CMU and Stanford, to say nothing of Cambridge and other institutions outside of the US.

We left out from the table those institutions that had only one future Turing laureate among the students they granted bachelor's degrees to ${ }^{60}$. Among those institutions that are only represented by one Turing Award winner at the undergraduate level : Princeton, Yale, ETH Zurich and the University of Michigan - to name a few.

Table 4: Bachelor disciplines ranked by respective number of Turing award winners

\begin{tabular}{|l|l|}
\hline Discipline & Bachelor students $n$ (\%) \\
\hline Mathematics* & $34(53 \%)$ \\
\hline Electrical engineering** & $11(17 \%)$ \\
\hline
\end{tabular}

\footnotetext{
${ }^{59}$ See appendix for full table.

${ }^{60}$ The full list can be found in the appendix.
} 


\begin{tabular}{|l|l|}
\hline Physics*** & $11(17 \%)$ \\
\hline Electronics engineering & 1 \\
\hline Mechanical engineering & 2 \\
\hline Civil engineering & 1 \\
\hline Chemistry & 1 \\
\hline Astronomy & 1 \\
\hline Political science & 1 \\
\hline Liberal arts & 1 \\
\hline "Greats" & 1 \\
\hline
\end{tabular}

$\mathrm{n}=64 \mathrm{t}=64$

400 In calculating percentages, we do not count Robert Floyd's first bachelor degree in liberal arts, but still list it.

* Includes 4 laureates who studied "Applied Mathematics", "Mathematics and physics", "Mathematics and Engineering" and "Mathematics and molecular biology" 61 .

** Includes Kenneth Thompson's bachelor degree listed as "EECS" and as having been obtained in $1965^{62}$.

*** Includes Robert Floyd's second bachelor degree.

The oldest student in our sample of Turing award winners, Maurice Wilkes, was born in 1913 and obtained his bachelor degree in 1934, thus at a time when computer science was not a subject.

This configuration applies to all Turing award winners as they all were awarded bachelor's degrees before 1965, when the first computer science departments had just begun to being formed in the USA.

The analysis of the bachelor subjects of Turing award laureates offers a unique perspective into the question of where computer scientists came from

\footnotetext{
${ }^{61}$ In a previous attempt at categorization, we had subsumed these under "Applied mathematics (various)" separately.

${ }^{62}$ See our previous discussion of this at the beginning of this paper.
} 
before computer science and the answer that we can provide based on our analysis of Turing award winners is largely from mathematics.

More than half of Turing Award laureates (34 of 64) had studied mathematics as a bachelor's degree subject, $17 \%$ of Turing award winners had obtained a physics bachelor degree (11 of 64) and the same amount an electrical engineering degree with an additional Turing laureate having obtained a degree in electronics engineering (a closely related discipline).

The group of physicists includes Tim Berners-Lee, Donald Knuth is among the mathematicians while Ken Thompson is part of the undergraduate students in electrical engineering - to give a few examples.

It might seem remarkable that in a study dedicated to computer scientists, none of them should possess an undergraduate degree in that discipline, but as already mentioned before this is in large parts related to and inherent to our demographic study of Turing Laureates, whose birth dates range from 1916 to 1943, making it so that by the time of their entry into college they would have been studying between roughly 1934 and 1961, hence at a time when departments of computer science, and indeed computer science itself, as a discipline that could be studied in undergraduate college or in which one could obtain a bachelor's degree, was virtually unheard of and non-existent.

${ }_{435}$ Departments of computer science are largely a creation of the 1960s. Purdue founded its own, described as the first in the United States ${ }^{63}$, and possibly the world, in 1962. It awarded its first M.S. degrees in that discipline in 1964 and its first B.S. degrees in $1968^{64}$. Stanford's was established in $1965^{65}$. The University of Wisconsin-Madison was possibly the first to award PhDs in computer science, starting May $1965^{66}$.

"When I entered the Comp Lab in 1955 there were no models for a curriculum in the subject that today is called computer science. The young faculty

\footnotetext{
${ }^{63}$ Rice and Rosen 1994.

${ }^{64}$ Ibid.

${ }^{65}$ Knuth 1972.

${ }^{66}$ See the following historical database of $\mathrm{PhD}$ students hosted at the University of Wisconsin-Madison http://research.cs.wisc.edu/includes/textfiles/phds.65-70.txt.
} 
offered courses in numerical analysis, switching theory, data processing, computational linguistics and operations research, and outside the Lab I took a variety of courses in applied mathematics, electrical engineering, probability and statistics." writes Richard Karp of his time at the Harvard Computation Lab ${ }^{67}$. "Computer science didn't exist when I started in '57. And, it didn't come into existence until at least 10 years later." said Frances Allen in her Grace Hopper speech reflecting on her Turing award ${ }^{68}$.

Before this, departments of mathematics, and electrical engineering, were often where what would later come to be called distinctively and independently computer science was being done (e.g. Princeton, where Von Neumann was a professor and Turing a doctoral student, Manchester, where Turing later worked, and the Moore School of Electrical Engineering at the University of Pennsylvania, where the ENIAC and EDVAC were created and Von Neumann was a consultant). ${ }^{69}$.

A small minority of Turing laureates, three in total, or $4 \%$ of the total population, had obtained undergraduate in one of the humanities or social sciences, we discuss this in more detail further below.

In the second step of our research on the educational origins of Turing Award laureates, we look at their post-graduate institutions. This population comprises Master and PhD students. Where Turing award winners went on to seek a PhD, we register this, otherwise their Master's degrees.

Table 5: Universities ranked by the number of Turing award winners at the post-graduate level

\begin{tabular}{|l|l|l|l|}
\hline Institution & Students & Previously & $\begin{array}{l}\% \\
\text { in/decrease }\end{array}$ \\
\hline
\end{tabular}

\footnotetext{
${ }^{67}$ Karp $1999: 148$.

${ }^{68}$ Allen 2008.

${ }^{69}$ But, this is not a historical artifact only as recent contributions continue to come from mathematicians e.g. Ryan Dahl, creator of Node.js, is a mathematician by training.

${ }^{70}$ At bachelor level.
} 


\begin{tabular}{|l|l|l|l|}
\hline Berkeley & 8 & 6 & $33 \%$ \\
\hline Harvard & 6 & 4 & $50 \%$ \\
\hline Stanford & 6 & 2 & $200 \%$ \\
\hline Princeton & 6 & 1 & $500 \%$ \\
\hline MIT & 4 & 3 & $33 \%$ \\
\hline University of Michigan & 3 & 1 & $200 \%$ \\
\hline Caltech* & 2 & 3 & $-33 \%$ \\
\hline CMU & 2 & 4 & $-50 \%$ \\
\hline UUIC ${ }^{71}$ & 2 & 0 & \\
\hline Weizmann Institute of Science & 2 & $-* *$ & \\
\hline Cambridge & 1 & 4 & $-75 \%$ \\
\hline Oxford*** & 1 & 3 & $-66 \%$ \\
\hline University of Chicago & 1 & 3 & $-66 \%$ \\
\hline Duke & 1 & 2 & $-50 \%$ \\
\hline Technion & 0 & 2 & \\
\hline ETH Zurich & 0 & 1 & \\
\hline Ivy League**** & & 14 & $133 \%$ \\
\hline
\end{tabular}

$\mathrm{n}=58^{72} \mathrm{t}=58^{73}$

* California Institute of Technology.

** The Weizmann Institute of Science only offers post-graduate education.

*** Including Hoare's postgraduate certificate in statistics.

**** Including Cornell (1) and the University of Pennsylvania (1).

At graduate level, Turing award winners increasingly concentrate at institutions that are more prestigious and are often a "step-up" from their undergraduate college. This places them in a better position to have their work recognized, for this to happen early on and to meet the right people e.g. those

\footnotetext{
${ }^{71}$ University of Illinois at Urbana-Champaign

${ }^{72}$ The full table can be found in the appendix.

${ }^{73}$ The population of Turing Award laureates who have a post-graduate education.
} 
able to make an impact in their careers and recommend them effectively in and possibly outside the academic world as well.

This trend is found in the increasing number of future Turing award winners at MIT and Princeton, in the latter case a staggering $500 \%$ increase, in the East. On the West coast, they move towards Stanford and Berkeley. Robert Tarjan and Fernando Corbato both leave the California Institute of Technology for Stanford and MIT respectively.

The University of Michigan knows a $200 \%$ increase at the postgraduate level. Meanwhile Michigan State looses its only student.

Another notable statistic is the increase of $133 \%$ in Ivy League colleges attended by Turing award winners between undergraduate and graduate studies. Let us again move closer to the lived realities of the(se) individuals and have a look at what this means in detail : Charles Bachman moves from Michigan State to UPenn, John Hopcroft from Seattle University to Harvard, Richard Stearns from Carleton College and John McCarthy from Caltech to Princeton.

But, this trend also means a depletion of talent from European institutions. This affects even the very best of European universities, including Oxford ($66 \%)$, Cambridge (-75\%) and ETH Zurich. In one case, a student, born in Switzerland, moved from an excellent European university, ETH Zurich, to a relatively minor North American one, the French-language Universite Laval, where he obtained a Master, and then from there upgraded to Berkeley for $\mathrm{PhD}^{74}$.

Of the sixty-four Turing award winners, six do not have degrees past a bachelor, they are : Tim Berners-Lee (1955; Oxford; physics), Whitfield Diffie (1944; MIT; mathematics), Robert Floyd (1936; Chicago; physics), Arthur Milner (1934; Cambridge; mathematics), and James Wilkinson (1919; Cambridge; mathematics). Neither birth dates, ranging from one extreme to the other of the wider cohort, nor other indicators such as quality of undergraduate education,

\footnotetext{
${ }^{74}$ Niklaus Wirth. This was in the late 1950s, early 1960s. As such, we assume that these international educational moves cannot be attributed to the immediate events of WW2, which did affect the trajectory of numerous Turing laureates and their parents.
} 
with cases representing some of the best attainable outcomes possible in the entire population $^{75}$, or disruption through events like war, absent in two, make any sort of generalization hard.

Lastly, we looked at the highest educational attainments of and the overarching type of degrees obtained - STEM or humanities and social sciences - by Turing winners.

Table 6: Proportion of bachelor and PhD degrees

\begin{tabular}{|l|l|}
\hline Degree type & among Turing Award laureates \\
\hline Bachelor & $100 \%(64)$ \\
\hline $\mathrm{PhD}$ & $81 \%(52)$ \\
\hline Master or $\mathrm{PhD}$ & $90 \%(58)$ \\
\hline
\end{tabular}

9 out of 10 Turing award winners have education at the post-graduate level. 8 out of 10 have a PhD degree. All Turing award winners possess a bachelor's degree.

But, is a PhD degree necessary to do significant contributions to computer science such as the ones recognized by the ACM's Turing Award? No.

Twelve Turing award winners have not obtained a PhD. Among them, some of computer science's most important contributors and revered figures : Kenneth Thompson, creator of UNIX, Tim Berners-Lee, inventor of the World Wide Web, Whitfield Diffie, who with Hellman, laid out the foundations of public key cryptography, Antony Hoare, who developed major sorting algorithms, and John Backus, to whom we owe the Backus-Norm-Form, which is helpful in classifying languages in terms of their logical structures / grammars.

Here too we think important to connect the statistics we have established 520 with the lived realities and actual experience of actors. That the issue of the $\mathrm{PhD}$, or the missing $\mathrm{PhD}$ in this case, matters we establish with a document from the period. And, although it does not hinder a portion of our population,

${ }^{75}$ James Wilkinson was Senior wrangler, and at Cambridge was at Trinity college. 
one fifth to be exact, from rising to the top of their field, it shows the great concern attached to the issue. This is not without cause as, in fact, certain academic positions, are, in theory at least, only accessible to holders of appropriate academic titles. And, so, when Donald Knuth wrote a letter of recommendation on behalf of Robert Floyd, he thought good and perhaps even important to note at the end :

"One further remark is perhaps necessary, considering contemporary 'standards of society'. Floyd has never gone through the formalities of obtaining a Ph.D. degree. I believe this was due primarily to the fact that he entered graduate school at the University of Chicago when he was only 16 or 17 yours [sic] old, as part of an experimental accelerated education program; this was not a mature enough age to do graduate work. [Bob was born 8 June 1936, and he began graduate school after receiving a B.A. degree in 1953 at age 17about five years earlier than usual for American students at the time.] Certainly he has written at least a dozen papers by now each of which is superior to any Ph.D. thesis I have ever seen in computer science, so the mere fact that he has never formally received the degree should be quite irrelevant." 76

Finally, we asked if a degree in mathematics, physics, engineering, biology, chemistry, computer science or one of the neighbooring disciplines - contemporanously called STEM - was necessary to do significant contributions to computer science later in life, the kind recognized by the Turing?

Table 7: STEM vs. humanities and social sciences degrees amongst Turing laureates

\begin{tabular}{|l|l|l|}
\hline & STEM & Humanities and Social Sciences \\
\hline
\end{tabular}

\footnotetext{
${ }^{76}$ Knuth 2003: 7 .
} 


\begin{tabular}{|l|l|l|}
\hline Bachelor & $95 \%(61)$ & $4 \%(3)$ \\
\hline $\mathrm{PhD}$ & $100 \%$ & None \\
\hline Master or $\mathrm{PhD}$ & $100 \%(58)$ & None \\
\hline
\end{tabular}

This seems to be the case overall : the great majority of Turing award winners, or $95 \%$, have done their undergraduate degrees in a STEM subject, and $100 \%$ beyond that.

But, the history of computer science, mathematics and physics is full of outliers and while all Turing Award winners either have a bachelor's degree or Master or $\mathrm{PhD}$ in a STEM subject, some of them come originally from a background in the humanities or the social sciences ${ }^{77}$.

Though, note that of the three Turing award winners who received a bachelor in one of the humanities and social sciences subjects : Herbert Simon majored in political science at Chicago, one of the most quantitatively intensive disciplines outside of STEM, at an institution that played a key role in the mathematization of the social sciences, economics in particular, Antony Hoare, who studied Classics at Oxford, "chose to study modern philosophy, which provided a path to understand logic" ${ }^{78}$, an important part of computer science and computer science education $^{79}$, while Robert Floyd, also at Chicago, did obtain a liberal arts degree but later supplemented it with a second bachelor's degree in physics.

Past the undergraduate level however, all Turing winners have a degree in science, technology, engineering or mathematics.

\footnotetext{
${ }^{77}$ John Guttag, professor of computer science at MIT, has a BA in English. David Malan, professor of computer science at Harvard, had first studied government before switching subjects. Alston Householder, mathematician and president of the ACM, had a BA and MA in philosophy before earning a $\mathrm{PhD}$ in mathematics. Lastly, Einstein famously worked as a patent office employee for 7 years, a work he described later to be that of a "cobbler", after having been unable to find work as a teacher for almost two years.

${ }^{78}$ This is according to his Turing Award biography.

${ }^{79}$ E.g. boolean algebra, set theory, etc.
} 


\section{Geographical origins and movements of Turing winners}

565 distribution of Turing Award winners and find that they gather at a handful of destinations, heavily skewed toward the USA and within, its coastal regions in particular.

One question we received in reaction to these and other findings, from a researcher who was very concerned about "performance" in science studies, was why this was important and "what the point [was]". This fits into the wider debates happening in fields of research as diverse as those concerned with the role of English in science and the effects of rankings and prizes.

We will answer this question before : our findings indicate that the Turing an international organization ("members from more than 100 countries" 80 ), is in fact very limited in its scope and pool of recipients as we show. It is biased towards countries where English is the main language, it is also biased towards computer scientists who have attended universities from English-speaking countries, thus putting into question whether the Turing Award rewards "lasting contributions" independently of their place of origin.

Table 8: Place of birth of Turing Award laureates

\begin{tabular}{|l|l|}
\hline Country & Turing laureates \\
\hline USA & $41(64 \%)$ \\
\hline England & $5(7 \%)$ \\
\hline Israel & $3(4 \%)$ \\
\hline British Empire* & 2 \\
\hline Canada & $2(3 \%)$ \\
\hline China & 1 \\
\hline Denmark & 1 \\
\hline
\end{tabular}

80 "ACM at a Glance". https://www.acm.org/membership/acm-at-a-glance 


\begin{tabular}{|l|l|}
\hline Germany** & 1 \\
\hline Greece & 1 \\
\hline Hungary & 1 \\
\hline Italy & 1 \\
\hline Latvia & 1 \\
\hline Netherlands & 1 \\
\hline Norway & 1 \\
\hline Switzerland & 1 \\
\hline Venezuela & 1 \\
\hline - America & $44(68 \%)$ \\
\hline - Europe & $14(21 \%)$ \\
\hline - East Asia & 1 \\
\hline - Rest of the World & $6(9 \%)$ \\
\hline
\end{tabular}

$\mathrm{n}=64 \mathrm{t}=64$

* Ceylon (now Sri Lanka) and British India.

** Germany (now Wroclaw, Poland).

From these data alone, one can tell as much : the pool from which Turing laureates are selected from is extremely biased towards America, particularly the USA. Entire regions of the world are absent, Africa for example, while some of the most populous ones, like East Asia, are grossly underrepresented with only one Turing award winner born in China.

$59068 \%$ of Turing Award winners were born in America while almost two thirds, or $64 \%$, were born in the USA alone. Just $18 \%$ of Turing award winners were born in the current European Union and about half of them are from England. Less than $10 \%$ of Turing laureates, or 6 in total, come from the rest of the World (outside the USA and Europe), including 3 from Israel, 2 from former colonies of the British Empire, one of which in turn is Antony Hoare whose father was a colonial civil serveant, and 1 from China.

The next biggest country of origin for Turing winners is Israel, with two out 
of its three Turing winners emigrating to the USA eventually ${ }^{81}$. One Turing winner was born in Venezuela : his parents, Jewish, had emigrated there from Europe $^{82}$

These findings are at odds with what the ACM writes about the Turing Award in its fact sheet. In one passage, it emphasizes :

"Turing Laureates have hailed from countries around the world including Canada, China, Denmark, India, Latvia, Netherlands, Norway, Israel, Italy, Switzerland, the United Kingdom and the United States." 83

But, while this statement is positively correct, it does not accurately represent the disproportionate frequency at which US American scientists receive the prize. Not all countries stand on an equal footing when it comes to their scientists' potential to receive the Turing Award. This is one conclusion that could be drawn from our data. As such statements never fail to raise objections, we must specify that we do not look so much at the intentions or policies of the ACM or the Turing Award, whether claimed or otherwise agreed upon as policy or even passed as law, but at its verifiable practices. This we do by counting how many Turing laureates come from each country based on information established by the ACM itself.

By placing the United Kingdom and the United States at the end of its list of countries, an order which does not reflect the alphabetical order, but is the exact order we have established in the above statistics, except in reverse, the ACM makes clear that is most likely aware of its biases and the issues discussed here.

On the other hand, if such conclusion were wrong, one of few remaining

\footnotetext{
${ }^{81}$ Judea Pearl had emigrated to the US by the time of his Master's degree while Amir Pnueli went there first as a post-doctoral student and later as a professor at NYU, he died in New York.

${ }^{82}$ Manuel Blum.

83 "About the ACM A.M. Turing Award Fact Sheet." https://www.acm.org/binaries/ content/assets/awards/about-the-acm-a.m.-turing-award-fact-sheet.pdf
} 
outcomes would be that all countries standing an equal chance to see one of their citizens receive the prize, the USA is the producer of much better computer scientists, such that it would only be logical for the great majority of Turing award winners to come from that country as well.

To further study these phenomena, we took at look at distribution of Turing laureates within the United States, the majority producer of this population $(64 \%)$.

Table 9: State distribution of Turing award winners within the US

\begin{tabular}{|l|l|}
\hline State & Turing Award laureates \\
\hline New York & $9(21 \%)$ \\
\hline California & $8(19 \%)$ \\
\hline Massachusetts & $4(9 \%)$ \\
\hline D.C. & $2(4 \%)$ \\
\hline North Carolina & 2 \\
\hline Pennsylvania & 2 \\
\hline New Jersey & 2 \\
\hline Wisconsin & 2 \\
\hline Alberta & $1(2 \%)$ \\
\hline CT & 1 \\
\hline Illinois & 1 \\
\hline Kansas & 1 \\
\hline Louisiana & 1 \\
\hline Nebraska & 1 \\
\hline Oregon & 1 \\
\hline TX & 1 \\
\hline Virginia & 1 \\
\hline Washington & 1 \\
\hline
\end{tabular}

$\mathrm{n}=41 \mathrm{t}=41$ 
This analysis unveils that more than half of all US Turing laureates come from 3 states only : New York, California and Massachussets.

There is, beyond this, a strong concentration of future Turing laureates around the Northeast : New York, New Jersey, D.C., Massachussets and further away Pennsylvania represent 19 Turing winners or almost half of all laureates based on place of birth.

In total, 17 states have produced at least 1 Turing laureate. This also means in return that of the current 50 states (then 48 states and the 2 territories of Alaska and Hawaii ${ }^{84}, 33$ are absent.

We move forward in our analysis of geographical distribution by using places of study as the next reference point. We later do the same for graduate institutions to follow the population's movements and transits.

Table 10: Geographical distribution of Turing award winners by (based on) bachelor-granting institutions

\begin{tabular}{|l|l|l|}
\hline Continent, Country, State & $\%$ & Previously (born) \\
\hline North America & $44(68 \%)$ & \\
\hline - USA & $42(65 \%)$ & \\
\hline - California & $11(17 \%)$ & 8 \\
\hline - Massachusetts & $7(10 \%)$ & 4 \\
\hline New York metropolitan area* & 6 & \\
\hline - New York & 4 & 9 \\
\hline - Pennsylvania & 4 & 2 \\
\hline - Illinois & 3 & \\
\hline - Michigan & 2 & \\
\hline - North Carolina & 2 & \\
\hline
\end{tabular}

\footnotetext{
${ }^{84}$ The time range of births of our population is 1916 to 1952 . Alaska and Hawaii became states in 1959 .
} 


\begin{tabular}{|l|l|l|}
\hline- Colorado & $1(1,5 \%)$ & \\
\hline- Connecticut & 1 & \\
\hline - Minnesota & 1 & \\
\hline - New Jersey & 1 & 2 \\
\hline - Oregon & 1 & \\
\hline - Texas & 1 & \\
\hline - Virginia & 1 & \\
\hline - Washington & 1 & \\
\hline - Canada & 2 & \\
\hline Europe & $14(21 \%)$ & 14 \\
\hline - England & $7(10 \%)$ & \\
\hline - Denmark & 1 & \\
\hline - Germany & 1 & \\
\hline - Greece & 1 & \\
\hline - Italy & 1 & \\
\hline - Netherlands & 1 & \\
\hline - Norway & 1 & \\
\hline - Switzerland & 1 & \\
\hline Asia & $6(9 \%)$ & \\
\hline - (British) India & 1 & \\
\hline - Israel & $4(6 \%)$ & \\
\hline - Taiwan & 1 & \\
\hline
\end{tabular}

$\mathrm{n}=64 \mathrm{t}=64$

${ }_{645} *$ New York, New Jersey and Connecticut.

The analysis of the geographical distribution of Turing award winners at the undergraduate level unveils further the large dominance of the USA over all other places (as ascertained by proxy of their bachelor-granting institutions) : no other country comes close to their $2 / 3$ total share of future Turing award 
laureates.

In Europe, we note no difference between the situation observed in the context of birth places and the stage of bachelor's degrees : those born in Europe among the Turing laureates stay there for undergraduate studies. This, as we will find later on, will change over time as Turing laureates move towards postgraduate education.

Next, we analyze the movements of Turing Award laureates as they move from their respective undergraduate colleges to their respective graduate schools.

Table 11: Geographical destinations of Turing award winners for post-graduate education

\begin{tabular}{|l|l|l|l|l|}
\hline & State (\% of country) & Increase state & Country & $\begin{array}{l}\text { Continent } \\
\text { (previously } \\
\text { bachelor) }\end{array}$ \\
\hline North America & & & & $49(44)$ \\
\hline - USA & & & $48(82 \%)$ & \\
\hline- California & $17(29 \%)$ & $70 \%$ & & \\
\hline- Massachusetts & $11(18 \%)$ & $72 \%$ & & \\
\hline- New Jersey & $6(10 \%)$ & $72 \%$ & & \\
\hline- Michigan & 3 & & & \\
\hline- Pennsylvania & 3 & & & \\
\hline- New York & 3 & & & \\
\hline New York metropolitan area* & 9 & & & \\
\hline- Illinois & 2 & & & \\
\hline- Nebraska & 1 & & & \\
\hline- North Carolina & 1 & & & \\
\hline- Utah & 1 & & & \\
\hline - Canada & & & & \\
\hline Europe & & & & \\
\hline - England & & & & \\
\hline
\end{tabular}




\begin{tabular}{|l|l|l|l|l|}
\hline - Denmark & & & 1 & \\
\hline — Greece & & & 1 & \\
\hline - Netherlands & & & 1 & \\
\hline - Norway & & & 1 & \\
\hline Asia & & & & $2(6)$ \\
\hline - Israel & & & 2 & \\
\hline
\end{tabular}

$\mathrm{n}=58 \mathrm{t}=58$

* New York, New Jersey and Connecticut.

In the same way that we observed a shift towards more prestigious universities as Turing award winners entered postgraduate schools, we register a big geographical shift towards the USA, both being linked of course ; and, within that country, a big shift towards the major centers of education and research that are California, where almost $1 / 3$ of all Turing Award winners attend graduate school, and Massachusetts, $1 / 5$.

The diversity of outcomes dwindles as now most Turing award winners aggregate at common places : they increasingly attend colleges located in the same states. Attendance of a college in California as well as Massachusetts raises by $70 \%$, in New Jersey the number of future Turing Award winner grows from 1 to 6 total.

Looking even closer, at happenings within the USA, we note an influx towards California (previously 8 born there, now 11 studying) and Massachusets (4 born, later 7 studying), while important states with comparatively lesser colleges such as New York lose their population of Turing laureates (9 born, less than half studying or 4).

This has multiple by-effects, but as noted before, the most obvious ones are a depletion of talent from other states and countries and continents. Where previously 16 states hosted institutions attended by future Turing award winners at the bachelor level, now that number is only 10. The number of Turing laureates in Europe is halved, in Canada, halved, in Israel also and England 
more than halved.

Looking closer, more disparities become clear as the only international institutions outside of the US and Europe remaining ie. attended by Turing award winners for postgraduate studies are all in Israel. This is compared to bachelorlevel statistics where three countries, including India and Taiwan, where still represented at that stage of our analysis. An additional English university, outside of Oxford and Cambridge, Warwick, appears however post-graduation.

\section{Social origins of Turing laureates}

We are interested in knowing "where do Turing award winners come from and who are they?" and further "what social regularities can be unveiled (observed) from the study of their collective biographies, in other words, what do they have in common?" This is yet another attempt at answering this basic question, but from a different different assumptions or perspectives.

Here, we study social origins of which we know that they are - along with other categories of analysis such as education, gender or "race" - important properties of social actors/agents.

At the beginning of last century, Durkheim wrote that few things were more important to the development and understanding of human social behavior than family and education ${ }^{85}$. This has since been verified in countless sociological studies, but amongst many historians of science, these various levels of experiences remain absent. The world that they create, the one that they lay down on paper when writing about famed and anonymous science makers alike seems

\footnotetext{
85 "Education is the influence exercised by adult generations on those that are not yet ready for social life. Its object is to arouse and to develop in the child a certain number of physical, intellectual and moral states which are demanded of him by both the political society as a whole and the special milieu for which he is specifically destined. (...) Education varies from one caste to another; that of the patricians was not that of the plebeians; that of the Brahman was not that of the Sudra. Similarly, in the Middle Ages, what a difference between the culture that the young page received, instructed in all the arts of chivalry, and that of the villein, who learned in his parish school a smattering of arithmetic, song and grammar! Even today, do we not see education vary with social class, or even with locality?" This is from a posthumous publication entitled Education and Sociology. See Durkheim 1956 : $27 ; 67$.
} 
eerily disconnected from them, although they themselves must have an immediate or intimate knowledge of their importance for having experienced their impact in their own personal lives.

This is an attempt to show how such an analysis could unfold, and what might be gained from it, although we were not able to go as far as we would have liked.

To compile this information, we have used the Turing award biographies. Where other sources were used, we specify them in the appendix where the reader will also be able to find a much more detailed table containing the individual information on each winner as well as intermediary categories (i.e. categories in various intermediary states of abstraction). And, whereas in the full table, we still made us of a mix of intermediary and final categories, in the following, we present the results of the analysis with broad categories.

Unfortunately, for a number of Turing award winners we were not able to find any relevant biographical information in their Turing award notices nor in other places. And, as can be expected from such enquiries, the more one moves up in time the less information is available. This makes a good case for more oral history to be undertaken.

Hence note that this analysis is based on a sample of our total population (as we make clear by indicating that it relies on a number of 48 individuals instead of the full 64). This means that the statistics presented provide an indication for the tendencies of the overall population but are subject to a margin of error.

Table 12: Social origins of Turing Award laureates

\begin{tabular}{|l|l|l|}
\hline Background & Total & $\%$ \\
\hline Academic* & 21 & $48 \%$ \\
\hline Business** & 5 & $11 \%$ \\
\hline Low*** & 5 & \\
\hline Engineering & 3 & $6 \%$ \\
\hline Military & 3 & \\
\hline
\end{tabular}




\begin{tabular}{|l|l|l|}
\hline Religious profession & 2 & \\
\hline Other & 4 & \\
\hline- Civil service & 1 & \\
\hline- Professional sports & 1 & \\
\hline- Artistic & 1 & \\
\hline- Press & 1 & \\
\hline
\end{tabular}

$725 \mathrm{n}=43 \mathrm{t}=64$

* E.g. mathematician, adjunct professor, professor at UCLA, high school physics.

** E.g. stockbroker, aerospace executive, president of a power company.

*** E.g. appliance salesman, sea captain, janitor, farmer.

We found that almost 50\% of Turing Award winners for whom relevant biographical information was available had at least one parent employed in a teaching or research position or otherwise in possession of an advanced degree like the $\mathrm{PhD}$ or Master.

As most Turing award winners come from the United States, we relied on North-American data to compare these findings with those available on the general population over the same period.

For this purpose, we looked at the percentage of the US population with a college degree, i.e. a bachelor's degree or higher, based on information made available by the United States Census Bureau ${ }^{86}$.

They indicate that in 1940, barely $4 \%$ of the total adult population, aged 25 and older, were in possession of a bachelor or better. During the 1940s, 1950s and much of the 1960s this proportion never reached more than $10 \%$.

Note that the median birth year of our population is 1941 with the oldest Turing Award winner born in 1916 and the oldest in 1952, which would put the birth years of their parents roughly between 1890 and 1930 .

We have all reasons to believe, considering the steadily upwards trend of the curve that now puts the same demographic sample at $33 \%$, that adults in pos-

${ }^{86}$ United States Census Bureau 2017. 
session of a higher education degree were consistently lower than $5 \%$ in previous decades. The Census Bureau however does not publish such information before 1940 to our knowledge.

Based on this, we think safe to say that : academic backgrounds were vastly overrepresented amongst families of Turing Award laureates, whose parents held college degrees in disporpotionately higher frequency than the rest of the population with many of them holding advanced degrees including Master's and PhDs at a time when these were much more seldom.

This must have played a role in making the future Turing award winners : having one parent with an academic background or involved in academia should have exposed them early on to books and contributed to their education at home or in getting them interested in school or otherwise having them perform well there.

That these statistics are not only of meaning "on paper", but also affected the Turing Award winners intimately, in their lives and during childhood, we can ascertain from a qualitative review of their biographies.

About Martin Hellman, inventor of public key cryptography (together with Diffie and Merkle, we know from his biography that : "His father was a high school physics teacher, whose influence and collection of books helped to inspire Hellman's early interest in science and mathematics." Of Sutherland we learn that his father was a "practicing engineer with a Ph.D. in civil engineering" and his mother "a teacher who engendered in him and his brother Bert a love of learning."

A particularly striking case of early exposure to culture is Alan Kay. "I had the misfortune or the fortune to learn how to read fluently starting about the age of three. So I had read maybe 150 books by the time I hit first grade." ${ }^{87}$. From other biographic sources, we learn that in his childhood there were "nearly 6,000 books in the house and many drawings and illustrations." 88

\footnotetext{
${ }^{87}$ The Davis Group 2011.

${ }^{88}$ Shasha and Lazere 1995.
} 
"Since my father was a scientist and my mother was an artist, the atmosphere during my early years was full of many kinds of ideas and ways to express them. I did not distinguish between "art" and "science" and still don't. My maternal grandmother was a schoolteacher, suffragette, lecturer, and one of the founders of UMASS, Amherst. My maternal grandfather was Clifton Johnson, a fairly well-known illustrator, photographer, and writer $(100+$ books $)$. He was also a musician, and played piano and pipe organ.

One book I read was called Rockets, Missiles, and Space Travel by Willi Ley. The thing that struck me was that when you go from one planet to another, you wouldn't go the way you thought you would. You don't aim the rocket ship at the planet, you aim the rocket ship at where the planet is going to be.

By the time I got to school, I had already read a couple of hundred books" 89

Meanwhile, at the other end of the social spectrum or scale, Hopcroft, whose father worked as a janitor, "claims that because of the lack of family experience with higher education, it never occurred to him to look at other than the local Seattle University." Interestingly, Hopcroft, having gone through undergraduate education and having presumably been able to gather then the experience he lacked from home, moved to Stanford.

There may disagreements with our categorization of elementary, middle school or even high-school teachers as belonging inside an academic category, or at least in the same fashion as college professions. But, leaving these a priori, theoretical debates aside, and actually listening to or reading about the experiences of the Turing award winners does give insight, beyond the objective world we try to capture, of what the actual, felt reality was, for them. Again, we present evidence for this. Richard Karp, for instance, whose father was a

${ }^{89}$ Shasha and Lazere 1995. 
middle-school math teacher, has recounted that :

"Education was very much paramount in my parent's worldview. There were four of us, and I'm the oldest of four, and they spaced us out at intervals of a college career, so that they could have one kid in college at a time. I think the greatest admiration I felt for my father was when I visited his class." 90

His interviewer, Christos Papadimitriou, a noted computer scientist himself,

810 whose own father was also a middle school math teacher, asks Karp if they ever talked about math together : "We did, but he really didn't have very advanced mathematical knowledge. He was pretty much limited to what he was teaching. But, his presence and sense of command in the classroom was something that I wanted to emulate. And, I think it's not an accident that I went into teaching eventually." 91 But, this influence is not limited only to the immediate circle of parents, as Richard Karp's case also makes clear : "I had a young aunt (...) who taught me how to read, so I read quite early and for that reason I skipped a grade. And, so I ended up being a year and a half younger than my classmates" 92 .

In the following, we give for appraisal a longer passage that makes visible and unveils the sometimes very extensive educational strategies used by parents of future Turing award laureates.

"- Interviewer. You went to public schools in the Boston area? What suburb were you in?

- Stonebraker. We lived in a town called Newbury, which is right next to Newburyport. And my father chose that town deliberately because at the time they did not have a high school and the town would pay the tuition for anyone who could get accepted at Governor

\footnotetext{
${ }^{90}$ Simons Foundation 2013.

${ }^{91}$ Ibid.

${ }^{92}$ Ibid.
} 
Dummer Academy, which happens to be within the town boundaries.

It's in the same general league as St. Mark's, Milton Academy and Browne and Nichols, those kinds of places. Both of my brothers and I got to go to Governor Dummer as day students with tuition paid by the town, which would not have been financially possible otherwise. - Interviewer. That was certainly very shrewd on his part. What were the particular subjects you were interested in when you were going to school?

- Stonebraker. Well my SATs sort of say it all. I made 800 on the math SAT (...)"93

Note 800 is the highest score attainable on the Math portion of the SAT, the standardized test used for colledge admission in the United States. Stonebraker himself went to Princeton after high school.

Next, we looked at the relationship between social origins and precocity i.e. the age at which the laureates obtained the Turing award.

Looking at the 10 youngest Turing award winners, we found that over $50 \%$ came from households where at least one of the parents held an advanced degree, Master and beyond, or was otherwise engaged in an intellectual profession.

Table 13: Youngest Turing laureates and social background

\begin{tabular}{|l|l|}
\hline Name & Family background \\
\hline Donald Knuth & Academic (Teacher) \\
\hline Robert Tarjan & Academic (Psychiatrist, APA president) \\
\hline Kenneth Thompson & $\mathrm{n} / \mathrm{a}^{94}$ \\
\hline Dennis Ritchie & Academic (Bell Labs) \\
\hline
\end{tabular}

\footnotetext{
${ }^{93}$ Computer History Museum 2007.

${ }^{94}$ The only available information on Kenneth Thompson's father is "US Navy", which we have coded as military in the table in appendix, but we do not know what position he held there or what his educational attainments were.
} 


\begin{tabular}{|l|l|}
\hline Marvin Minsky & Academic (Surgeon) \\
\hline Edsger Diskstra & Academic (Teacher) \\
\hline Robert Floyd & n/a \\
\hline Stephen Cook & Academic (Professor) \\
\hline Alan Perlis & n/a \\
\hline John McCarthy & Non-academic (Labor organizer, Manager Daily Worker) \\
\hline Dana Scott & n/a \\
\hline
\end{tabular}

Among the eleven youngest Turing winners, whose ages ranged from 36 to 44 at the time of their nomination, more than half come from academic backgrounds. This includes the following professions for their parents : one professor, two teachers, one Bell Labs employee, one surgeon and one psychiatrist APA president.

Even amongst Turing winners with formally non-academic backgrounds, their family circumstances are such that they have access to culture early. This is the case of McCarthy for example, who was born "into a politically engaged family in Boston", his father was a labor organizer and Business Manager of the Daily Worker, a Communist newspaper, while his mother "was active in the suffrage movement" and "both parents were members of the Communist Party" 95 .

860 To trial-control this information, we have also looked at the same data for the oldest Turing Award winners, who ranged from age 77 to 68 at the time their work was recognized by the ACM and the Turing award given to them.

Table 14: Oldest Turing winners and social background

\begin{tabular}{|l|l|}
\hline Name & Family background \\
\hline Peter Naur & Non-academic (Painter and heiress) \\
\hline Judea Pearl & n/a \\
\hline
\end{tabular}

\footnotetext{
${ }^{95}$ Markoff 2011.
} 


\begin{tabular}{|l|l|}
\hline Frances Allen & Academic (low) (Farmer and elementary-school teacher) \\
\hline Douglas Engelbart & Non-academic (Electrical engineer, radio shop owner) \\
\hline Leslie Lamport & $\mathrm{n} / \mathrm{a}$ \\
\hline Michael Stonebraker & Academic (School teacher) \\
\hline Whitfield Diffie & Academic (Professor) \\
\hline Ole-Johan Dahl & Non-academic (Sea captain) \\
\hline Martin Hellman & Academic (Teacher) \\
\hline Barbara Liskov & Academic (Harvard Law Review Lawyer) \\
\hline Frederick Brooks & $\mathrm{n} / \mathrm{a}$ \\
\hline
\end{tabular}

Due to the lack of information on certain laureates' background it is hard to make any definitive claims, but from the information we have available we noted that among the demographic of oldest Turing winners, families were more often more distant from academic background and their professions more heterogenous.

\section{Networks of Turing Award winners}

Who studied under whom? Who wrote with whom? Who worked with whom? Who teaches with whom? Who employs whom? Who wrote about whom? Lastly, who penned whose necrology? We found all of these questions (and relationships) to apply to our object of study.

In following up with our intention to better understand who the Turing winners are and their sociological characteristics, we lastly looked at their networks.

We started by assembling a number of relationships, such as student-advisor relationships. In parentheses, we identify Turing award winners by the year of their nomination.

Table 15: Networks of Turing award winners, $\mathrm{PhD}$ advisor/student

\begin{tabular}{|l|l|}
\hline PhD advisor & PhD student \\
\hline
\end{tabular}




\begin{tabular}{|l|l|}
\hline Alonzo Church & Alan Turing \\
\hline & Michael Rabin (1976) \\
\hline & Dana Scott (1976) \\
\hline Claude Shannon & Ivan Sutherland (1988) \\
\hline Howard Aiken & Kenneth Iverson (1979) \\
\hline & Frederick Brooks (1999) \\
\hline John McCarthy (1971) & Dabbala Reddy (1994) \\
\hline & Barbara Liskov (2008) \\
\hline Herbert Simon (1975) & Edward Feigenbaum (1994) \\
\hline Marvin Minsky (1969) & Manuel Blum (1995) \\
\hline Robert Floyd (1978) & Ronald Rivest (2002) \\
\hline & Robert Tarjan (1986) \\
\hline Manuel Blum (1995) & Shafi Goldwasser (2012) \\
\hline & Silvio Micali (2012) \\
\hline
\end{tabular}

We found the relations of type advisor to student to be particularly significant : at least 8 future Turing Award laureates studied under previous winners. 10 Turing winners, which is to say 5 pairs, had the same $\mathrm{PhD}$ advisor.

In one case, we found this relationship type to be particularly strong : a Turing winner, Manuel Blum, who had himself been advised by a Turing winner, Marvin Minsky, went on to advise 2 future Turing award winners, Shafi Goldwasser and Silvio Micali ${ }^{96}$.

885 We extended this into a graphical network analysis and concentrated on the relations between Turing Award winners of type student and advisor, where we identified a minimum of 20 edges.

\section{Graph : networks of Turing award winners}

We present here the first results of what may become a larger research on

${ }^{96}$ They themselves may well go on to advised or have already advised future Turing winners 
works amongst Turing winners and computer scientists.

These results are in their early stages and as such were not able to present all of the research.

We were interested in knowing how much personal networks affected Turing award winners.

895

We asked : was it significant when students wrote their dissertation under previous winners? Was it significant when they wrote articles together with them? Did this correlate with them winner the prize later?

Below, we present some pointers. We start by looking at the networks between $\mathrm{PhD}$ students and advisors. We find that there are many relationships binding future and past winners at this stage.

We then moved on to study relationships between co-authors and co-workers.

Table 16: Networks of Turing Award laureates, co-authors

\begin{tabular}{|l|l|}
\hline & Co-author $(s)$ \\
\hline Alan Perlis (1966) & Allen Newell (1975) [1967] \\
\hline & Herbert Simon (1975) [1967] \\
\hline John Cocke (1987) & Frances Allen (2006) [1971 $\left.{ }^{97} ; 1976\right]$ \\
\hline
\end{tabular}

Table 17: Networks of Turing Award laureates, co-workers

\begin{tabular}{|l|l|}
\hline & Colleague(s) \\
\hline Alan Perlis (1966) & Allen Newell (1975) [Carnegie] \\
\hline & Herbert Simon (1975) [Carnegie] \\
\hline John Cocke (1987) & Frances Allen (2006) [IBM] \\
\hline Kenneth Iverson (1979) & Frederick Brooks (1999) [Harvard] \\
\hline Donald Knuth (1974) & Robert Floyd (1978) [Stanford] \\
\hline & George Forsythe (ACM President) [Stanford] \\
\hline
\end{tabular}

${ }^{97}$ Allen and Cocke 1972. 
As a convention, we list the Turing Award winner with the earliest nomination on the left. In the case of colleagues, and co-authors, the direction of the relationship, and its structure, cannot be identified as readily as between $\mathrm{PhD}$ advisor and PhD Student : a PhD advisor advises the student and commonly has many students.

Table 18: Networks of Turing award winners, professor/student

\begin{tabular}{|l|l|}
\hline Professor & Student \\
\hline Donald Knuth (1974) & Robert Tarjan (1986) [PhD course advisor $]^{98}$ \\
\hline Howard Aiken & Frederick Brooks $(1999)^{99}$ \\
\hline Ivan Sutherland (1988) & Alan Kay (2003) ${ }^{100}$ \\
\hline
\end{tabular}

Table 19: Networks of necrologies (amongst Turing laureates)

\begin{tabular}{|l|l|}
\hline Living scientist & Dead scientist \\
\hline Peter J. Denning (ACM President) & Alan Perlis (1966) $)^{101}$ \\
\hline Donald Knuth (1974) & George Forsythe (ACM President) ${ }^{102}$ \\
\hline & Robert Floyd (1978) $)^{103}$ \\
\hline Edward Feigenbaum (1994) & Herbert Simon $(1975)^{104}$ \\
\hline
\end{tabular}

As we have done in previous developments, we are not merely concerned with (interested in) capturing objective relationships, but also to explore what their incidences are in the actual, lived lives of the actors. And, so, what exactly does it mean to have a network and what advantages might, in this case the Turing winners, gain from it?

\footnotetext{
${ }^{98}$ Tarjan 2012.

${ }^{99}$ Hosch 2018.

${ }^{100}$ Packer and Jordan 2002 : 122.

${ }^{101}$ Denning 1990.

${ }^{102}$ Knuth 1972.

${ }^{103}$ Knuth 2003.

${ }^{104}$ Feigenbaum 2001.
} 
We look at the example of the relationships, primarily at Stanford, between Knuth and Floyd and to some extent Forsythe. The three of them, two Turing winners, and one ACM president, build a strong network of self-referential recommendations and support and promotions ${ }^{105}$

In 1962, Donald Knuth first became award of Robert Floyd through his 1961 article "A descriptive language for symbol manipulation"106. During the 1960s, Robert Floyd contributed "a great deal of his time" to work on Knuth's landmark The Art of Computer Programming. Meanwhile, from 1964 to 1966, 20 George Forsythe had been ACM president. In 1965, he co-founded the department of computer science at Stanford with mathematician John Herriot ${ }^{107}$. In 1968, Donald Knuth joined Stanford's newly formed CS department. George Forsythe then asked Knuth to write a letter of recommendation for Floyd to be appointed professor at Stanford that same year ${ }^{108}$. Here is a sample of its content :

"I don't know anyone I could recommend more highly. He is the most gifted man in his 'age bracket' that I have ever met. Several of his published papers have been significant mileposts in the development of computer science (...). I have also had the pleasure of carrying on frequent correspondence with him for five years (...) While I was editing the ACM Communications and Journal, I asked him to serve as referee for several papers (...) He is a true Computer Scientist!"

That same year of 1968, Floyd joined Stanford. In 1973, he succeeded Forsythe as chair of the department of computer science at Stanford as the dean's choice. He remained in that position for three years. In 1974, Donald Knuth was awarded the Turing Award. 4 years later, Robert Floyd was awarded

\footnotetext{
${ }^{105}$ The source for all following developments, unless otherwise stated, is Knuth himself, see Knuth 2003.

${ }^{106}$ Floyd 1961.

${ }^{107}$ Knuth 1972.

${ }^{108}$ We do not know what prompted this, or how and when the Forsythe-Floyd relations started.
} 
the same ${ }^{109}$.

This recommendation was followed by many other. In 1974 Knuth wrote another letter for the American Academy of Arts and Sciences. In 1975 he wrote yet another to the John Simon Guggenheim Memorial Foundation.

Relationships, or edges, don't stop at recommendations for faculty positions or places in academic societies, but also take on the more indirect and perhaps less obvious form of scientific references ; of which we know especially in the contemporary period just how great and powerful their role can be for the advancement of one's career ${ }^{110}$.

And, in the The Art of Computer Programming, the discipline's perhaps most revered book in the field of algorithms, if not in its entirety, no other author is more quoted than Floyd. Its publication spans from 1968 to the present day, although it was undertaken in 1962. In the 1997 third edition of 950 Volume 1, Knuth thanks two people by name : his wife and Robert Floyd.

"I have, of course, received assistance from a great many people during the years I have been preparing these books and for this I am extremely thankful. Acknowledgements are due, first to my wife (...) ; secondly, to Robert W. Floyd, who contributed a great deal of his time towards the enhancement of this material during the 1960s." 111

In 2001 Robert Floyd died. In 2002 Donald Knuth gave a one-hour keynote speech to the Stanford Computer Forum. In 2003 he wrote a necrology for Floyd.

When looking back at their relationships, Knuth wrote unequivocally : "Nobody has influenced my scientific life more than Bob Floyd. Indeed, were it not for him, I might well have never become a computer scientist."

As such, we could write with a biographer of Turing that "when looking at

\footnotetext{
${ }^{109}$ Unfortunately, we do not possess information on who was on the Turing Award committee during that period.

${ }^{110}$ This is due to the increasing importance of various rankings.

${ }^{111}$ Knuth 1997 : x.
} 
the work of influential thinkers it is easy to underestimate the role that others played in their work. Having an active, supportive mentor can make all the difference, and Newman played this role for Turing throughout his professional life." 112 For Floyd, we can say that Knuth played that role.

But, sometimes these kinds of relationships, and their directions, take on much more indirect ways such as when Alan Kay later in life recruited the brother of Ivan Sutherland at Xerox.

"Alan knew my brother Ivan Sutherland from his time at Utah, and

I suspect that Alan had a hand in recruiting me to Xerox PARC

SSL." 113

Besides the immediate relationships between Turing award laureates, we found significant the relationships they had indirectly through common, prominent computer scientists :

We lastly found significant that many Turing laureates had studied or been advised by very prominent figures of computer science, which certainly must have helped in getting their work exposed to the ACM or the Turing committee.

Sutherland was advised by Shannon, Iverson and Brooks as already mentioned by Howard Aiken.

\section{Gender (1) : the ACM council and Turing Award jury (1947-2018)}

In three successive sections, we study the incidence of gender in the context of computer science and the Turing Award in particular. We answer successively : how are women represented within 1 . the jury of the award 2. the ACM as a whole 3. the Turing Award itself.

In large parts, the history that we write, the statistics we drew from the various archives, left little place for other, alternative narratives, is a history of exclusion.

\footnotetext{
112 Bernhardt 2016 : 147.

${ }^{113}$ Piumarta and Rose 2010 : 30.
} 
In short : women are underrepresented at all levels of the prize and its

990 (2 men for every woman), the ACM (it took the association 40 years to agree on a female president) and among laureates, most of all there.

In the following table series, we explore the overarching theme of gender and the ACM. In the first of these tables, we look at the composition of the ACM 995 council, the body that governs the ACM.

Table 20: Gender of ACM presidents (1947-2018)

\begin{tabular}{|l|l|l|}
\hline Decade & Men & Women \\
\hline $1947-1949$ & 2 & 0 \\
\hline $1950-1959$ & 5 & 0 \\
\hline $1960-1969$ & 5 & 0 \\
\hline $1970-1979$ & 4 & 1 \\
\hline $1980-1989$ & 4 & 1 \\
\hline $1990-1999$ & 3 & 2 \\
\hline $2000-2009$ & 3 & 2 \\
\hline $2010-2018$ & 3 & 1 \\
\hline
\end{tabular}

Table 21: gender of ACM vice-presidents (1947-1975)

\begin{tabular}{|l|l|l|}
\hline Decade & Men & Women \\
\hline $1947-1949$ & 2 & 0 \\
\hline $1950-1959$ & 5 & 0 \\
\hline $1960-1969$ & 5 & 0 \\
\hline $1970-1975$ & 2 & 1 \\
\hline
\end{tabular}

In her history of the ACM, Cochran remarks that "Sammet was the first woman to lead ACM and became president after many years of activity in the 
association"114. This is to say that for the first 27 years of its existence the ACM had only had male presidents.

A review of the ACM council unveils further that in the first 25 years of its existence, it had only had male presidents and male vice-presidents.

Further, for the first forty years of its existence, the ACM had only been been succesful in finding two qualified and willing female presidents : Adele Goldberg followed in the footsteps of Sammet exactly a decade later.

By the time it had existed for half a century, the ACM had only had three female presidents : Jean Sammet, from 1974 to 1976, Adele Goldberg, from 1984 to 1986, and Gwen Bell, from 1992 to 1994.

The ACM, we do not know when this tradition started, but it existed at least in 1975, publishes letters by acting presidents : in them, they for instance outline their vision for the ACM or discuss current issues within the organization (e.g. lacking finances) amongst other things.

In trying to better understand, gender relations, especially at its highest echelon, of which we know from other domains, that it is there that gender inequalities are the most intense, to the detriment of women who are rarely present at such a level ${ }^{115}$, we looked at the "president's letters" of Jean Sammet.

We were all the more surprised when Sammet entitled hers, a series of six letters of roughly two pages each, "The Great Diversity in ACM", but never acknowledged in them her own situation as the first female president or what we can only assume based on our statistics, both of the Turing award and the ACM council, must have been a stark underrepresentation of women in leading positions (at the ACM).

Instead, she describes as the most controversial issues those pertaining to whether the ACM should engage in critical debates on the role of technology in society (she cites as examples the "Unique Identifier, ABM [and] privacy

\footnotetext{
${ }^{114}$ Cochran 1987 : 869.

${ }^{115}$ Only $5 \%$ of the largest listed companies in Europe have a woman for (as) CEO. See European Commission 2016.
} 
legislation" $\left.{ }^{116}\right) \cdot{ }^{117}$

This coincides with the research of Toland into the politics of the ACM. In her article we learn that Sammet, while being in favor of women's rights, specifically the Equal Rights Amendment, that was hotly debated within and outside the ACM in around 1972 she felt that it was not the role of the ACM to become a voice in those debates, much to the anger of other ACM members and staff who saw things differently ${ }^{118}$.

At around the same time as Sammet published her president's letters, that same year, in, 1975, former vice-president of the ACM Council, Bruce Gilchrist published a report in Communications of the ACM called "Discrimination in the Employment of Women in the Computer Industry", in which he refers to a previous piece of legislature, the Equal Pay Act of 1964, and assures that "the lack of qualified individuals", by which he means women, "does not, of course, explain the unequal pay", but ultimately concludes that "caution should be exercised before making unequivocal claims of wage discrimination against women." 119

Despite his experience, twice, as secretary, from 1960 to 1962, and vicepresident, from 1962 to 1964, it does not occur to him, as it had neither to Sammet, to address the situation at the ACM itself, which at that time had very much stayed a men's club until the arrival of the latter, if one takes for criterium the composition of the ACM Council.

By the turn of the 20th century, something happened within the ACM, or perhaps it was the changes in society that made the ACM change, that made it

\footnotetext{
${ }^{116}$ We assume that UUID, a large number that serves to uniquely identify pieces of software or hardware on computers, or the system as a whole, and agent-based modeling, a statisticalcomputational technique used to predict behaviors based on data collected on (about) individuals or groups, for instance potential criminal activity as infered or determined from various personal characteristics, are what Sammet refers to here. It would be hard to pinpoint what pieces of legislation she meant, possibly none in particular as she also hints at the future, but note that two years before she wrote this the Privacy Act of 1974 had been enacted in her country ; whose purpose it was to establish a framework under which personally identifiable information could be gathered about individuals by US federal agencies.

${ }^{117}$ Sammet 1996 : 53.

118 Toland 2017.

${ }^{119}$ Weber and Gilchrist 1975 : 417-418.
} 
so that its gender politics, as we can tell externally from looking at the statistics, were radically redefined to include women.

But, it took the ACM almost sixty years to start actively looking for female staff at its highest level. This, we conclude from the sudden (abrupt) jump in frequency at which women start to appear as presidents of the ACM starting with the term of Gwen Bell : in short succession, Barbara Simons (1998-2000), Maria Klawe (2002-2004) and Wendy Hall (2008-2010) were elected president.

In the case of the US-based ACM, we believe that of much importance are the events immediately preceding and accompanying the nomination of Bell in the years 1991 and 1992.

The first saw the highly publicized testimony of Anita Hill against then Supreme Court nominee, now member Clarence Thomas, whose assistant she had been at the Department of Education and the EEOC, for sexual harassment ${ }^{120}$. This was followed in 1992, the latter dubbed "Year of the Woman", by a wave of women elected to Senate and House the following year. But, as a retrospective editorial of the New York Times makes clear : "The law changed, too. The month after the hearings, Congress passed a law that allowed sexual harassment victims to seek damage awards as well as back pay and reinstatement." 121

In 1993, the Vienna Declaration and Programme of Action was adopted by the United Nations in June of 1993. It read : "The full and equal participation of women in political, civil, economic, social and cultural life, at the national, regional and international levels, and the eradication of all forms of discrimination on grounds of sex are priority objectives of the international community".

From all the information that we have at our disposal, we can only assume

\footnotetext{
${ }^{120}$ This made the front page of several widely distributed national magazines and newspapers such as Time, whose October 211991 issue was entitled "America's watershed debate on sexual harassment". This was followed by the October 28 issue of People, whose title read : "Anita Hill put the issue on the front page." In New York, where the ACM is headquarted, this also made the front page of the New York Post, "Hill Passes Lie Detector", it read in bold print on October 14 of that same year. (Refer to the appendix for this) See appendix 2)

${ }^{121}$ New York Times 2011.
} 
that the ACM took note of these wider changes within society, be it in law, in popular opinion, in politics, in the media or in the workplace, at the highest of employed.

Table 22: Gender and big technology companies' CEOs and presidents $(1914-2013)$

\begin{tabular}{|l|l|l|l|}
\hline CEO / President & IBM (1914-2011) & Bell Labs (1925-2013) & Intel (1968-2013) \\
\hline Men & 11 & 8 & 5 \\
\hline Women & 0 & 0 & 0 \\
\hline
\end{tabular}

IBM appointed its first female CEO in 2012, almost a century after its creation. Bell Labs has yet to appoint a woman as president. In 2018, Intel has yet to appoint a female $\mathrm{CEO}$ as the company celebrates its 50th anniversary.

Gender-exclusionary practices are common place and have been common place for decades at big technology companies such as IBM and Intel, if we take the way they look at and treat how they select their leadership as measurement.

As such we should look at the ACM's own practices a little less harshly : it had committed, beginning at the latest in the 1990s, to correct its gender gap. But, the ACM only appears progressive in comparison to peers who have, in some cases, century old track records of ignoring women for its highest executive position.

We know from other research, that individuals, when expressing opinions on women's rights or LGBT individuals, answer differently depending on the setting 
and their interlocutor ${ }^{122}$. IBM does not mind female typists, it does not mind female programmers, it does not mind even female vice-presidents. But, in the same way as certain individuals express support for progressive causes in public, and express opposite ones at home, there is few better instances to ascertain the actual positions of companies, including those and in particular those active in the technology sector who have long claimed otherwise, than when they select what is most precious to them, when making those decisions that could affect them in the equally most beneficial and detrimental fashion. "Women cannot be entirely trusted to perform at the highest of levels" would be an accurate expression of their intimate views. Little more can be concluded from the above statistics. And, if their intentions were different or other than what could be interpreted from numbers, we should quote Virginia Woolf, who wrote in Orlando that : "A woman knows very well that, though a wit sends her his poems, praises her judgment, solicits her criticism, and drinks her tea, this by no means signifies that he respects her opinions [or] admires her understanding" ${ }^{123}$.

9.1. Gender, the jury and the award (1966-2018)

Table 23: gender balance within the Turing award committee

\begin{tabular}{|l|l|l|}
\hline Year & Men & Women \\
\hline $2012^{124}$ & $50 \%(4)$ & $50 \%(4)$ \\
\hline $06 / 2013^{125}$ & $60 \%(3)$ & $40 \%(2)$ \\
\hline $08 / 2013^{126}$ & $66 \%(4)$ & $33 \%(2)$ \\
\hline $10 / 2013^{127}$ & $62 \%(5)$ & $37 \%(3)$ \\
\hline $08 / 2014^{128}$ & $57 \%(4)$ & $42 \%(3)$ \\
\hline $10 / 2014^{129}$ & $62 \%(5)$ & $37 \%(3)$ \\
\hline $09 / 2015^{130}$ & $62 \%(6)$ & $37 \%(2)$ \\
\hline
\end{tabular}

\footnotetext{
${ }^{122}$ Two meta-studies give an overview on the state of research in psychology into (this area) these areas : Paluck and Green 2009 and Pettigrew and Tropp 2006.
}

${ }^{123}$ Woolf 2008. 


\begin{tabular}{|l|l|l|}
\hline $11 / 2016^{131}$ & $87 \%(7)$ & $12 \%(1)$ \\
\hline $07 / 2017^{132}$ & $85 \%(6)$ & $14 \%(1)$ \\
\hline $07 / 2017^{(2)}{ }^{133}$ & $83 \%(5)$ & $16 \%(1)$ \\
\hline $09 / 2017^{134}$ & $66 \%(6)$ & $33 \%(3)$ \\
\hline $05 / 2018^{135}$ & $66 \%(6)$ & $33 \%(3)$ \\
\hline Average & 5.08 & 2.33 \\
\hline
\end{tabular}

The jury for the award is consistently skewed towards men. At no point, in the interval that we have had access to, which encompasses seven years of committee changes, though incomplete in some parts, were we able to observe a jury that was in majority women. At best, there was a short equilibrium ${ }^{136}$. At worst, men outnumbered women 7 to 1 in the jury of the Turing Award ${ }^{137}$.

This means that, on average, for the period from 2012 to 2018, more than double the men sat on the jury of the Turing award than did women (approximately 15 men for every 7 women).

There is much to believe, based on our review of ACM council staff, for which we had access to much older archives, as well as other information presented elsewhere here, that gender ratios within the jury of the Turing award were for long periods of time during its history, especially in earlier decades, of the kind we observed and possibly much worse.

\footnotetext{
${ }^{124}$ Archive from 09/11/12.

${ }^{125}$ Archive from $02 / 06 / 13$.

${ }^{126}$ Archive from $28 / 08 / 13$.

${ }^{127}$ Archive from $15 / 10 / 13$.

${ }^{128}$ Archive from $21 / 08 / 14$.

${ }^{129}$ Archive from 04/10/14.

${ }^{130}$ Archive from $06 / 09 / 15$.

${ }^{131}$ Archive from 30/11/16.

132 Archive from 03/07/17.

${ }^{133}$ Archive from $21 / 07 / 17$.

${ }^{134}$ Archive from 20/09/17.

${ }^{135}$ Archive from 10/05/18.

${ }^{136}$ Jury composition on $09 / 11 / 2012$.

${ }^{137}$ Jury composition on $30 / 11 / 2016$.
} 
Because the committee headed by a chair, we also provide information on

\section{Gender (2) : Winners and losers}

We turn now to the laureates. We avoid here explicitly the term winners, as, we find that, there are losers among the winners. And, that demographic is women.

Table 24: gender distribution of Turing award winners

\begin{tabular}{|l|l|}
\hline Men & Women \\
\hline $95 \%(61)$ & $4 \%(3)$ \\
\hline
\end{tabular}

$\mathrm{n}=64 \mathrm{t}=64$

1135

In the 50 years of the Turing award, $95 \%$ of recipients of the prize have been men. It took the jury of the Turing award 40 years to find its first qualified female (women) prize winner in Frances Allen, in 2006.

Only 3 women won the Turing award between 1966 and 2016. They are Frances Allen, Barbara Liskov and Shafi Goldwasser. Their awards were all given in rapid succession, in 2006, 2008 and 2012.

From scholarship written on other awards, we know that this is part of a very consistent pattern : of the Nobel Prize, a 1991 study of female laureates opens by saying that "barely 10 times has [it] been awarded to women since its creation in 1901." 138

Did the ACM and the Turing award change or did the world around them? 
In any case, these drastic changes can probably be viewed as fitting inside wider movements, demands and reforms within society, in the U.S. and many parts of the rest of the world.

Note that this also coincides, as we show elsewhere here, with changes within the governance of the ACM itself that make it so that women begin to be elected as presidents of the ACM starting in the mid-1990s ; and we have much reason to believe similar changes to take place in the Turing Award committee, though this cannot be said for certain without access to the relevant archives.

Table 25: gender distribution of Turing award winners split by decade (1940s-2010s)

\begin{tabular}{|l|l|l|}
\hline Decade & Women & Men \\
\hline $1966-1969$ & $0(\%)$ & $4(100 \%)$ \\
\hline $1970-1979$ & $0(\%)$ & $13(100 \%)$ \\
\hline $1980-1989$ & $0(\%)$ & $12(100 \%)$ \\
\hline $1990-1999$ & $0(\%)$ & $12(100 \%)$ \\
\hline $2000-2009$ & $2(\%)$ & $14(87.5 \%)$ \\
\hline $2010-2016$ & $1(\%)$ & $9(90 \%)$ \\
\hline
\end{tabular}

As such, we cannot help but ask : was the jury unable to find qualified female applicants in previous decades, in fact for much of its history, because the ACM itself was an institution that did not value, or otherwise encourage, and at least objectively did not practice diversity within its governance?

Do women start to appear among the winners of the prize at the beginning of this century, because at the turn of the previous one the ACM started appointing women as presidents and included them in the jury of the prize as well?

That an award dedicated to computer science need not necessarily be this way, we can ascertain by looking at other, similar awards' practices, in this case we have consistently used the IEEE, the other big association relevant to computing and computer science, as reference point and specifically its Computer 
In the case of the Computer Pioneer Award, the first award made to a woman was in the year 1997, Frances Snyder-Holberton, which puts it almost 10 years before the same was done for Frances Allen by the Turing Award. This means, put otherwise, that it took the IEEE and the Committee of the Computer Pioneer Award about 15 years to reward women with its highest distinction in the discipline since its creation in 1981.

Finally, we asked : how long did it take for women to be recognized for their work, in the context of the Turing award, compared to their male peers or counterparts?

Table 26: Number of years needed to obtain the Turing Award, split by gender

\begin{tabular}{|l|l|l|}
\hline & Men & Women \\
\hline Age (avg) & 55 & 65 \\
\hline
\end{tabular}

$\mathrm{n}=64 \mathrm{t}=64$

On average, it took women 10 years longer than their male counterparts to obtain the Turing award. This, we measured by calculating the difference between the year of birth of Turing winners and the year they won the award.

Frances Allen, the first woman to win the award, was 74 at the time of her nomination, Barbara Liskov 69, and Shafi Goldwasser, who has obtained the award the most recently of all three, 54. This makes Allen the third oldest Turing award winner ever and Liskov the tenth.

The youngest 10 Turing Award winners ranged from age 36 to 44. In more detail yet, this also means that the youngest 25 Turing award winners were all men. The youngest Turing award winner ever was Donald Knuth, who obtained it when he was 36 years old, followed by Robert Tarjan, 38 and Kenneth Thompson, 40. They are followed by four individuals who obtained it at age 42 respectively : Dennis Ritchie, Marvin Minsky, Edsger Dijkstra and Robert 
Floyd. ${ }^{139}$

Let us look closer at these happenings and at two examples in particular that we hold for exemplary of the disparities between both sexes when it comes to the recognition of their work within computer science.

After completing a bachelor's degree in mathematics, Frances Allen worked as a high school math teacher for two years before obtaining a master's degree in that same discipline from the University of Michigan, where she learned how to program on an IBM 650 from Bernard Galler ${ }^{140}$, and joining IBM Research as a programmer in 1957. Her first assignment there was to teach Fortran to employees, which lead her to study the Fortran compiler developed by John Backus. Much of her work at IBM from then on focused on compilers ${ }^{141}$. This included developing a compiler for Stretch and Harvest - Stretch, one of the earliest supercomputers, and Harvest, a coprocessor developed by the NSA for codebreaking - with support for three programming languages including Alpha which she had worked on. She then contributed to Project $\mathrm{Y}^{142}$, whose goal was to be many times faster than the previous project, Stretch. For the Project Y computer, a compiler was built whose optimizer ${ }^{143}$ Allen wrote. Project Y later became ACS, IBM's Advanced Computing System. The ACS-1 had in turn for

\footnotetext{
${ }^{139}$ Note Dennis Ritchie was a close collaborator of Kenneth Thompson and their Turing was awarded jointly, while Robert Floyd was Donald Knuth's most important scientific influence according to himself.

${ }^{140}$ President of the ACM between 1968 and 1970, Vice-president from 1966 to 1968. See appendix.

${ }^{141} \mathrm{~A}$ compiler is a piece of software "that reads a program written in one language (...) and translates it into an equivalent program in another language". This definition is based on Aho, Sethi and Ullman 1986: 1 .

${ }^{142}$ In her interview with Guy Steele, who also wrote her Turing biography, Allen refers to the project as "System Y". See Steele 2011. Brian Randell, who worked on the project from 1964 to 1966, and Lynn Conway, from 1965 onwards, (both colleague of Allen and Cocke at IBM,) keep with the nomenclature "Project Y". See Randell 2015 and Conway 2011.

${ }^{143}$ In the classic compiler design book Compilers: Principles, Techniques, and Tools, which descends from a previous book by Aho and Ullman published in 1977, Aho, Sethi and Ullman write of code optimization : "Ideally, compilers should produce target code that his as good as can be written by hand. The reality is that this goal is achieved only in limited cases (...). However, the code produced by straightforward compiling algorithms can often be made to run faster or take less space, or both. This process is achieved by program transformations that are traditionally called optimizations. Compilers that apply code-improving transformations are called optimizing compilers.
} 
ambition to be many times faster than the reference machine at that point ${ }^{144}$ and later evolved into ACS-360 when a decision was made to support another system $^{145}$. It was abandonned in 1969. After this, Frances Allen went on to work on ECS, the Experimental Compiling System ${ }^{146} \cdot{ }^{147}$

On both of these projects, Y and ACS, Allen collaborated with John Cocke, who was seven years her senior and was also key in the development of the RISC architecture.

Together they wrote a series of articles and reports that reflected much of her practical work done at IBM on optimizing compilers such as the 1971 "A Catalog of Optimizing Transformations" ${ }^{148}$. These joint publications were preceded by Allen's own, including "Program Optimization", published internally in $1966^{149}$. In 1969 Cocke and Schwartz' Programming languages and their compilers was published at the Courant Institute, "an extremely good summary of the work done in the field" ${ }^{150}$, followed in 1970 by Cocke's own paper (research) on (compiler) optimization "Global common subexpression elimination"151.

In recognition of her contributions, the ACM wrote in her Turing citation that it had awarded her its highest distinction : "For pioneering contributions to the theory and practice of optimizing compiler techniques that laid the foundation for modern optimizing compilers and automatic parallel execution."

And, yet, it awarded Cocke and Allen the Turing Award in 1987 and 2006 respectively. This is to say that between both nominations lie almost 20 years.

Is is important to mention in this context, that, compared to the IEEE's own

\footnotetext{
${ }^{144}$ The IBM 7090 mainframe computer.

${ }^{145}$ The IBM System/360 mainframe.

${ }^{146}$ See Allen at al. 1980 for an overview of this project.

${ }^{147}$ Unless otherwise stated, the sources for these information are : the Turing Award biography of Frances Allen ; Smotherman 2017 ; Steele : 2011.

${ }^{148}$ IBM Research Report RC 3548 from September 1971. Republished in Allen and Cocke 1972 .

${ }^{149}$ Allen 1969. “Allen's seminal paper on Program Optimization (published internally in April, 1966 and in an expanded version in the open literature in 1969), resulted from the ACS work." according to the her IEEE Computer Pioneer award biography. https://www. computer.org/web/awards/pioneer-frances-allen ${ }^{150}$ Cocke and Schwartz 1969 ; Pollack 1971.

${ }^{151}$ Cocke 1970.
} 
practices, the gap between Cocke's and Allen's nomination for the Computer

1230 Pioneer Award is similar. The latter prize was awarded to both of them in 1989 and 2004 respectively hence a gap in differentiated recognition of 15 years (versus 19 years).

Margaret Rossiter who has looked at the wider history of women in science in the USA and has written what is to our knowledge the reference text on the subject for that country, the three-volume Women Scientists in America, has sought to generalize her findings by postulating the "Matilda Effect" in science.

In the abstract to her seminal article, she writes : "Recent work has brought to light so many cases, historical and contemporary, of women scientists who have been ignored, denied credit or otherwise dropped from sight that a sexlinked phenomenon seems to exist" 152 .

Perhaps the best example for such phenomena is the fate of Lise Meitner, who not only had to overcome the great prejudices of her times against women in both secondary and higher education ${ }^{153}$, as the second woman ever to obtain a $\mathrm{PhD}$ in physics at the University of Vienna ${ }^{154}$, but whose 30 year collaboration with Otto Hahn had for outcome that he only was awarded the Nobel prize.

Much of the same could be written about Marie Curie, the first woman to win the Nobel, whose 1903 Nobel prize in physics was only jointly awarded to her as well as her husband, in addition to Becquerel, on account of the intervention of prominent Swedish mathematician Mittag-Leffler ; and other important female scientists of past periods.

In the preface to her monograph on female Nobel winners, Folsing writes : "At the yearly Nobel Prize ceremony, in Stockholm, the Swedish king almost only deals with an assortment of men. Women, if at all, appear to the ceremony as wives and as such fulfill a role barely more than decorative. Only in the most

\footnotetext{
${ }^{152}$ Rossiter 1993.

${ }^{153}$ Women in Austria were not allowed to study at university up until 1899. They were also banned from attending high school, at least this was the case in 1892 in Vienna, where Meitner was born. See Folsing 1991 : 148.

${ }^{154}$ Sime 1996.
} 
155 Folsing 1991 : 7. Our translation.

${ }^{156}$ Conway was staff at IBM and also worked on the ACS project, see Conway 2011.

${ }^{157}$ Conway 2016.

${ }^{158}$ Mead and Conway 1980

${ }^{159}$ See appendix.

${ }^{160}$ Conway 2000; Hiltzik 2000. 
areas of computer science, with women computer scientists in employment in

others.

Indeed, we see no coincidence in the fact that the most prominent women computer scientists all did work in software-related areas like compilers, as Allen did, like Hopper did, and the "original ladies of the ENIAC". They did so because men were busy doing the real work of machine design, like Cocke himself did, like Neumann did before him, and he whomever he may be who came before them.

Regarding this balance of tasks, Alan Kay has said of his employment of programmer in the US Army in the early 1960s :

"They needed programmers. This was back in the days when programming was a low status profession and most of the programmers were women. My boss was a woman. They also were taking linguists who had served in Europe when they came back to the United States. It was actually a pretty interesting bunch. I had a friend who was a black guy who did what today we would call an operating system." 161

This is in complete reversal with our knowledge of current happenings in the technology sector, where the most prestigious positions are all within software (e.g. AI, ML) while women may be found, if at all, in systems engineering jobs, or subaltern accounting or support positions, often the only women present at these companies ${ }^{162}$.

The labor division within computer science research can be traced back to its very beginnings : Babbage created the analytical engine, while Ada wrote programs for it, wrote a report for it and helped document/promote it. What was unexpected, however, was that it was she, an amateur mathematician with little more than basic knowledge of mathematics as one historian of science

${ }^{161}$ Shasha and Lazere 1995.

${ }^{162}$ This relies on ethnographic observations. 
highlights ${ }^{163}$, would be the one to understand and theorize on the true nature and important role of the new machin. She understood clearly, and wrote accordingly in her notes, that it was its potential to compute more than just numbers that mattered ${ }^{164}$.

This divide between machines (contemporaneously called "systems" 165 , also alternatively referred to as "hardware", "computer architecture", "computer systems", or indeed simply "systems", and in past centuries as "engines") and software is at the heart of many developments within computer science. Historically, women have made contributions in those areas, men in the former ones. This is all the more significant, as the formerly prestigious area of hardware systems originally populated primarily by men has become subordinate to computational software developments (AI) and this balance is now reversed.

In the following we ask the questions : what areas have attracted female Turing award winners? Ultimately is there a link between gender and research $1320 \quad$ areas?

To answer this, we looked at the various domains of computer science that Turing award winners had made contributions in and correlated them with gender (of which the following table is the outcome).

We listed the areas in descending order according to the number of women that we found in them (as a percentage of total Turing award winners within these areas) together with other key areas ${ }^{166}$.

Table 27: gender distribution of Turing award winners by research areas

\begin{tabular}{|l|l|}
\hline Area & Women $(\%$ of total) \\
\hline Compilers & $1(33 \%)$ \\
\hline
\end{tabular}

\footnotetext{
${ }^{163}$ Swade 2008.

${ }^{164}$ Lovelace 1843

${ }^{165}$ Although, this is also applied to (large) software and although this can also mean virtual machines.

${ }^{166}$ The full table is available in the appendix
} 


\begin{tabular}{|l|l|}
\hline Operating Systems & $1(25 \%)$ \\
\hline Computational Complexity & $1(14 \%)$ \\
\hline Cryptography & $1(14 \%)$ \\
\hline Programming Languages & $1(11 \%)$ \\
\hline Computer Architecture & $0 \%$ \\
\hline Computer Hardware & $0 \%$ \\
\hline Computer Systems & $0 \%$ \\
\hline
\end{tabular}

Of 32 total areas listed by the ACM, 5 only feature women, or $15 \%$. They are : compilers, operating systems, computational complexity, cryptography and programming languages. In turn, this also means that 27 areas are completely void of women : the Turing Award committee seems to come to the conclusion that in all of those 27 areas there were no women that had made "lasting contributions" that were on the same level as those of the men whose work had respectively been recognized as worthy of the distinction.

The areas from which women are absent include much of systems, algorithms (combinatorial algorithms, analysis of algorithms) and various other fields of mathematics (e.g. numerical analysis, numerical methods).

The table reveals on the other hand "feminine" areas of computing, which is to say areas of computing were women are not only active but were judged worthy of the prize, we list them again here with their respective percentages 1340 : compilers (33\%), operating systems (25\%), computational complexity (14\%), cryptography (14\%) and programming languages (11\%).

This fits with our general knowledge of the historic participation of women in computing, which saw them mostly working with programming languages during and after $\mathrm{WW} 2^{167}$.

\footnotetext{
${ }^{167}$ We refer to the quote by Alan Kay provided elsewhere here and especially to the monograph by Abbate, Recoding Gender, which contains many interviews with female computer scientists and programmers from that period.
} 
give indications as to gender ratios and the proportion of men vs. women working within certain areas, with compilers and operating systems, both strongly connected domains, and often taught in combination, being the most "feminine" areas of computer science, at least based on the historical statistics drawn from the Turing Award.

In the following we attempt a broad classification of areas that go beyond the results exhibited previously ${ }^{168}$.

Table 28: big areas of computing and female Turing award winners

\begin{tabular}{|l|l|}
\hline Main areas & Women (\% of total) \\
\hline Software & $\mathbf{8 . 6 \%}$ \\
\hline - Compilers & $33 \%(1)$ \\
\hline - Operating Systems & $25 \%(1)$ \\
\hline - Programming Languages & $11 \%(1)$ \\
\hline - Objected Oriented Programming & $0 \%(0)$ \\
\hline - Software Engineering & $0 \%(0)$ \\
\hline - Software & $0 \%(0)$ \\
\hline - Programming & $0 \%(0)$ \\
\hline - Databases & $0 \%(0)$ \\
\hline Systems (Hardware) & $\mathbf{0 \%}$ \\
\hline - Computer Architecture & $0 \%(0)$ \\
\hline - Computer Hardware & $0 \%(0)$ \\
\hline - Personal Computing & $0 \%(0)$ \\
\hline - Computer Systems & $0 \%(0)$ \\
\hline Artificial Intelligence and Machine Learning & $\mathbf{0 \%}$ \\
\hline - Artificial Intelligence & $0 \%(0)$ \\
\hline - Machine Learning & $0 \%(0)$ \\
\hline
\end{tabular}

\footnotetext{
${ }^{168}$ The full table is available in the appendix. As with all such attempts, trying to subsume complexity into simpler forms necessarily means loosing some of their distinctive qualities. We feel there is room for improvement here.
} 


\begin{tabular}{|l|l|}
\hline Cryptography & $\mathbf{1 4 \%}$ \\
\hline - Cryptography & $14 \%(1)$ \\
\hline Computational complexity & $\mathbf{7 \%}$ \\
\hline - Computational Complexity & $14 \%(1)$ \\
\hline - Analysis of Algorithms & $0 \%(0)$ \\
\hline Mathematics (other) & $\mathbf{0 \%}$ \\
\hline - Combinatorial Algorithms [comb. optimization] & $0 \%(0)$ \\
\hline - Numerical Analysis & $0 \%(0)$ \\
\hline - Numerical Methods & $0 \%(0)$ \\
\hline - Proof Construction & $0 \%(0)$ \\
\hline Misc. & - \\
\hline - Education & $0 \%(0)$ \\
\hline - Graphics & $0 \%(0)$ \\
\hline - Interactive Computing & $0 \%(0)$ \\
\hline - Internet Communications & $0 \%(0)$ \\
\hline - List Processing & $0 \%(0)$ \\
\hline - Verification of Hardware and Software Models & $0 \%(0)$ \\
\hline - Parallel Computation & $0 \%(0)$ \\
\hline - Data Structures & $0 \%(0)$ \\
\hline - Error Correcting Codes & $0 \%(0)$ \\
\hline - Program Verification & $0 \%(0)$ \\
\hline
\end{tabular}

Note : categories are not listed alphabetically, but by order of number of women, then degree (including of certainty) to which the individual category belongs to the overarching one (e.g. Software, Systems, etc.).

To provide some more context for these developments and to extrapolate on them, we try to integrate these findings into the broader history of women's place in computing.

It is interesting that the history of computers, computer science and com- 
puting in general, should be so strange. Indeed, it subverts much of our current notions on the role and place of women within technology. There they operate various, for the most part experimental machines, and program their novel systems, while here they are grossly underrepresented, in education, in industry, in academia and various other places.

Early computer pioneers, starting with Ada Lovelace in the previous century, were in fact women. Babbage created the analytical engine, but she was the one who understood its purpose was much bigger than just that of calculator. "It might act upon other things besides number", she wrote in her notes ${ }^{169}$.

Women in computing are met again during WW2 when men became unavailable and thus many women were thrusted into technological employment, as someone had to operate the emerging wave of computers after all. They became typists, programmers, they punched cards to be processed by these new machines, some made extraordinary contributions, in fact many of the early programming languages and compilers were the works of women.

In the late 1950s, as men had come back from duty, women were courted by big companies such as IBM, presumably because they were the ones who had primarily operated computers during the war and as such had the most experience. In one famous brochure, from the "My Fair Ladies" campaign, a typewritter with flowers overlaid on top catered to women especially ${ }^{170}$.

In the 1960s and 1970s, it had become common for major manufacturers of computers to display women as objects of their advertisements : they were alternatively seen typing while holding manuals, filing various tapes and in one ad a woman wearing high heel boots and not much else is stepping on a computer ${ }^{171}$.

In the late 2010s, male recruits in major Chinese tech companies such as Baidu, the leading search engine in that country among other things, and Alibaba, a leader in e-commerce, are lured with promises of working in the same

\footnotetext{
${ }^{169}$ Lovelace 1843

${ }^{170}$ See appendix.

${ }^{171}$ See appendix
} 
company as attractive young women : one is dancing on a pole while two other's presumably scripted dialogue include the line "I love tech boys" 172 .

A brief history of women in computing sees them going from amateur mathematicians to programmer typists to ad-pinups, from 1850 to the present, with a very late recognition starting to happen at the end of the last century when the IEEE gave its higest distinction in computing to one of the original ladies of the ENIAC, Frances Snyder-Holberton, in 1997 and when the ACM followed in 2006 by giving Frances Allen its Turing Award.

\section{Ethnicity and the Turing Award}

We use "race", because of its prevalence in US-centric discussions and use that term, as it is commonly understood there, equivalently with ethnicity.

Looking at the ethnicity or "race" of Turing award winners, we come to the conclusion that here as well entire groups are objectively excluded from its select - both academically and also socially as we have shown - pool of winners.

In a first attempt, we use birth place as proxy and reassess previously presented data to this effect.

Table 29: Turing laureates from outside North America and Europe

\begin{tabular}{|l|l|}
\hline Country & Turing winners \\
\hline North America* & $43(64 \%)$ \\
\hline Europe & $14(21 \%)$ \\
\hline Outside Europe / North America & 7 \\
\hline - Israel & $3(4 \%)$ \\
\hline - British India & 1 \\
\hline - Ceylon & 1 \\
\hline - China & 1 \\
\hline - Venezuela & 1 \\
\hline
\end{tabular}

\footnotetext{
${ }^{172}$ See appendix.
} 
* USA and Canada.

But, we are able to go further as we know in detail, from our prosopography, who are behind the countries and what their circumstances are : in the case of Ceylon, Antony Hoare, who is white, in the case of Venezuela, Manuel Blum, whose Jewish parents had left Europe, in the case of British India, Dabbala Reddy who is not white.

None of the Turing laureates are black. None of them come from Africa. None of them are American-African or Hispanic.

The table we established based on this knowledge and our findings, may not be perfect but it should be attempted :

Table 30: Race and Turing laureates

\begin{tabular}{|l|l|}
\hline Demographics & Turing Award laureates \\
\hline Whites & $59(92 \%)$ \\
\hline - North America* & 43 \\
\hline — Europe & 14 \\
\hline - Ceylon** & 1 \\
\hline - Venezuela*** & 1 \\
\hline Non-whites & $5(7 \%)$ \\
\hline - Israel & 3 \\
\hline - British India & 1 \\
\hline - China & 1 \\
\hline
\end{tabular}

$\mathrm{n}=64 \mathrm{t}=64$

1415 This analysis is based on places of birth and our knowledge of the population based on collective biography (prosopography).

* There are no African-Americans among the Turing Award laureates.

** Antony Hoare, whose father was a colonial civil servant and who is white. *** Manuel Blum, whose parents emigrated to Venezuela from Europe.

${ }_{1420}$ Over $90 \%$ of Turing laureates are white and only $7 \%$ are non-white. 
To establish this, and to provide more evidence, we have also approached the problem from another perspective. The ACM provides not only biographies from Turing Award laureates, but also photographies. We have used this ressource as well.

We proceeded to make a collage from them by using simple HTML code to load the images of Turing winners directly from the ACM website. The result of this is as follows, in the figure entitled "Ethnic (and gender) diversity amongst Turing winners".

In our review of Turing award winners between 1966 and 2016, we were only able to distinguish 2 non-white Turing Award laureates. They are Raj Reddy and Andrew Yao, of Indian and Chinese descent respectively. The overwhelming majority of Turing laureates is primarily from European ancestry. A significant portion is of Jewish origin ${ }^{173}$.

\section{Making an award : the politics of careful biographical attribution and the erasure of diversity}

When Alfred Nobel established the Nobel Prize at the end of the 19th century, he explicitly named physics, chemistry, physiology or medicine, literature and peace in his 1895 will $^{174}$. For these disciplines or areas, the first Nobel Prizes were awarded in $1901 .{ }^{175}$

The original provisions of the Nobel prize did not - and sometimes could not - include a number of subjects, such a prominently mathematics or economics. Another one is computer science, which only became an individual discipline during the 1960s. In the case of mathematics, the Fields Medal serves as the discipline's highest distinction ${ }^{176}$.

\footnotetext{
${ }^{173}$ Goldwasser, Feigenbaum, Blum, etc.

${ }^{174}$ A copy of the relevant parts of Nobel's will can be found in Nobel Foundation $1972: \mathrm{x}$. ${ }^{175}$ Ibid : 638-639.

${ }^{176}$ For a discussion of the absence of a Nobel in mathematics, see Morrill 1995. He concludes, citing various previous commentaries, that Nobel may not have felt that mathematics had "sufficient relevance to human development" and rejects in the process competing explanations regarding a supposed rivalry between Nobel and mathematician Mittag-Leffler.
} 
Figure 1: ethnic and gender diversity amongst Turing winners

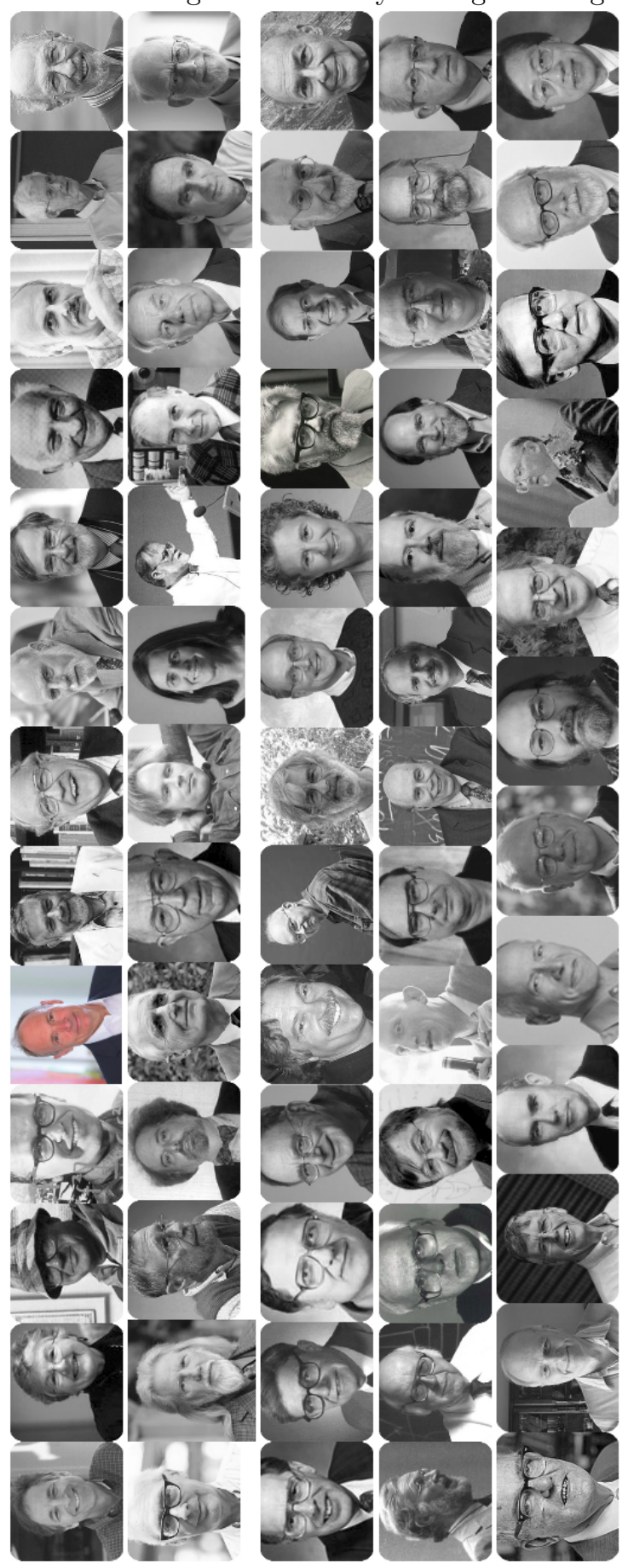



up as follows : how to give stature and prestige to something just recently created? Historically, there have been a number of ways that groups behind such awards have employed to deal with this fundamental problem, such as naming their prize a distinguished figure, associating it with an established

hosts a collection of materials relating to the event, redirects to it as "Promotional Video". We hypothesize that this may have been the context for its creation.

${ }^{177}$ Lebaron 2002

${ }^{178}$ The most authoritative account of the history of women in science is perhaps Rossiter's three-volume monograph called Women Scientists in America. For Europe, see the work of Annette Vogt amongst others.

179 "A.M. Turing Award Video". https ://amturing.acm.org/amtv.cfm. The title or mention "The origins of the ACM A.M. Turing Award" stands above the video as well. This page links to https://www.youtube.com/watch?v=f_8s451zYYE entitled "The ACM A.M. Turing Award".

${ }^{180}$ The platform on which the video is hosted, YouTube, gives the following indication "Published on 16 Jan 2013", but we believe the date of its creation to be 2011. This is based on the following URL, delivery.acm.org/10.1145/2330000/2322176/AMTuringACM2011.mp4 (note that this URL has been stripped from parameters, as its delivery is dependent on various individual information such as IP, it is not directly accessible). The URL https: //dl.acm.org/citation.cfm?id=2322176, title "ACM Turing Centenary Celebration", which 
the award" 179180 . It is more than two-thirds a biography of Alan Turing - this includes the first minute - while less than twenty seconds of its almost 2 minute running time is on the award itself proper.

In this brief passage that concerns the award, as opposed to selected passages from Turing's life, the narrator explains : "In 1966, the Association for Computer Machinery instituted the Turing award to honor the memory of Alan Turing. Over the years, it has become universally recognized as computing's most prestigious award, given each year to individuals selected for making lasting major technical importance to the computing community." In this both presentational and representational video the words "lasting major technical words" are highlighted. But, it is also useful to note what is not.

No biography is neutral, neither in form nor in content, and in this case, it takes on the format of a list or succession of Turing's various accomplishments : his 1936 paper "On computable numbers", Bletchley Park, his later work on artificial intelligence ${ }^{181}$ ("Can machines think?") are referenced. ${ }^{182}$

But, both what is mentioned and left out is of importance : no word on his personal life. This is noteworthy in the sense that the Prize does not shy away from politics in other instances, for instance when it mentions the political activities of one winner who had been been an opponent to Norway's joining of the European Union. As such, it would be surprising that where Alan Turing was concerned, any bits of private biography, of which we now know just how important they are to understanding his life, would suddenly be considered irrelevant.

"But Kristen was not just a pioneer and researcher in informatics. He was an engaged social and political citizen, involved in several aspects of society, including politics. During the intense political

\footnotetext{
${ }^{181}$ Turing 1950.

${ }^{182}$ It should be mentioned here that where common or popular presentations of Turing's contributions to computer science go, recent scholarship has sought to reevaluate the exact role played by Turing and the nature of his legacy. See Haigh 2014, Daylight 2014 and 2015 and Bullynck et al. 2015.
} 
fight before the 1972 Referendum on whether Norway should become member of the European Common Market, he worked as coordinator for the large majority of youth organizations that worked against membership. He also was the leader (1990-1995) of Norway's No to the EU movement, which argued against Norwegian membership of the European Union and led to victory in the 1994 referendum." 183

In the biographies of the laureates it publishes, the ACM neither blends out politics, nor family life, nor marrital details, and the various conclusions because "it was his individual freedom of mind, including his sexuality, that

\footnotetext{
${ }^{183}$ Turing Award biography of Kristen Nygaard.

${ }^{184}$ Turing Award biography of John Cocke.
} 
mattered" 185 .

One might even be tempted to use the words that professor Hofstadter has used when talking of Sara Turing, the mother of Alan Turing, "whitewash"186, and conclude that the ACM found attractive the idea of naming their prize after the most iconic of all computer scientists, but found very advantage in the notion that this man had also lived a life outside of mainstream society and been homosexual.

At a minimum, we must paraphrase him in writing that this was most likely because the organizers of the prize, like his mother, "wore conventional blinders and did not want to see, let alone say" ${ }^{187}$. In fully embracing the name and legacy of Turing, the ACM could have contributed to the progressive civil rights movements of the times that saw the creation of the award in the late $1960 \mathrm{~s}$, by stating all that he had been, the resilience he had shown both in science and life ${ }^{188}$. And, that in any case they had used his name, the name of another man, because it was those kinds of characteristics they hoped to see in future winners (in addition to scientific merit).

But, it seems that, even now, this is a part of Alan Turing's life and legacy the ACM would rather not be seen associated with openly. It cherry picked parts from his biography, only those parts it deemed the best, creating a fairy tale of a well-fitted, neither too modest, for he had been a great man and this was to be an equally great prize, nor too abrasive portrait of a complex person

\footnotetext{
${ }^{185}$ Hodges 2014 : xv.

${ }^{186}$ Hodges 2014 : xii.

${ }^{187}$ Hodges 2014 : xiii.

${ }^{188}$ Alan Turing was subject of a lawsuit on 31st of March 1952, Regina $v$. Turing and Murray. Considering his status and the nature of the lawsuit ("gross indecency" based on the Criminal Law Amendment Act 1885, a Victorian era legal phrase for gay sex), it seems likely that in the following almost 15 years between this event and the creation of the Turing award, knowledge of this must have been public, including in America. Hodges refers to one newspaper article from that period ("University Reader Put on Probation. To have OrganoTherapic Treatment" by the Wilmslow newspaper) and also cites an episode where Turing announced the events to Max Newmann in the refectory, presumably of the University of Manchester, "in a particularly loud voice", for all to hear. See Hodges 2014 : 464, 471, 472. But, he also writes that during the inquest, which had been attended by "a row of journalists", "nothing was mentioned that hinted at sex, the trial, blackmail or anything of the kind" and that following this event "the national press made remarkably little of it, and nothing was said regarding the 1952 trial". For this, see Hodges 2014 : 488.
} 
; an image of a person that is ultimately non-existent for no one lives, not even the greatest of mathematicians, not even and everyone knows not Archimedes, in the abstract, otherworldly confines of mathematical research alone ; the same kind of willful denial and misplaced politeness that had made Turing's existence so hard and ultimately tragic in lifetime, and his place inside the rigid structures left over by Victorian society so unlivable, painful and strange ${ }^{189}$.

This is all the more incomprehensible and incompatible with a view of a computer science prize that only cared about intrinsically scientific discoveries if such a view was tenable, to which many philosophers and historians of science would have a very different one to oppose, one grounded in the actual, historical development of sciences - as the Turing Award pages inject many elements from personal life into the biographies they craft for the Turing laureates, highlighting often the most original and colorful aspects of their personalities and lives this winner worked as a store clerk after emigrating to America and another was a poor student throughout high school - in portraits that ultimately culminate in a synthesis of scientific advancements and personal life, often deeply interwoven, and where biography has a value other than (is not) merely accidental or incidental or otherwise anecdotal.

Alan Turing was born in 1912. He died in 1953 at age 41. Neither Bletchley Park, nor his much quoted paper of 1936 gives us any insight into the anomaly that was his shortened life or helps us understand much of it, but an authentic portrait would. He died prematurely because he had the misfortune of being

\footnotetext{
${ }^{189}$ For the sake of exhaustivity, we should mention that many poor biographies have been written about Turing, starting with his own mother's, who, as Hodges states, was writing about a stranger whose work she had not the intellectual capabilities to understand and whose personal life she arranged to her own satisfaction. Jack Copeland, a philosophy professor, has managed the incredible feat of discussing Turing's death over ten pages from the perspective of plausible modes, reviewing in great detail the many possibilities he had conjured up in his mind, without considering in his expose the cummulative sum of social climate, the law, the lawsuit, the chemical castration, the general reprobation against homosexuality, the absence of a normal future, the absence of a normal past, that can never be made good, or anything that would have occurred to anyone discussing the suicide, since it has been ruled so, of a homosexual man in early 20th century Britain, having gone through the legal and medical and criminal apparatus reserved to gay men of that time. We are aware of other biographies that attempt to assess the lawsuit against Turing from the point of view of Logic.
} 
born into a society whose entire fabric, founded on the latest of scientific, political, psychological, psychiatric, judicial, criminal and societal consensus, seemed to agree, for the most part, that homosexuality was wrong and abnormal and that those who were it thus deserved reprobation, prison and exclusion from normal lives ; a society deeply unkind to and unfit for people like him. For this, he lost his employment and underwent chemical castration to avoid imprisonment. He killed himself shortly after ${ }^{190}$

We must mention that subsequently, there has been disagreement about the nature of Turing's death, much of it originating from his mother, Sara Turing, who argued early on it was an accident ${ }^{191}$. However, we also know from Hodges that she had a strong inclination for shaping her son's legacy according to her own preconceptions and wishes, rather than truth ${ }^{192}$. This thesis was later reactivated by Jack Copeland in his book Turing. Pioneer of the Information Age, in which he goes to great length to discuss all thinkable alternatives, including murder, whilst also simultaneously paying extraordinarily little concern to the social context ${ }^{193}$ Further, he employs, by choice or ignorance, none of the critical tools that are common place amongst historians where the use of primary sources are concerned. Of Sara Turing's biography, he comments for instance naively "Turing's mother Sara provides an intimate and often amusing picture of him in her biography"194. In this, Hodges' discussion of the role of Sara Turing in shaping her son's legacy immediately after his death, and the ways she has constructed her biography, her narrative choices, and the incomplete source material she has drawn from, is far superior ${ }^{195}$. The influence of her biography cannot be understated as this served as source for many publications during the 1960s and 1970s ${ }^{196}$. Chris Bernhardt follows Copeland in his own

\footnotetext{
${ }^{190}$ The cause of death was established as suicide (by the inquest), see Hodges $2014: 488$. ${ }^{191}$ Ibid.

${ }^{192}$ Hodges 2014 : 531-533.

${ }^{193}$ Copeland 2014 : 223-234.

${ }^{194}$ Copeland 2014 : 239.

${ }^{195}$ Hodges 2014 : 530-533

${ }^{196}$ Hodges 2014 : 533
} 
book, Turing's Vision, but provides no new information ${ }^{197}$.

We were not able to find any references anywhere on the pages of the ACM to any of these events and with certainty not in the video that is meant to introduce the award. In this context, we also reviewed the 2012 "ACM Turing Centenary Celebration" : its event program ${ }^{198}$, a 20-page brochure/pamphlet, also does not mention any of these details. Interestingly enough, however, the first panel is dedicated to "Turing the man", but it relegates history largely to the episodic narration of "amusing incidents" 199 and its role to little more than that of cocktail party entertainment. We also reviewed the content produced on the occasion of the 50th anniversary of the Turing award in 2017 and were neither there able to find any comprehensive biography of the man they had chosen to name their prize after. For this event, they produced a 5 minute video, as well as a shorter 2 minute version, and it both cases as soon as the "Computing and Machinery Intelligence" part of Turing's biography is reached, published in 1950, or 2 years before his death, the narration abruptly comes to a stop 200 .

These are the politics of careful attribution by which one is able to claim for themselves the stature, not of an older prize, as the so-called "Nobel in economics" had done, but of a great man who had preceded them, and whose many noteworthy accomplishments presumably made him palatable to the committee when settling on a name for their newly created prize, without having to deal with those deemed less consensual or perhaps marketable parts that make up a person's life. ${ }^{201}$

But, from his biographers we know now that Alan Turing "took no particular

\footnotetext{
197See Bernhardt $2016: 159-161$.

198 "ACM Turing Centenary Celebration. Official Program." https://portalparts.acm. org/2330000/2322176/fm/frontmatter.pdf

${ }^{199}$ Ibid : 4. (Page 4 of the pamphlet.)

${ }^{200}$ For the 5 minute version, see https://www. youtube. com/watch?v=MuTGa_xvCgc\&feature= youtu.be. The 2 minute version is found here https://www.youtube.com/watch?v= 17qprcl6a-Y. More information on this event can be found here : https://www.acm.org/ turing-award-50

${ }^{201}$ Bullynck et al. have argued that what specifically made Turing attractive to the ACM was that he represented a theoretical foundation for computing, see Bullynck et al. 2015.
} 
pains to hide [his sexuality]" 202 at a time when homosexuality was a criminal offense (punished by imprisonment and what was in many cases, objectively, the death of one's social life). Alan Turing had lived an authentic personal life, as much as the society he had lived in, and their (dominant) belief system, permitted. And, it was this that was whitewashed.

Essential to giving legitimacy to the criminalization of homosexuality were scientific societies like the ACM : they gave scientific seating to the aforementioned laws and policies. In the case of homosexuality, one association particularly stands out, the APA, the American Psychiatric Association, responsible for the formulation of the $D S M^{203}$, a large body of prescriptive text used by psychologists and psychiatrists in the treatment of their patients that has both national and international influence ${ }^{204}$. In its first edition, DSM I, published in 1952, the APA classified homosexuality amongst mental disorders under the overarching category of "000-x60 Sociopathic Personality Disturbance" as "000-x63 Sexual deviation", along with "pedophilia, fetishism and sexual sadism (including rape, 625 sexual assault, mutilation)." ${ }^{205}$ In DSM-II, published in 1968, homosexuality remained a mental disorder except that it was now part of the reworked nomenclature of "302 Sexual deviations" ; of sexual deviations, the APA writes "[t]his category is for individuals whose sexual interests are directed primarily toward objets other than people of the opposite sex, toward sexual acts not usually associated with coitus, or toward coitus performed under bizarre circumstances as in necrophilia, pedophilia" ${ }^{206}$. First listed amongst such practices : "302.0 Homosexuality". ${ }^{207}$

These were the times Alan Turing lived in, this was the context in which he

\footnotetext{
${ }^{202}$ Hodges 2014 : xiii.

${ }^{203}$ Diagnostic and Statistical Manual of Mental Disorders.

${ }^{204}$ The power held by their profession prompted Canguilhem to note, with the University of Paris in mind, that from the Faculty of psychology to the nearest police station, one had only to walk the street down.

${ }^{205}$ American Psychiatric Association 1952 : 39.

${ }^{206}$ American Psychiatric Association 1968: 44.

${ }^{207}$ In recent history, the APA, has done much of what it had done for the pathologization of homosexuality, for transgenderism, from $D S M$ - $I I I$ onwards, thus shifting it into a psychiatricpsychological matter instead of a civil and general medical one.
} 
produced his work, these were the psychological elites of his day. It is a part of

\begin{abstract}
"An awards program (...) would be a fitting activity for the Association as it enhances its own image as a professional society. (...) The award itself might be named after one of the early great luminaries in the field" 214
\end{abstract}

With such detachment, could the then chairman of the ACM Awards Committee write on the day of 29th of August of 1966, shortly before the creation of the Turing Award.

\footnotetext{
${ }^{208}$ The ACM in fact did consider naming the Turing Award the Von Neumann award in 1966, see ACM 1966.

${ }^{209}$ Historians of the Middle ages, no doubt, would have called this document a hagiography had this material belonged and been relevant to their objects and time period of study.

${ }^{210}$ Sexual Offences Act $196 \%$.

${ }^{211}$ Davies 2013.

212 Policing and Crime Act 2017.

213 Duncan 2017.

${ }^{214}$ Association for Computing Machinery 1966.
} 


\section{Conclusion}

We wanted to make sense of complex human behaviors, linked to academic and career choices, and, perhaps more importantly, look at them rationally where his work as a scientist was made harder because of it, that it was interrupted by it and that his early interests in science may have stemmed from an early love $^{216}$

\footnotetext{
${ }^{215}$ For a speech by Frances Allen on this important issue, see Allen 2008.

$216 "$ I regarded my interest in my work, and in such things as astronomy (to which he introduced me) as something to be shared with him and I think he felt a little the same about me." he wrote to the mother of Christopher Morcom. See Hodges 2014 : 61.
} 
The Turing Award represents what it seeks to objectively, at least impartially recognize : a field that for the most part, though through many clever marketing tricks it tries to make appear otherwise, remains closed off to much of the population, women, visible minorities, and much of the world demographic outside of the United States and Europe.

A growing field within the social sciences is preoccupied with the "reflexivity" of measurements, that is to say the effects that rankings, of which awards are one variety, have on the reality they try or claim to capture ; in other words what Marx had long called before them "real effects". The Turing Award is a prime example of such an occurrence. It does not find women, because it does not reward women. It does not find minorities to reward, because it does not reward minorities.

This was, essentially, the history of the Turing award in the 20th century. Will it operate differently in this one?

We have raised some questions, important questions as we felt, that we do we were not always able to answer. But, we have done our best to present the evidence and where mistakes were made, they were honest.

We anticipate or hope they will be useful to those, in the present, in the here and now of the 21st century $\mathrm{CE}$, who are entangled in the contemporary debates around gender gaps in technology, in politics, in the universities, among presidents of scientific organizations, such as the ACM, or private companies such as IBM and its many new competitors.

To questions such as "what is the point of all this?", we can only say that, and maintain that, there is intrinsic value in uncovering these happenings.

It is significant perhaps that when the ACM ordered, we assume, a book to be made on its history and released it last year, none of the research, and none of the researchers, sought to study these questions ${ }^{217}$.

\footnotetext{
${ }^{217}$ Its index table features a total of five 5 entries relating to the Turing Award. Nikivincze does point out that so far only 3 women have won the Turing Award in the context of her study of female PhDs in computer science. In the same volume, Toland has done remarkable work on the SIGCAS, the Special Interest Group on Computers and Society, of the ACM : see Toland 2017, in particular the appendix.
} 
Communities of Computing is described as "the first book-length history of the Association for Computing Machinery (ACM)". "Featuring insightful profiles of notable ACM leaders (...) and honest assessments of controversial episodes, the volume deals with compelling and complex issues involving ACM have mattered, on a personal level ${ }^{221}$, and few others matter more, to the people that it employed : to the women it did not promote to top roles in particular, to the many women it did not consider for the Turing Award, and the award itself for which it created a partial biography of a man, mirroring much of what

\footnotetext{
${ }^{218}$ SIGs are specific interest groups within the ACM, each dedicated to one area of computing or computer science.

${ }^{219}$ Wilson 1954.

220 the result of which is the 1962 article listed in the bibliography.

221 "Instead of repeating the abstruse technicalities of my trade, I would like to talk informally about myself, my personal experiences, my hopes and fears, my modest successes, and my rather less modest failures." With those words, started the Turing award lecture of Antony Hoare. See Hoare 1980.
} 
Actors have a view of history, and their own most of all. But, that is only one thing. And, it is explicitly not enough for historians to give their own of theirs. The other, just as important, are the structures they live in, and those that determine their lives, not completely, but in some ways certainly. History, as we understand it, as one of the social sciences, begins at the meeting of these two levels, between subjectively felt and structural reality.

In Europe, the major centers of computing are barely a mystery : in England, Cambridge, Oxford and London, in Switzerland, Zurich and Lausanne, in Scotland, Edinburgh. And, so, the question is rather which researchers will do the work and more pragmatically which institutions will support them.

In 1993, mathematician and computer pioneer (scientist) Herman Goldstine, one of the creators of the ENIAC, the first electronic digital computer, wrote in the preface to The Computer from Pascal to von Neumann, a history he had himself shaped : "It is now 20 years (...) ; the world has been totally changed by the impact of the computer on our ways of thinking and acting. We all know, or at least sense, the many ways in which computer technology and its applications have modified our lives and ways of thought. They are so manifold that it would serve no useful purpose for me to detail examples here." ${ }^{222}$ The history of computer science and computing cannot be premature. It is belated, but at this point, better late than never.

"Without the right to tinker and explore, we risk becoming enslaved by technology" 223 according to computer scientist Andrew Huang. Historians, particularly historians of science, have a crucial role to play in this context. And a responsibility too. They do so at much less risk than the "applied sociologists" of this world and the next.

We quoted Brecht at the beginning of this paper, according to whom because

\footnotetext{
222 Goldstine 1993 : ix.

${ }^{223}$ Huang 2013 : ii.
} 
things were the way the way they were, they do not need to stay the way they are.

History is one of the primary tools by which we can bring strangeness into our present and turbulence and cracks into a seemingly well structured and homogeneous surface, folly and unreason into a we are assured well-adjusted present ; it helps us step back from our daily lives and gives us the means to 1770 reconsider the normal, current order of things as, objectively, one version of many possible and attainable others.

In this century, data has become the currency with which we pay for a variety of services. We pay for them by exchanging our memories. But, they, who rob us of our dreams, rob us of our lives. 
1775 In the days when Sussman was a novice, Minsky once came to him as he sat hacking at the PDP-6.

"What are you doing?", asked Minsky.

"I am training a randomly wired neural net to play Tic-tac-toe", Sussman replied.

1780 "Why is the net wired randomly?", asked Minsky.

"I do not want it to have any preconceptions of how to play", Sussman said.

Minsky then shut his eyes.

"Why do you close your eyes?" Sussman asked his teacher.

"So that the room will be empty." 


\section{Acknowledgements}

S. : thank you for getting me interested in computer science, and everything. 


\section{REFERENCES}

Abbate, Janet. 1999. Inventing The Internet. Cambridge, MA : (The) MIT Press.

-. 2012. Recoding Gender. Women's Changing Participation in Computing. Cambridge, Massachusetts : MIT Press.

Abelson, Harold and Sussman, Jay. 1985. Structure and Interpretation of Computer Programs. Cambridge, Massachusetts : MIT Press.

Aho, Alfred and Ullman, Jeffrey. 1977. Principles of Compiler Design. Reading, MA : Addison-Wesley.

Aho, Alfred, Sethi, Ravi and Ullman, Jeffrey. 1986. Compilers: Principles, Techniques, and Tools. Reading, MA : Addison-Wesley.

Allen, Frances. 1969 "Program Optimization" Annual Review in Automatic Programming 5 : 239-307.

-. 2008. "Fran Allen, 2006 recipient of the ACM Turing Award".

https: //www . youtube. com/watch?v=oilK7mXVw18

Allen, Frances and Cocke, John. 1972. "A catalog of optimizing transformations" In Design and Optimization of Compilers, edited by Randall Rustin, 1-30. Englewood Cliffs, NJ : Prentice-Hall.

Allen, Frances et al.. 1980. "The experimental compiling system" IBM Journal of Research and Development 24(6) : 695-715.

Alt, Franz. 1962. "Fifteen Years ACM" Communications of the ACM 5(6) : 300-307.

American Journal of Psychiatry. 1993. "In memoriam George Tarjan, M.D. 1912-1991" American Journal of Psychiatry 150(5) : 691-694.

American Psychiatric Association. 1952. Diagnostic and Statistical Manual Mental Disorders. Washington : American Psychiatric Association. 
American Psychiatric Association. 1968. DSM-II. Diagnostic and Statistical Manual of Mental Disorders. Second edition. Washington : American Psychiatric Association.

Association of Computing Machinery. 1966. "ACM Council Meeting". 'Saul Gorn Papers', University of Pennsylvania, 29/08/1966.

Austing, Richard. 1977. "The GRE Advanced Test in Computer Science". Communications of the ACM 20(9) : 642-645.

Bernhardt, Chris. 2016. Turing's Vision. The Birth of Computer Science. Cambridge, MA : MIT Press.

Bullynck, Maarten, Daylight, Edgar and De Mol, Liesbeth. 2015. "Why Did Computer Science Make a Hero Out of Turing?" Communications of the ACM 58(3) : 37-39.

Calude, Christian, ed. 1999. People $\mathcal{E}$ Ideas in Theoretical Computer Science. Springer: New York.

Canguilhem, Georges. 2011. Ecrits philosophiques et politiques 1926-1939. Paris : Vrin.

Cochran, Anita. 1987. "ACM: The Past 15 Years 1972-1987" Communications of the ACM 30(10): 866-872.

Cocke, John. 1970. "Global common subexpression elimination" SIGPLAN $5(7): 20-24$.

Cocke, John and Schwartz, Jacob. 1969. Programming languages and their compilers. Preliminary notes. Courant Institute of Mathematical Sciences, New York University.

Communications of the ACM. 2014. "ACM's Turing Award prize raised to $\$ 1$ million" Communications of the ACM 57(12) : 20.

Computer History Museum. 2006. "Oral History of Sir Antony Hoare" Computer History Museum, 08/09/2006. 
—. 2007. "Oral History of Michael Stonebraker" Computer History Museum, $23 / 08 / 2007$.

—. 2010. "Oral History of Adele Goldberg" Computer History Museum, 10/05/2010.

Conway, Lynn. 2000. "Lynn's Interactions with IBM Corporation: Seeking an 'expression of regrets' for her firing"

http://ai .eecs.umich.edu/people/conway/ACS/IBM/IBM-Interactions.html

—. 2011. "IBM-ACS: Reminiscences and Lessons Learned from a 1960's Supercomputer Project" In Dependable and Historic Computing. Essays Dedicated to Brian Randell on the Occasion of His 75th Birthday, edited by Cliff Jones and John Lloyd, 185-224. Berlin : Springer-Verlag.

—. 2016. "Lynn Conway "An Invisible Woman" @ GVPL Nov. 10th, 2016". https: //www . youtube. com/watch?v=7ncuhRYmf Jw

Copeland, Jack. 2012. Turing. Pioneer of the Digital Age. Oxford : Oxford University Press.

Davies, Caroline. 2013. "Enigma codebreaker Alan Turing receives royal pardon" The Guardian 24/12/13.

Daylight, Edgar. 2014. "A Turing Tale" Communications of the ACM 57(10) : 36-38.

-. 2015. "Towards a Historical Notion of 'Turing-the Father of Computer Science"" History and Philosophy of Logic 36(3) : 205-228.

Denning, Peter. 1990. "Alan J. Perlis 1922-1990" Communications of the ACM $33(5): 604-605$.

Docampo, Domingo. 2013. "Reproducibility of the Shanghai academic ranking of world universities results" Scientometrics 94(2) : 567-587.

Donovan, Alan and Kernighan, Brian. 2015. The Go Programming Language. New York: Addison-Wesley.

Dubb, Steve and Costello, Amy. 2018. "The Sackler family made billions from 
OxyContin. Why do top US colleges take money tainted by the opioid crisis?" The Guardian, 27/01/2018

Duncan, Pamela. 2017. "Gay relationships are still criminalised in 72 countries, report finds" The Guardian 27/07/2017

Durkheim, Emile. 1956. Education and Sociology. New York : Simon and Schuster.

Ettling, John. 1981. The Germ of Laziness. Rockefeller Philanthropy and Public Health in the New South. Cambridge, MA : Harvard University Press.

European Commission. 2016. "Gender balance on corporate boards".

http://ec.europa.eu/justice/gender-equality/files/womenonboards/factsheet_ women_on_boards_web_2015-10_en.pdf

Feigenbaum, . 2001. "Herbert A. Simon, 1916-2001" Science 291(5511) : 2107.

Ferry, Georgina. 2018. "Mary Lee Berners-Lee obituary" The Guardian 23/01/2018.

Florian, Razvan. 2007. "Irreproducibility of the results of the Shanghai academic ranking of world universities" Scientometrics 72(1) : 25-32.

Folsing, Ulla. 1991l. Nobel-Frauen : Naturwissenschaftlerinnen im Portrat. Munchen : Beck.

Galler, Bernard. 1969. "President's Letter to the ACM Membership. The AFIPS Constitution" Communications of the ACM 12(3) : 188.

Goldstine, Herman. 1993. The Computer from Pascal to Neumann. Princeton : Princeton University Press.

Haigh, Thomas. 2014. "Actually, Turing Did Not Invent the Computer" Communications of the ACM 57(1) : 36-41.

Hiltzik, Michael. 2000. "Through the Gender Labyrinth" Los Angeles Times $19 / 11 / 2000$.

Hoare, Antony. 1961. "Algorithm 64: Quicksort". Communications of the 
ACM 4(7) : 321-322.

- 1980. "The emperor's old clothes" Communications of the ACM 24(2) : 75-83.

Hodges, Andrew. 2014. Alan Turing: The Enigma. Princeton : Princeton University Press.

Hosch, William. 2015. "Joseph Sifakis" Britannica, 15/05/2015. https://www . britannica.com/biography/Joseph-Sifakis

—. 2018. "Frederick Phillips Brooks, Jr." Britannica, 12/04/2018. https: //www.britannica.com/biography/Frederick-Phillips-Brooks-Jr

Householder, Alston. 1956. "Presidential Address to the ACM, Philadelphia, September 14, 1955" Journal of the ACM 3(1) : 1-2.

Huang, Andrew. 2013. Hacking the Xbox. An Introduction to Reverse Engineering. San Francisco : No Starch Press.

Human Rights Watch. 2018. "China: Gender Discrimination in Job Advertising". https://www . youtube.com/watch?v=tN_zsYxhRJ4

Jerome, Richard. 2000. "Lending An Ear" People 18/09/2000.

Karp, Richard. 1999. "The mysteries of algorithms." In People 63 Ideas in Theoretical Computer Science, edited by Christian Calude, 146-162. Springer : New York.

Knuth, Donald. 1972. "George Forsythe and the Development of Computer Science" Communications of the ACM 15(8): 721-726.

-. 1997. The Art of Computer Programming. Fundamental Algorithms. Volume 1. Third edition. Reading, MA : Prentice-Hall.

-. 1997b. "Donald Knuth: A life's work in the art of programming".

http://www . amazon.com/exec/obidos/tg/feature/-/4165

—. 2003. "Robert W Floyd, In Memoriam" ACM SIGACT News 34(4) : 3-13. 
Kossack, Carl and Henschke, Claudia. 1975. Introduction to Statistics and Computer Programming. San Francisco : Holden-Day.

Kuo, Lily. 2018. "II love tech boys': Chinese job ads mirror sexist attitudes to women, study finds" The Guardian, 23/04/2018.

Lebaron, Frederique. 2002. "Le "Nobel" d'economie. Une politique" Actes de la Recherche en Sciences Sociales 141-142: 62-65.

Lee, J.A.N. 1995. Computer Pioneers. Los Alamitos : IEEE Computer Society Press.

Lecuyer, Christophe. 2006. Making Silicon Valley. Innovation and the Growth of High Tech, 1930-1970. Cambridge, MA : (The) MIT Press.

Lovelace, Ada. 1843. Notes to "Sketch of the Analytical Engine invented by Charles Babbage" In Scientific Memoirs 3, edited by Richard Taylor, 666-731. London : Richard and John E. Taylor.

Markoff, John. 2005. What the Dormouse Said: How the Sixties Counterculture Shaped the Personal Computer Industry. New York : Penguin.

—. 2011. "John McCarthy, 84, Dies; Computer Design Pioneer" The New York Times 25/10/2011.

Mead, Carver and Conway, Lynn. 1980. Introduction to VLSI Systems. Reading, MA : Addison-Wesley.

Misa, Thomas, ed. 2017. Communities of Computing: Computer Science and Society in the ACM. New York: Association for Computing Machinery.

Morrill, John. 1995. "A Nobel Prize in Mathematics" The American Mathematical Monthly 102(10): 888-892.

New York Times. 1985. "Charles W. Bachman" New York Times 16/12/1985.

—. "Sexual Harassment 20 Years Later" New York Times, 21/10/2011.

Nikivincze, Irina. 2017. "Solving a Career Equation: The First Doctoral Women 
in Computer Science" In Communities of Computing, edited by Thomas Misa, 71-90. New York : Association for Computing Machinery.

Nobel Foundation. 1972. Nobel, the man $\&$ his prizes. New York : Elsevier.

Packer, Randall and Jordan, Ken, eds. 2002. Multimedia: From Wagner to Virtual Reality. New York: W.W. Norton \& Company.

Paluck, Elizabeth and Green, David. 2009. "Prejudice reduction: what works? A review and assessment of research and practice." Annual Review of Psychology $60: 339-367$.

Pettigrew, Thomas and Tropp, Linda. 2006. "A meta-analytic test of intergroup contact theory" Journal of Personality and Social Psychology 90(5) : 751-83.

Piumarta, Ian and Rose, Kimberly, eds. 2010. Points of View: a tribute to Alan Kay. Glendale, California : Viewpoints Research Institute.

Pollack, Bary. 1971. An Annotated Bibliography on The Construction of Compilers Stanford University 12/1971.

Randell, Brian. 2015. "Reminiscences of Project Y and the ACS Project" IEEE Annals of the History of Computing 37(3) : 56-66.

Revens, Lee. 1972. "The First 25 Years: ACM 1947-1962" Communications of the $A C M$ 15(7) : $485-490 .^{224}$

Rice, John and Rosen, Saul. 1994. "History of the Computer Sciences Department of Purdue University" In Studies in Computer Science. In honor of Samuel D. Conte, edited by Richard Demillo and John Rice, 45-72. New York : Plenum Press.

Rossiter, Margaret. 1982. Women Scientists in America. Volume 1. Struggles

\footnotetext{
${ }^{224}$ This article is wrongly printed as "The First 25 Years: ACM 1947-1962", which does not make sense mathematically. It does handle the period up to 1972. This article was reprinted in Communications in 1987, with no modifications as far as we could tell, other than cosmetic, with the same mistake, together with Cochran's which extends it by covering the (period) ACM's history from 1972 to 1987, as well as Franz Alt's original 1962 article on the first 15 years of the ACM.
} 
and Strategies to 1940. Baltimore : John Hopkins University Press.

-. 1993. "The Matthew Matilda Effect in Science" Social Studies of Science $23: 325-341$.

-. 1995. Women Scientists in America. Volume 2. Before Affirmative Action, 1940-1972. Baltimore : John Hopkins University Press.

- 2012. Women Scientists in America. Volume 3. Forging a New World Since 1972. Baltimore : John Hopkins University Press.

Rosenzweig, Alyssa. 2017. "Diversity at Bletchley Park".

https://rosenzweig.io/blog/diversity-at-bletchley-park.html

Sammet, Jean. 1975. "The Great Diversity Within ACM" Communications of the ACM 18(8): 430 .

—. 1976. "Relation of ACM to the World Outside ACM" Communications of the ACM 19(2) : 53-54.

San Francisco Chronicle. 2010. "Jane Siegel” San Francisco Chronicle 24/01/2010.

Shasha, Dennis and Lazere, Cathy. 1995. Out of Their Minds: The Lives and Discoveries of 15 Great Computer Scientists. New York : Copernicus Books.

Siegmund-Schultze, . 2001. Rockefeller and the Internationalization of Mathematics Between the Two World Wars. Basel : Birkhäuser Verlag.

Simons Foundation. 2013. (Video interview of) Richard Karp.

https://www. simonsfoundation.org/2013/12/13/richard-karp/

Sime, Ruth. 1996. Lise Meitner: A Life in Physics. Berkeley : University of California Press.

Simon, Herbert. 1980. "Herbert A. Simon". In A history of psychology in autobiography. Volume 7, pp. 435472. San Francisco : Freeman.

Smotherman, Mark. 2017. "IBM Advanced Computing Systems (ACS) - 1961

- 1969", 02/01/2017. https://people.cs.clemson.edu/ mark/acs.html 
Steele, Guy. 2011. "An Interview with Frances E. Allen" Communications of the ACM 54(1) : 39-45.

Stone, Lawrence. 1971. "Prosopography" Daedalus 100(1) : 46-79.

Swade, Doron. 2008. "Doron Swade: "Charles Babbage and Difference Enginge No. 2" - Talks at Google", 08/05/2008. https://www.youtube.com/watch? $\mathrm{v}=7 \mathrm{~K} 5 \mathrm{p}_{-} \mathrm{tBcrd0 \& t}$

Swedin, Eric. 2005. Science in the Contemporary World. An Encyclopedia. Santa Barbara : ABC-CLIO.

Tarjan, Robert. 2012. "Curriculum Vitae", 17/12/2012. https://www.cs . princeton.edu/ ret/Vita2012A1.pdf

The Davis Group. 2011. "The Generational Divide", 05/03/2011. https: //vimeo.com/20673320

The Harvard Crimson. 1926. "Harvard Law Review Elects 19" The Harvard Crimson 28/09/1926.

Toland, Janet. 2017. "“Deeply Political and Social Issues": Debates within ACM 1965-1985." In Communities of Computing, edited by Thomas Misa, 111141. New York: Association for Computing Machinery.

Turing, Alan. 1936. "On computable numbers, with an application to the Entscheidungsproblem" Proceedings of the London Mathematical Society 42(1) : 230-265.

—. 1950. "Computing Machinery and Intelligence" Mind 49:433-460.

United States Census Bureau. 2017. "Highest Educational Levels Reached by Adults in the U.S. Since 1940" United States Census Bureau 30/03/2017. https://www . census .gov/newsroom/press-releases/2017/cb17-51.html Weber, Richard and Gilchrist, Bruce. 1975. "Discrimination in the Employment of Women in the Computer Industry" Communications of the ACM 18(7) : 416418. 
Williams, Samuel. 1954. "The Association For Computing Machinery" Journal of the ACM 1(1): 1-3.

Woolf, Virginia. 2008. Orlando. Oxford : Oxford University Press. 


\section{Appendix}

Listing of supplementary documents

- Table: Turing Award laureates (1966-2016)

- Table: Turing Award laureates by bachelor institutions

- Table : ACM council (1947-2018)

- Table series : CEOs/Presidents of IBM, Bell Labs and Intel (1914-2018)

- Table series : Turing award committees (2012-2018)

- Table : Female Turing winners and areas of computing

- Image series : Gender through corporate archives (1950s-present)

- Table : social origins of Turing winners (full table)

- Table : IEEE Computer Pioneer Award winners (1981-2018) 
Table 31: Turing Award laureates (1966-2016)

\begin{tabular}{|c|c|}
\hline Year & Winner \\
\hline 1966 & Perlis, Alan J \\
\hline 1967 & Wilkes, Maurice V. \\
\hline 1968 & Hamming, Richard W \\
\hline 1969 & Minsky, Marvin \\
\hline 1970 & Wilkinson, James Hardy ("Jim") \\
\hline 1971 & McCarthy, John \\
\hline 1972 & Dijkstra, Edsger Wybe \\
\hline 1973 & Bachman, Charles William \\
\hline 1974 & Knuth, Donald ("Don") Ervin \\
\hline \multirow[t]{3}{*}{1975} & Newell, Allen \\
\hline & Nabin, Michael O. \\
\hline & Simon, Herbert ("Herb") Alexander \\
\hline \multirow[t]{2}{*}{1976} & Rabin, Michael O. \\
\hline & Scott, Dana Stewart \\
\hline 1977 & Backus, John \\
\hline 1978 & Floyd, Robert (Bob) W \\
\hline 1979 & Iverson, Kenneth E. ("Ken") \\
\hline 1980 & Hoare, C. Antony ("Tony") R. \\
\hline 1981 & Codd, Edgar F. ("Ted") \\
\hline 1982 & Cook, Stephen Arthur \\
\hline \multirow[t]{2}{*}{1983} & Ritchie, Dennis M.* \\
\hline & Thompson, Kenneth Lane \\
\hline 1984 & Wirth, Niklaus E \\
\hline 1985 & Karp, Richard ("Dick") Manning \\
\hline \multirow[t]{2}{*}{1986} & Hopcroft, John E \\
\hline & Tarjan, Robert (Bob) Endre \\
\hline 1987 & Cocke, John \\
\hline
\end{tabular}




\begin{tabular}{|c|c|}
\hline 1988 & Sutherland, Ivan \\
\hline 1989 & Kahan, William ("Velvel") Morton \\
\hline 1990 & Corbato, Fernando J ("Corby") \\
\hline 1991 & Milner, Arthur John Robin Gorell ("Robin") \\
\hline 1992 & Lampson, Butler W \\
\hline \multirow[t]{2}{*}{1993} & Hartmanis, Juris \\
\hline & Stearns, Richard ("Dick") Edwin \\
\hline \multirow[t]{2}{*}{1994} & Feigenbaum, Edward A ("Ed") \\
\hline & Reddy, Dabbala Rajagopal ("Raj") \\
\hline 1995 & Blum, Manuel \\
\hline 1996 & Pnueli, Amir \\
\hline 1997 & Engelbart, Douglas \\
\hline 1998 & Gray, James ("Jim") Nicholas \\
\hline 1999 & Brooks, Frederick ("Fred") \\
\hline 2000 & Yao, Andrew Chi-Chih \\
\hline \multirow[t]{2}{*}{2001} & Dahl, Ole-Johan \\
\hline & Nygaard, Kristen \\
\hline \multirow[t]{3}{*}{2002} & Adleman, Leonard (Len) Max \\
\hline & Rivest, Ronald (Ron) Linn \\
\hline & Shamir, Adi \\
\hline 2003 & Kay, Alan \\
\hline \multirow[t]{2}{*}{2004} & Cerf, Vinton ("Vint") Gray \\
\hline & Kahn, Robert ("Bob") Elliot \\
\hline 2005 & Naur, Peter \\
\hline 2006 & Allen, Frances ("Fran") Elizabeth \\
\hline \multirow[t]{3}{*}{2007} & Clarke, Edmund Melson \\
\hline & Emerson, E. Allen \\
\hline & Sifakis, Joseph \\
\hline 2008 & Liskov, Barbara \\
\hline
\end{tabular}




\begin{tabular}{|l|l|}
\hline $\mathbf{2 0 0 9}$ & Thacker, Charles P. (Chuck) \\
\hline $\mathbf{2 0 1 0}$ & Valiant, Leslie Gabriel \\
\hline $\mathbf{2 0 1 1}$ & Pearl, Judea \\
\hline $\mathbf{2 0 1 2}$ & Goldwasser, Shafi \\
\hline & Micali, Silvio \\
\hline $\mathbf{2 0 1 3}$ & Lamport, Leslie \\
\hline $\mathbf{2 0 1 4}$ & Stonebraker, Michael \\
\hline $\mathbf{2 0 1 5}$ & Diffie, Whitfield \\
\hline & Hellman, Martin \\
\hline $\mathbf{2 0 1 6}$ & Berners-Lee, Tim \\
\hline
\end{tabular}


Table 32: Shanghai Ranking of universities in computer science and engineering (2007-2017)

\begin{tabular}{|l|l|l|l|l|l|}
\hline Institution & CS \& ENG* 2017 & $C S^{*}$ 2009-2015 & $E N G^{*}$ 2010-2016 & ENG 2008-2009 & ENG 2007 \\
\hline MIT & 1 & 2 & 1 & 1 & 1 \\
\hline Stanford & 3 & 1 & 2 & 2 & 2 \\
\hline Berkeley & 2 & 3 & 3 & 4 & 5 \\
\hline
\end{tabular}

* Computer Science \& Engineering

** Computer Science

*** Engineering/Technology and Computer Sciences

Sources :

- Academic Subjects - Computer Science \& Engineering (2017)

http://www. shanghairanking.com/shanghairanking-subject-rankings/computer-science-engineerin html

- ARWU-SUBJECT / ARWU-Computer Science

http://www . shanghairanking.com/SubjectCS2009.html

http://www. shanghairanking.com/SubjectCS2010.html

http://www . shanghairanking. com/SubjectCS2011.html

http://www . shanghairanking.com/SubjectCS2012.html

http://www . shanghairanking.com/SubjectCS2013.html

http://www . shanghairanking.com/SubjectCS2014.html

http://www. shanghairanking. com/SubjectCS2015.html

- ARWU-FIELD / ARWU-ENG / Engineering/Technology and Computer Sciences

http://www . shanghairanking. com/FieldENG2007.html

http://www. shanghairanking. com/FieldENG2008.html

http://www. shanghairanking.com/FieldENG2009.html

http://www . shanghairanking. com/FieldENG2010.html

http://www. shanghairanking. com/FieldENG2011.html

http://www . shanghairanking. com/FieldENG2012.html

http://www . shanghairanking. com/FieldENG2013.html

http://www . shanghairanking. com/FieldENG2014.html

http://www. shanghairanking. com/FieldENG2015.html

http://www . shanghairanking.com/FieldENG2016.html 
Table 33: universities ranked by number of Turing award winners based on bachelor's degrees (full)

\begin{tabular}{|l|l|}
\hline Institution & Bachelor students $\mathrm{n}(\%)$ \\
\hline Berkeley & 6 \\
\hline Cambridge & 4 \\
\hline Carnegie Mellon University* & 4 \\
\hline Harvard & 4 \\
\hline California Institute of Technology & 3 \\
\hline MIT & 3 \\
\hline Oxford & 3 \\
\hline University of Chicago & 3 \\
\hline Duke & 2 \\
\hline Stanford & 2 \\
\hline Technion & 2 \\
\hline Carleton College & 1 \\
\hline Case Institute of Technology & 1 \\
\hline City College of New York & 1 \\
\hline Columbia & 1 \\
\hline Copenhagen University* & 1 \\
\hline ETH Zurich & 1 \\
\hline Hebrew University & 1 \\
\hline Queen's University & 1 \\
\hline Leiden University** & 1 \\
\hline Marburg & 1 \\
\hline Michigan State & 1 \\
\hline National Technical University of Athens & 1 \\
\hline National University of Taiwan & 1 \\
\hline New York State College for Teachers**** & 1 \\
\hline NYU & 1 \\
\hline
\end{tabular}




\begin{tabular}{|l|l|}
\hline Oregon State University & 1 \\
\hline Oslo***** & 1 \\
\hline Princeton & 1 \\
\hline Sapienza University, Rome & 1 \\
\hline Seattle University & 1 \\
\hline Tel Aviv University & 1 \\
\hline Toronto & 1 \\
\hline University of Colorado at Boulder & 1 \\
\hline University of Madras****** & 1 \\
\hline University of Michigan & 1 \\
\hline University of Texas at Austin & 1 \\
\hline University of Virginia & 1 \\
\hline Yale University & 1 \\
\hline
\end{tabular}

$\mathrm{n}=64 \mathrm{t}=64$

* Previously, Carnegie Institute of Technology.

** Registered by the ACM as University of Leyden.

*** Now, State University of New York at Albany.

**** Proxy by Master's degree.

******* Now, Anna University, Chennai. 
Table 34: Universities ranked by the number of Turing award winners at the post-graduate level (full)

\begin{tabular}{|l|l|}
\hline Institution & Students \\
\hline Berkeley & 8 \\
\hline Harvard & 6 \\
\hline Princeton & 6 \\
\hline Stanford & 6 \\
\hline MIT & 4 \\
\hline University of Michigan & 3 \\
\hline Caltech* & 2 \\
\hline CMU** & 2 \\
\hline UUIC*** & 2 \\
\hline Weizmann Institute of Science & 2 \\
\hline Brandeis & 1 \\
\hline Cambridge & 1 \\
\hline Columbia & 1 \\
\hline Copenhagen & 1 \\
\hline Cornell & 1 \\
\hline Duke & 1 \\
\hline National Technical University of Athens & 1 \\
\hline Oslo & 1 \\
\hline Oxford**** & 1 \\
\hline Polytechnic Institute of Brooklyn***** & 1 \\
\hline Toronto & 1 \\
\hline UCLA & 1 \\
\hline University of Amsterdam & 1 \\
\hline University of Chicago & 1 \\
\hline University of Pennsylvania & 1 \\
\hline University of Utah & 1 \\
\hline
\end{tabular}




\begin{tabular}{|l|l|}
\hline Warwick & 1 \\
\hline
\end{tabular}

$\mathrm{n}=58 \mathrm{t}=58$

Methodology : we register the $\mathrm{PhD}$ institution, where a laureate has a $\mathrm{PhD}$, and the Master's degree institution otherwise, for postgraduate study.

* California Institute of Technology.

** Previously, Carnegie Institute of Technology.

$* * *$ University of Illinois at Urbana-Champaign.

**** Including Hoare's postgraduate certificate in statistics.

***** Now, New York University Tandon School of Engineering. 
Table 35: universities ranked by the number of Turing award winners based on $\mathrm{PhD}$ (full)

\begin{tabular}{|l|l|}
\hline Institution & Bachelor students $\mathrm{n}(\%)$ \\
\hline Berkeley & 7 \\
\hline Harvard & 6 \\
\hline Princeton & 6 \\
\hline Stanford & 6 \\
\hline MIT & 4 \\
\hline California Institute of Technology & 2 \\
\hline CMU 2 & \\
\hline University of Illinois Urbana-Champaign & 2 \\
\hline University of Michigan & 2 \\
\hline Weizmann Institute of Science & 2 \\
\hline Brandeis & 1 \\
\hline Cambridge & 1 \\
\hline Copenhagen & 1 \\
\hline Cornell & 1 \\
\hline Duke & 1 \\
\hline National Technical University of Athens & 1 \\
\hline Polytechnic Institute of Brooklyn & 1 \\
\hline Toronto & 1 \\
\hline UCLA & 1 \\
\hline University of Amsterdam & 1 \\
\hline University of Chicago & 1 \\
\hline University of Utah & 1 \\
\hline Warwick & 1 \\
\hline & \\
\hline
\end{tabular}

$\mathrm{n}=52 \mathrm{t}=52$ 


\section{Appendix : ACM council (1947 - 2018)}

Let us preface this by saying that we have a very good knowledge of the period going from the creation of the ACM in 1947 up to 1975, for which we possess information on all presidents, vice-presidents and secretaries, so far as we know. In this first table, empty cells imply that the personnel (listed) remains unchanged from one year to the other.

For the period from 1976 to 2016, we are missing many information, including (on) nearly all of the vice-presidents and some of the secretaries. In this second table, where appointments are presented in two-year spans, which correspond to the length of their term, empty cells take on the meaning of lack of information.

Table 36: ACM council (1947 - 2018)

\begin{tabular}{|l|l|l|l|}
\hline Year & President & Vice-president & Secretary \\
\hline 1947 & John H. Curtiss & John W. Mauchly & Edmund C. Berkeley \\
\hline 1948 & John W. Mauchly & Franz L. Alt & \\
\hline 1949 & & & \\
\hline 1950 & Franz L. Alt & Samuel B. Williams & \\
\hline 1951 & & & \\
\hline 1952 & Samuel B. Williams & Alston Scott Householder & \\
\hline 1953 & & & E. Bromberg \\
\hline 1954 & Alston Scott Householder & D. Lehmer & \\
\hline 1955 & & & \\
\hline 1956 & John W. Carr III & Richard W. Hamming & Jack Moshman \\
\hline 1957 & & & \\
\hline 1958 & Richard W. Hamming & Harry D. Huskey & \\
\hline 1959 & & & Bruce Gilchrist \\
\hline 1960 & Harry D. Huskey & Jack Moshman & \\
\hline 1961 & & & \\
\hline
\end{tabular}




\begin{tabular}{|c|c|c|c|}
\hline 1962 & Alan J. Perlis & Bruce Gilchrist & Herbert S. Bright \\
\hline \multicolumn{4}{|l|}{1963} \\
\hline 1964 & George E. Forsythe & Herbert S. Bright & E. H. Jacobs \\
\hline \multicolumn{4}{|l|}{1965} \\
\hline 1966 & Anthony Oettinger & Bernard A. Galler & Donne Parker \\
\hline \multicolumn{4}{|l|}{1967} \\
\hline 1968 & Bernard A. Galler & Walter M. Carlson & \\
\hline \multicolumn{4}{|l|}{1969} \\
\hline 1970 & Walter M. Carlson & Anthony Ralston & C. L. Bradshaw \\
\hline \multicolumn{4}{|l|}{1971} \\
\hline 1972 & Anthony Ralston & Jean Sammet & J. Hamblen \\
\hline \multicolumn{4}{|l|}{1973} \\
\hline 1974 & Jean Sammet & Hertbert R. J. Grosch & \\
\hline \multicolumn{4}{|l|}{1975} \\
\hline 1976-78 & Herbert R. J. Grosch & & \\
\hline $1978-80$ & Daniel D. McCracken & & \\
\hline $1980-82$ & Peter J. Denning & & \\
\hline $1982-84$ & David H. Brandin & & Adele Goldberg \\
\hline $1984-86$ & Adele Goldberg & & \\
\hline $1986-88$ & Paul W. Abrahams & & \\
\hline 1988-90 & Bryan S. Kocher & & \\
\hline 1990-92 & John R. White & & \\
\hline $1992-94$ & Gwen Bell & & \\
\hline 1994-96 & Stuart H. Zweben & & \\
\hline 1996-98 & Charles House & & \\
\hline $1998-2000$ & Barbara Simons & & \\
\hline 2000-02 & Stephen R. Bourne & & \\
\hline 2002-04 & Maria M. Klawe & & \\
\hline 2004-06 & David Patterson & & \\
\hline
\end{tabular}




\begin{tabular}{|l|l|l|l|}
\hline $2006-08$ & Stuart Feldman & & \\
\hline $2008-10$ & Dame Wendy Hall & & \\
\hline $2010-12$ & Alain Chesnais & & \\
\hline $2012-14$ & Vinton G. Cerf & & \\
\hline $2014-16$ & Alexander L. Wolf & & \\
\hline $2016-18$ & Vicki Hanson & Cherri M Pancake & Elizabeth F. Churchill \\
\hline
\end{tabular}

Sources :

This is compiled primarily from Revens 1972, "ACM Past Presidents" 225 and

"ACM Council". https://www.acm.org/governance/acm-council

Note that there is disagreement between these two sources on the appointment of John Mauchly as president. Revens gives 1948, the ACM 1949 as starting year. We followed Revens in adopting 1948. Further Revens lists Herbert Bright as "H.S. Bright" then "H. Bright".

For the following people, we provide this additional information : Richard Hamming is the 1968 Turing award winner. John Carr III published various articles in ACM publications between 1952 and $1986^{226}$. Alston Scott Householder was a mathematician (Oak Ridge National Laboratory) ${ }^{227}$. Jack Moshman, PhD mathematics (Oak Ridge National Laboratory, Rutgers, Bell Labs) ${ }^{228}$. Herbert S. Bright, MS eletrical engineering (Bell Labs) ${ }^{229}$. John Hamblen (University of Missouri-Rolla) was secretary of the ACM, 1972-1976 230 . Adele Goldberg became secretary of the ACM in $1982^{231}$

\footnotetext{
${ }^{225}$ https : //www.acm.org/governance/past-presidents

${ }^{226}$ For a list of his publications, see : https://dl.acm.org/author_page.cfm?id= $81100073002 \& \operatorname{coll}=$ DL\&dl=ACM\&trk $=0$

${ }^{227}$ For his presidential address to the ACM, see : Householder 1956

${ }^{228}$ This is based on information provided by his obituary published in the Washington Post, $26 / 08 / 2014$.

${ }^{229}$ See his biographical entry in Lee 1995.

${ }^{230}$ Austing $1977: 643$

${ }^{231}$ This, we know from the "Oral History of Adele Goldberg" undertaken by the Computer
} 
History Museum in 2010. Bruce Gilchrist (Columbia University) was a member of the ACM council and is the author of several publications in ACM journals ${ }^{232}$. (Is D. Lehmer, mathematician Derrick Henry Lehmer of UC Berkeley?) 
Table series : CEOs/Presidents of IBM, Bell Labs and Intel (19142018)

Table 37: CEOs of IBM (1914-2018)

\begin{tabular}{|l|l|}
\hline Year & President \\
\hline 1914-1956 & Thomas J. Watson \\
\hline 1956-1971 & Thomas J. Watson Jr. \\
\hline 1971-1973 & Thomas Vincent Learson \\
\hline 1973-1981 & Frank T. Cary \\
\hline 1981-1985 & John R. Opel \\
\hline 1985-1993 & John F. Akers \\
\hline 1993-2002 & Louis V. Gerstner Jr. \\
\hline 2002-2011 & Samuel J. Palmisano \\
\hline 2012-now & Virginia "Ginni" Rometty \\
\hline
\end{tabular}

Source :

- "Former CEOs". http://newsroom.ibm.com/former-CEOs

- "Virginia M. Rometty". https://www-03.ibm.com/ibm/history/exhibits/ chairmen/chairmen_11.html

Table 38: Presidents of Bell Labs (1925-2018)

\begin{tabular}{|l|l|}
\hline Year & President \\
\hline $1925-1940$ & Frank Jewett \\
\hline $1940-1951$ & Oliver Buckley \\
\hline $1951-1959$ & Mervin Kelly \\
\hline $1959-1973$ & James Fisk \\
\hline $1973-1979$ & William Baker \\
\hline $1979-1991$ & Ian Ross \\
\hline
\end{tabular}




\begin{tabular}{|l|l|}
\hline 1991-1995 & John Mayo \\
\hline 1995-1999 & Dan Stanzione \\
\hline $1999-2001$ & Arun Netravali \\
\hline $2001-2005$ & Dan Stanzione \\
\hline $2005-2013$ & Jeong Kim \\
\hline $2013-2013$ & Gee Rittenhouse \\
\hline $2013-$-now & Marcus Weldon \\
\hline
\end{tabular}

Source : "Presidents of Bell Labs". https://www.bell-labs.com/about/ history-bell-labs/presidents/

Table 39: CEOs of Intel (1968-now)

\begin{tabular}{|l|l|}
\hline Year & President \\
\hline $1968-1975$ & Robert Noyce \\
\hline $1975-1987$ & Gordon Moore \\
\hline $1987-1998$ & Andy Grove \\
\hline $1998-2005$ & Craig Barrett \\
\hline $2005-2013$ & Paul Otellini \\
\hline $2013-$-now & Brian Krzanich \\
\hline
\end{tabular}

Source :

- "Intel CEOs: A Look Back". https://newsroom.intel.com/editorials/ intel-ceos-a-look-back/

- "Brian Krzanich". https://newsroom.intel.com/biography/brian-m-krzanich/ 
Table series : Turing Award committees (2012-2018)

$09 / 11 / 2012$

\begin{tabular}{|l|l|l|}
\hline Position & Name & Affiliation \\
\hline Chair & Ravi Sethi & Avaya Labs \\
\hline Member & Frances Allen & Stanford University \\
\hline & Michael J Carey & IBM Fellow Emerita \\
\hline & Jennifer Chayes & Microsoft Research \\
\hline & Adele Goldberg & Neometron \\
\hline & Michael I. Jordan & UC, Berkeley \\
\hline & Barbara Liskov & MIT \\
\hline & David H Salesin & University of Washington/Adobe \\
\hline & Per O Stenstrom & Chalmers University of Technology \\
\hline
\end{tabular}

$02 / 06 / 2013$

\begin{tabular}{|l|l|l|}
\hline Position & Name & Affiliation \\
\hline Chair & Adele Goldberg & Pharma Capital Partners \\
\hline Member & Michael I. Jordan & UC, Berkeley \\
\hline & Barbara Liskov & MIT \\
\hline & David H Salesin & University of Washington/Adobe \\
\hline & Per O Stenstrom & Chalmers University of Technology \\
\hline
\end{tabular}

28/08/2013

\begin{tabular}{|l|l|l|}
\hline Position & Name & Affiliation \\
\hline Chair & Adele Goldberg & Pharma Capital Partners \\
\hline
\end{tabular}




\begin{tabular}{|l|l|l|}
\hline Member & Michael I. Jordan & UC, Berkeley \\
\hline & Barbara Liskov & MIT \\
\hline & David H Salesin & University of Washington/Adobe \\
\hline & Ravi Sethi & Avaya Labs \\
\hline & Per O Stenstrom & Chalmers University of Technology \\
\hline
\end{tabular}

$15 / 10 / 2013$

\begin{tabular}{|l|l|l|}
\hline Position & Name & Affiliation \\
\hline Chair & Adele Goldberg & Pharma Capital Partners \\
\hline Member & Michael I. Jordan & UC, Berkeley \\
\hline & Barbara Liskov & MIT \\
\hline & David H Salesin & University of Washington/Adobe \\
\hline & Ravi Sethi & Avaya Labs \\
\hline & Per O Stenstrom & Chalmers University of Technology \\
\hline & Eva Tardos & Cornell University \\
\hline & Leslie G Valiant & Harvard University \\
\hline
\end{tabular}

\section{1/08/2014}

\begin{tabular}{|l|l|l|}
\hline Position & Name & Affiliation \\
\hline Chair & Barbara Liskov & \\
\hline Member & Adele Goldberg & Pharma Capital Partners \\
\hline & Michael I. Jordan & UC, Berkeley \\
\hline & David H Salesin & University of Washington/Adobe \\
\hline & Per O Stenstrom & Chalmers University of Technology \\
\hline & Eva Tardos & Cornell University \\
\hline
\end{tabular}




\begin{tabular}{|l|l|l|}
\hline & Leslie G Valiant & Harvard University \\
\hline
\end{tabular}

04/10/2014

\begin{tabular}{|l|l|l|}
\hline Position & Name & Affiliation \\
\hline Chair & Barbara Liskov & \\
\hline Member & Alex Aiken & Stanford University \\
\hline & Adele Goldberg & Pharma Capital Partners \\
\hline & Michael I. Jordan & UC, Berkeley \\
\hline & David H Salesin & University of Washington/Adobe \\
\hline & Per O Stenstrom & Chalmers University of Technology \\
\hline & Eva Tardos & Cornell University \\
\hline & Leslie G Valiant & Harvard University \\
\hline
\end{tabular}

$06 / 09 / 2015$

\begin{tabular}{|l|l|l|}
\hline Position & Name & Affiliation \\
\hline Chair & Michael I. Jordan & \\
\hline Member & Alex Aiken & Stanford University \\
\hline & Barbara Liskov & MIT \\
\hline & David H Salesin & University of Washington/Adobe \\
\hline & Alfred Z Spector & \\
\hline & Per O Stenstrom & Chalmers University of Technology \\
\hline & Eva Tardos & Cornell University \\
\hline & Leslie G Valiant & Harvard University \\
\hline
\end{tabular}


$30 / 11 / 2016$

\begin{tabular}{|l|l|l|}
\hline Position & Name & Affiliation \\
\hline Chair & David H Salesin & \\
\hline Member & Alex Aiken & Stanford University \\
\hline & Michael J Carey & \\
\hline & David Heckerman & \\
\hline & Alfred Z Spector & \\
\hline & Per O Stenstrom & Chalmers University of Technology \\
\hline & Eva Tardos & Cornell University \\
\hline & Leslie G Valiant & Harvard University \\
\hline
\end{tabular}

03/07/2017

\begin{tabular}{|l|l|l|}
\hline Position & Name & Affiliation \\
\hline Chair & Alfred Z Spector & \\
\hline Member & Alex Aiken & Stanford University \\
\hline & Michael J Carey & \\
\hline & David Heckerman & \\
\hline & Per O Stenstrom & Chalmers University of Technology \\
\hline & Eva Tardos & Cornell University \\
\hline & Leslie G Valiant & Harvard University \\
\hline
\end{tabular}

$21 / 07 / 2017$

\begin{tabular}{|l|l|l|}
\hline Position & Name & Affiliation \\
\hline Chair & Alfred Z Spector & \\
\hline
\end{tabular}




\begin{tabular}{|l|l|l|}
\hline Member & Alex Aiken & Stanford University \\
\hline & Michael J Carey & \\
\hline & David Heckerman & \\
\hline & Eva Tardos & Cornell University \\
\hline & Leslie G Valiant & Harvard University \\
\hline
\end{tabular}

$20 / 09 / 2017$

\begin{tabular}{|l|l|l|}
\hline Position & Name & Affiliation \\
\hline Chair & Alfred Z Spector & \\
\hline Member & Alex Aiken & Stanford University \\
\hline & Michael J Carey & \\
\hline & Shafi Goldwasser & \\
\hline & David Heckerman & \\
\hline & Joseph Sifakis & \\
\hline & Olga Sorkine-Hornung & \\
\hline & Eva Tardos & Cornell University \\
\hline & Leslie G Valiant & Harvard University \\
\hline
\end{tabular}

16/05/2018 (current composition, no changes)

\begin{tabular}{|l|l|l|}
\hline Position & Name & Institution \\
\hline Chair & Alfred Z Spector & \\
\hline Member & Alex Aiken & Stanford University \\
\hline & Michael J Carey & \\
\hline & Shafi Goldwasser & \\
\hline & David Heckerman & \\
\hline
\end{tabular}




\begin{tabular}{|l|l|l|}
\hline & Joseph Sifakis & \\
\hline & Olga Sorkine-Hornung & \\
\hline & Eva Tardos & Cornell University \\
\hline & Leslie G Valiant & Harvard University \\
\hline
\end{tabular}


Table 52: Female Turing winners and areas of computing

\begin{tabular}{|l|l|}
\hline Area & Women (\% of total) \\
\hline Compilers & $33 \%(1)$ \\
\hline Operating Systems & $25 \%(1)$ \\
\hline Computational Complexity & $14 \%(1)$ \\
\hline Cryptography & $14 \%(1)$ \\
\hline Programming Languages & $11 \%(1)$ \\
\hline Analysis of Algorithms & $0 \%(0)$ \\
\hline Artificial Intelligence & $0 \%(0)$ \\
\hline Combinatorial Algorithms & $0 \%(0)$ \\
\hline Computer Architecture & $0 \%(0)$ \\
\hline Computer Hardware & $0 \%(0)$ \\
\hline Computer Systems & $0 \%(0)$ \\
\hline Data Structures & $0 \%(0)$ \\
\hline Databases & $0 \%(0)$ \\
\hline Education & $0 \%(0)$ \\
\hline Error Correcting Codes & $0 \%(0)$ \\
\hline Graphics & $0 \%(0)$ \\
\hline Interactive Computing & $0 \%(0)$ \\
\hline Internet Communications & $0 \%(0)$ \\
\hline List Processing & $0 \%(0)$ \\
\hline Machine Learning & $0 \%(0)$ \\
\hline Numerical Analysis & $0 \%(0)$ \\
\hline Numerical Methods & $0 \%(0)$ \\
\hline Objected Oriented Programming & $0 \%(0)$ \\
\hline Parallel Computation & $0 \%(0)$ \\
\hline Personal Computing & $0 \%(0)$ \\
\hline Program Verification & $0 \%(0)$ \\
\hline Programming & $0 \%$ \\
\hline
\end{tabular}




\begin{tabular}{|l|l|}
\hline Proof Construction & $0 \%(0)$ \\
\hline Software & $0 \%(0)$ \\
\hline Software Engineering & $0 \%(0)$ \\
\hline Verification of Hardware and Software Models & $0 \%(0)$ \\
\hline
\end{tabular}


Table 53: Turing award winners listed by age (asc)

\begin{tabular}{|l|l|}
\hline Age & Name \\
\hline 36 & Donald Knuth \\
\hline 38 & Robert Tarjan \\
\hline 40 & Kenneth Thompson \\
\hline 42 & Dennis Ritchie \\
\hline 42 & Marvin Minsky \\
\hline 42 & Edsger Dijkstra \\
\hline 42 & Robert Floyd \\
\hline 43 & Stephen Cook \\
\hline 44 & Alan Perlis \\
\hline 44 & John McCarthy \\
\hline 44 & Dana Scott \\
\hline
\end{tabular}


Table 54: social origins of Turing winners (full)

\begin{tabular}{|c|c|c|c|}
\hline & Father & Mother & Social category \\
\hline Adleman & Appliance salesman ${ }^{233}$ & Bank teller ${ }^{234}$ & Low \\
\hline Allen & Farmer $^{235}$ & Elementary-school teacher ${ }^{236}$ & Academic (low) \\
\hline Bachman & $\begin{array}{l}\text { College football coach (Michigan } \\
\text { State) })^{237}\end{array}$ & & $\begin{array}{l}\text { Professional } \\
\text { sports (Upper- } \\
\text { middle class) }\end{array}$ \\
\hline Backus & Wealthy stockbroker & & Business (high) \\
\hline Berners-Lee & $\begin{array}{l}\text { Mathematician and computer } \\
\text { scientist (Ferranti Mark I) }{ }^{238}\end{array}$ & $\begin{array}{l}\text { Mathematician and programmer } \\
(\text { Ferranti Mark I) }\end{array}$ & $\begin{array}{l}\text { Academic } \\
\text { (both) ((very) } \\
\text { high) }\end{array}$ \\
\hline \multicolumn{4}{|l|}{ Blum } \\
\hline \multicolumn{4}{|l|}{ Brooks } \\
\hline Cerf & Aerospace executive ${ }^{240}$ & Homemaker $^{241}$ & $\begin{array}{l}\text { Business (high) } \\
\text { (possibly } \\
\text { engineering) }\end{array}$ \\
\hline Clarke & & & \\
\hline
\end{tabular}

\footnotetext{
${ }^{233}$ Turing Award biography.

${ }^{234}$ Ibid.

${ }^{235}$ Turing Award biography.

${ }^{236}$ Ibid.

${ }^{237}$ Charles W. Bachman (1892-1985). See New York Times 1985. His biographical entry

at the College Football Hall of Fame provides further details : Northwestern, Kansas State

(1920-27), Florida (5 years), Michigan State (1933-42; 1944-46) and Hillsdale College, see

http: //www . collegefootball. org/famer_selected.php?id=30056

${ }^{238}$ Conway Berners-Lee (1921-).

${ }^{239}$ Mary Lee Woods (1924-2017). Sources : Ferry 2018.

${ }^{240}$ Vinton Thurston Cerf. Sources : Jerome 2000.

${ }^{241}$ Ibid.
} 


\begin{tabular}{|c|c|c|c|}
\hline Cocke & $\begin{array}{l}\text { President of Duke Power Com- } \\
\text { pany (Duke Energy) and mem- } \\
\text { ber of the Board of Trustees of } \\
\text { Duke University }^{242}\end{array}$ & & Business (high) \\
\hline Codd & Leather manufacturer ${ }^{243}$ & Schoolteacher ${ }^{244}$ & Academic \\
\hline Cook & $\begin{array}{l}\text { Chemist for a subsidiary of } \\
\text { Union Carbide and adjunct pro- } \\
\text { fessor at SUNY }\end{array}$ & $\begin{array}{l}\text { Homemaker and occasional En- } \\
\text { glish teacher at Erie Community } \\
\text { College }^{246}\end{array}$ & $\begin{array}{l}\text { Academic } \\
\text { (both) }\end{array}$ \\
\hline Corbato & $\begin{array}{l}\text { Professor of Spanish literature at } \\
\text { UCLA }^{247}\end{array}$ & $\begin{array}{l}\text { (graduate student at Berke- } \\
\text { ley) }\end{array}$ & $\begin{array}{l}\text { Academic } \\
\text { (both) }\end{array}$ \\
\hline Dahl & $\begin{array}{l}\text { (descended on both sides from } \\
\text { long lines of sea captains) }{ }^{249}\end{array}$ & Housewife $^{250}$ & $\begin{array}{l}\text { Low (("neither } \\
\text { his sister nor } \\
\text { his brother was } \\
\text { academically } \\
\text { inclined") })^{251}\end{array}$ \\
\hline Diffie & $\begin{array}{l}\text { Professor specializing in Iberian } \\
\text { history at City College of New } \\
\text { York }^{252}\end{array}$ & $\begin{array}{l}\text { Writer and scholar }{ }^{253} \text { (passed } \\
\text { away while he was in high school) }\end{array}$ & $\begin{array}{l}\text { Academic } \\
\text { (both) }\end{array}$ \\
\hline
\end{tabular}

\footnotetext{
${ }^{242}$ Turing Award biography.

${ }^{243}$ Turing Award biography.

${ }^{244}$ Ibid.

${ }^{245}$ Turing Award biography.

${ }^{246}$ Ibid.

${ }^{247}$ Turing Award biography.

${ }^{248}$ Ibid.

${ }^{249}$ Turing Award biography.

${ }^{250}$ Ibid.

${ }^{251}$ Ibid.

${ }^{252}$ Bailey Wally Diffie. Turing Award biography.

${ }^{253}$ Justine Louise Whitfield. Ibid.
} 


\begin{tabular}{|c|c|c|c|}
\hline Dijkstra & $\begin{array}{l}\text { High-school chemistry teacher } \\
\text { and president of the Dutch } \\
\text { Chemical Society }^{254}\end{array}$ & $\begin{array}{l}\text { "never held a formal job" ("had a } \\
\text { lasting influence on his approach } \\
\text { to mathematics and his emphasis } \\
\text { on elegance.") }{ }^{255}\end{array}$ & Academic \\
\hline \multicolumn{4}{|l|}{ Emerson } \\
\hline Engelbart & $\begin{array}{l}\text { Electrical engineer who owned a } \\
\text { radio shop (died when Engelbart } \\
\text { was } 9 \text { years old) })^{256}\end{array}$ & & Engineering \\
\hline Feigenbaum & $\begin{array}{l}\text { ("stepfather took him on fre- } \\
\text { quent visits to the Hayden Plane- } \\
\text { tarium of the American Museum } \\
\text { of Natural History") }{ }^{257}\end{array}$ & & \\
\hline \multicolumn{4}{|l|}{ Floyd } \\
\hline \multicolumn{4}{|l|}{ Goldwasser } \\
\hline Gray & $\begin{array}{l}\text { (U.S. Army ("an amateur in- } \\
\text { ventor, patented a design for a } \\
\text { ribbon cartridge for typewriters } \\
\text { that earned him a substantial } \\
\text { royalty stream")) }\end{array}$ & $\begin{array}{l}\text { English teacher ("raised by his } \\
\text { mother") } 258\end{array}$ & Academic \\
\hline Hartmanis & $\begin{array}{l}\text { Senior Latvian army officer (died } \\
\text { during WW2 })^{259}\end{array}$ & & Military \\
\hline Hellman & High school physics teacher ${ }^{260}$ & & Academic \\
\hline
\end{tabular}

\footnotetext{
${ }^{254}$ Turing Award biography.

${ }^{255}$ Ibid.

${ }^{256}$ Turing Award biography.

${ }^{257}$ Turing Award biography.

${ }^{258}$ Turing Award biography.

${ }^{259}$ Turing Award biography.

${ }^{260}$ Turing Award biography.
} 


\begin{tabular}{|c|c|c|c|}
\hline Hoare & Colonial civil servant ${ }^{261}$ & Daughter of a tea planter ${ }^{262}$ & $\begin{array}{l}\text { Civil service } \\
\text { (presumably } \\
\text { high) }\end{array}$ \\
\hline Hopcroft & $\begin{array}{l}\text { Janitor ("working class fam- } \\
\text { ily") }{ }^{263} \text { (Hopcroft's grandfather } \\
\text { was "Jacob Nist, founder of the } \\
\text { Seattle-Tacoma Box Company") }\end{array}$ & & Low \\
\hline Iverson & Rabbi & & $\begin{array}{l}\text { Religious } \\
\text { profession }\end{array}$ \\
\hline Kahan & Ran a factory ${ }^{264}$ & $\begin{array}{l}\text { Created dress designs for the fac- } \\
\text { tory run by her husband }\end{array}$ & Business $^{265}$ \\
\hline Kahn & $\begin{array}{l}\text { (Through his father, related to } \\
\text { futurist Herman Kahn) }\end{array}$ & & \\
\hline Karp & $\begin{array}{l}\text { Middle school math teacher }{ }^{266} \\
\text { (Junior high school teacher) }\end{array}$ & & Academic \\
\hline
\end{tabular}

\footnotetext{
${ }^{261}$ Sources : oral histories by the British Library and the Computer History Museum. https://sounds.bl.uk/related-content/TRANSCRIPTS/021T-C1379X0052XX-0000A0.pdf http://archive.computerhistory.org/resources/text/Oral_History/Hoare_Sir_Antony/ 102658017.05.01.pdf

${ }^{262}$ Ibid.

${ }^{263}$ Turing Award biography.

${ }^{264}$ Turing Award biography.

${ }^{265}$ Ibid.

${ }^{266} 2013$ video interview of Richard Karp by the Simons Foundation. https://www . simonsfoundation. org/2013/12/13/richard-karp/
} 


\begin{tabular}{|c|c|c|c|}
\hline Kay & $\begin{array}{l}\text { Scientist }^{267} \text { / physiologist, de- } \\
\text { signed prostheses for arms and } \\
\text { legs } \\
\text { prostheses }^{269} / \text { Designed arm and leg }\end{array}$ & $\begin{array}{l}\text { artist and musician } \\
\operatorname{cian}^{271}\end{array}$ & $\begin{array}{l}\text { Academic } \\
\text { (grandmother } \\
\text { was a lecturer } \\
\text { and one of the } \\
\text { founders of } \\
\text { UMASS) }\end{array}$ \\
\hline Knuth & $\begin{array}{l}\text { Teacher in a Lutheran high } \\
\text { school and a church organist }{ }^{272} \\
\text { (Ran a small printing company } \\
\text { and taught bookkeeping at Mil- } \\
\text { waukee Lutheran High School) }\end{array}$ & & Academic \\
\hline \multicolumn{4}{|l|}{ Lamport } \\
\hline Lampson & & & $\begin{array}{l}\text { ("Born in Wash- } \\
\text { ington DC and } \\
\text { educated at The } \\
\text { Lawrenceville } \\
\text { School, an elite } \\
\text { boarding school } \\
6 \text { miles from } \\
\text { Princeton New } \\
\text { Jersey." ) } 273\end{array}$ \\
\hline
\end{tabular}

\footnotetext{
${ }^{267}$ Shasha and Lazere 1995.

${ }^{268}$ Ibid.

${ }^{269}$ Turing Award biography.

${ }^{270}$ Shasha and Lazere 1995.

${ }^{271}$ Turing Award biography.

272 Turing Award biography.

${ }^{273}$ Turing Award biography.
} 


\begin{tabular}{|c|c|c|c|}
\hline Liskov & $\begin{array}{l}\text { Harvard, Harvard Law Review } \\
\text { "Distinguished tax lawyer in San } \\
\text { Francisco" } 274\end{array}$ & $\begin{array}{l}\text { Dancer (graduated from Berke- } \\
\text { ley) }\end{array}$ & $\begin{array}{l}\text { Academic } \\
\text { (Artistic / Lib- } \\
\text { eral professions) }\end{array}$ \\
\hline McCarthy & $\begin{array}{l}\text { Labor organizer and later Busi- } \\
\text { ness Manager of the Daily } \\
\text { Worker, a national newspaper } \\
\text { owned by the Communist Party } \\
\text { USA }^{276} \text { (Organizer for the Amal- } \\
\text { gamated Clothing Workers in } \\
\text { Los Angeles) }\end{array}$ & $\begin{array}{l}\text { Worked for a wire service, then } \\
\text { for the Daily Worker and finally } \\
\text { as a social worker }{ }^{277}\end{array}$ & $\begin{array}{l}\text { Press } \quad \text { (Busi- } \\
\text { ness) (Labor } \\
\text { organization) }\end{array}$ \\
\hline \multicolumn{4}{|l|}{ Micali } \\
\hline Milner & $\begin{array}{l}\text { Military family residing on the } \\
\text { South coast of England }{ }^{278}\end{array}$ & $\begin{array}{l}\text { Military family residing on the } \\
\text { South coast of England }\end{array}$ & Military $^{279}$ \\
\hline Minsky & Eye surgeon $^{280}$ & Jewish activist ${ }^{281}$ & $\begin{array}{l}\text { Academic } \\
\text { (Medical) }\end{array}$ \\
\hline Naur & Painter $^{282}$ & $\begin{array}{l}\text { "no particular profession but } \\
\text { came from a wealthy commercial } \\
\text { background" } 283\end{array}$ & $\begin{array}{l}\text { Artistic (Upper } \\
\text { class) }\end{array}$ \\
\hline
\end{tabular}

${ }^{274}$ Moses Samuel Huberman. San Francisco Chronicle 2010 ; The Harvard Crimson 1926.

${ }^{275}$ San Francisco Chronicle 2010.

${ }^{276}$ John Patrick McCarthy. Turing Award biography. Additional sourcee : Markoff 2011.

In Markoff 2005, there is an important information regarding the chronology : "an Irish immigrant who later became business manager of (...) The Daily Worker after the family moved to Los Angeles because of their young son's health problems."

${ }^{277}$ Ida Glatt. Ibid.

${ }^{278}$ Turing Award biography.

${ }^{279}$ Ibid.

${ }^{280}$ Swedin 2005 : 188.

${ }^{281}$ Ibid.

${ }^{282}$ Turing Award biography.

${ }^{283}$ Ibid. 


\begin{tabular}{|c|c|c|c|}
\hline Newell & $\begin{array}{l}\text { Prominent professor of radiology } \\
\text { at Stanford Medical School }{ }^{284}\end{array}$ & & Academic \\
\hline \multicolumn{4}{|c|}{ Nygaard } \\
\hline \multicolumn{4}{|l|}{ Pearl } \\
\hline \multicolumn{4}{|l|}{ Perlis } \\
\hline Pnueli & $\begin{array}{l}\text { Professor (one of the founders of } \\
\text { Tel-Aviv University and chaired } \\
\text { the Hebrew literature depart- } \\
\text { ment) }\end{array}$ & Teacher $^{286}$ & $\begin{array}{l}\text { Academic } \\
\text { (both) }\end{array}$ \\
\hline Rabin & Rabbi & & $\begin{array}{l}\text { Religious } \\
\text { profession }\end{array}$ \\
\hline Reddy & Farmer & Homemaker & $\begin{array}{l}\text { Low ("first } \\
\text { member of his } \\
\text { family to attend } \\
\text { college") }\end{array}$ \\
\hline Ritchie & AT\&T Bell Laboratories ${ }^{287}$ & & Academic \\
\hline \multicolumn{4}{|l|}{ Rivest } \\
\hline \multicolumn{4}{|l|}{ Scott } \\
\hline \multicolumn{4}{|l|}{ Shamir } \\
\hline Sifakis & & & \\
\hline
\end{tabular}

${ }^{284}$ Robert R. Newell. Turing Award biography.

${ }^{285}$ Prof. Shmuel Yeshayahu ("Shay") Pnueli. Turing Award biography.

${ }^{286}$ Henya Pnueli. Ibid.

${ }^{287}$ Turing Award biography. 


\begin{tabular}{|c|c|c|c|}
\hline Simon & $\begin{array}{l}\text { engineer Cutler-Hammer Man- } \\
\text { ufacturing Company, and later } \\
\text { also engaged in private practice } \\
\text { as a patent attorney. awarded } \\
\text { honorary doctorate in } 1934 \\
\text { by Marquette University }{ }^{288} \\
\text { Worked for the Cutler-Hammer } \\
\text { manufacturing company helping } \\
\text { to design control devices }{ }^{289}\end{array}$ & $\begin{array}{l}\text { Piano teacher until marriage, } \\
\text { then housewife }{ }^{290}\end{array}$ & Academic \\
\hline \multicolumn{4}{|l|}{ Stearns } \\
\hline Stonebraker & Engineer ${ }^{291}$ & School teacher ${ }^{292}$ & Academic \\
\hline Sutherland & $\begin{array}{l}\text { "Practicing engineer with a } \\
\text { Ph.D. in civil engineering" }{ }^{293}\end{array}$ & Teacher $^{294}$ & $\begin{array}{l}\text { Academic } \\
\text { (both) }\end{array}$ \\
\hline Tarjan & $\begin{array}{l}\text { Psychiatrist (president of the } \\
\text { APA) }{ }^{295} \text { (Child psychiatrist, ran } \\
\text { a state hospital) }\end{array}$ & & $\begin{array}{l}\text { Academic } \\
\text { (Medical) }\end{array}$ \\
\hline Thacker & $\begin{array}{l}\text { Electrical engineer }{ }^{296} \text { (in the } \\
\text { aeronautical industry (graduated } \\
\text { from Caltech) }\end{array}$ & $\begin{array}{l}\text { Cashier and secretary (raised } \\
\text { their two sons on her own) }\end{array}$ & Engineering (?) \\
\hline Thompson & $(\text { US Navy) })^{297}$ & & Military (?) \\
\hline
\end{tabular}

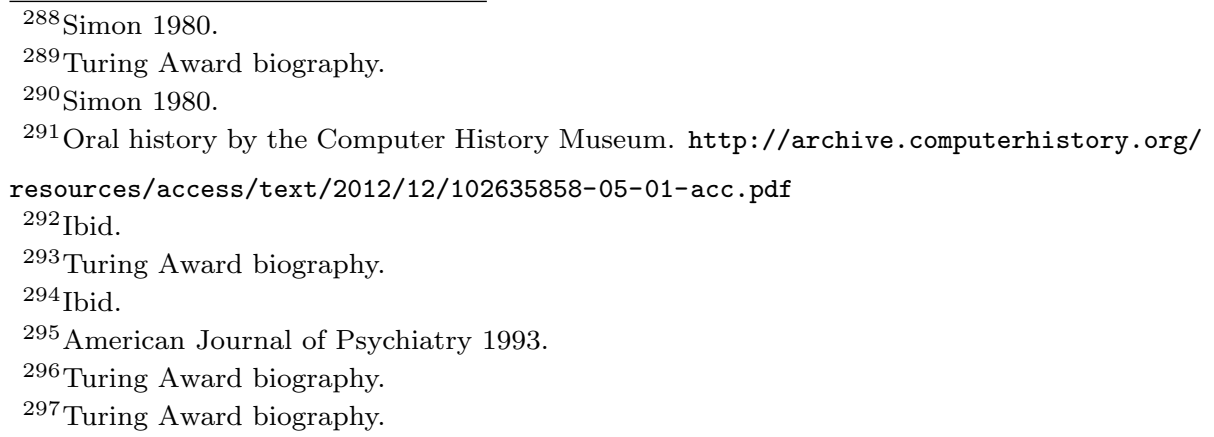




\begin{tabular}{|l|l|l|l|}
\hline Valiant & Chemical engineer ${ }^{298}$ & Multilingual translator $^{299}$ & Engineering \\
\hline Wilkes & $\begin{array}{l}\text { Financial officer for the estate of } \\
\text { the Earl of Dudley }\end{array}$ & Housewife $^{301}$ & Business \\
\hline Wilkinson & $\begin{array}{l}\text { "humble family in the dairy busi- } \\
\text { ness (...) of five children") })^{302}\end{array}$ & $\begin{array}{c}\text { "humble family in the dairy busi- } \\
\text { ness (...) of five children") })^{303}\end{array}$ & Low \\
\hline Wirth & & & \\
\hline Yao & & & \\
\hline
\end{tabular}

$\mathrm{n}=64 \mathrm{t}=64$

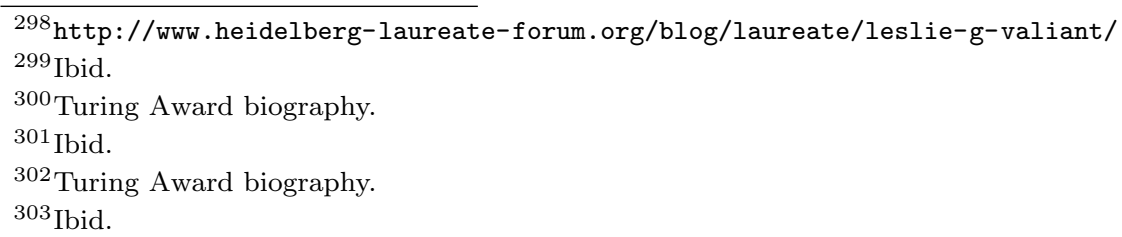


Image series : Gender through corporate archives (1950s-present)

Images : IBM's "My Fair Ladies" campaign (1950s)

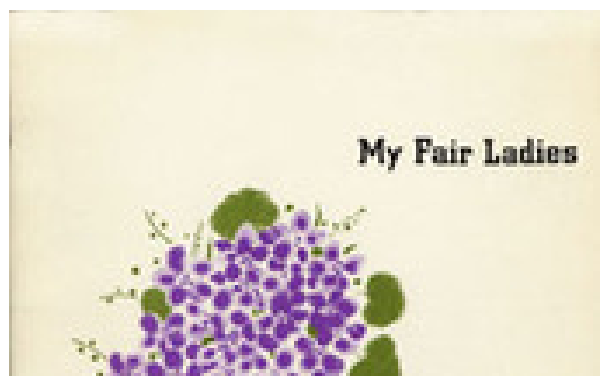

Source : IBM Archives ${ }^{304}$

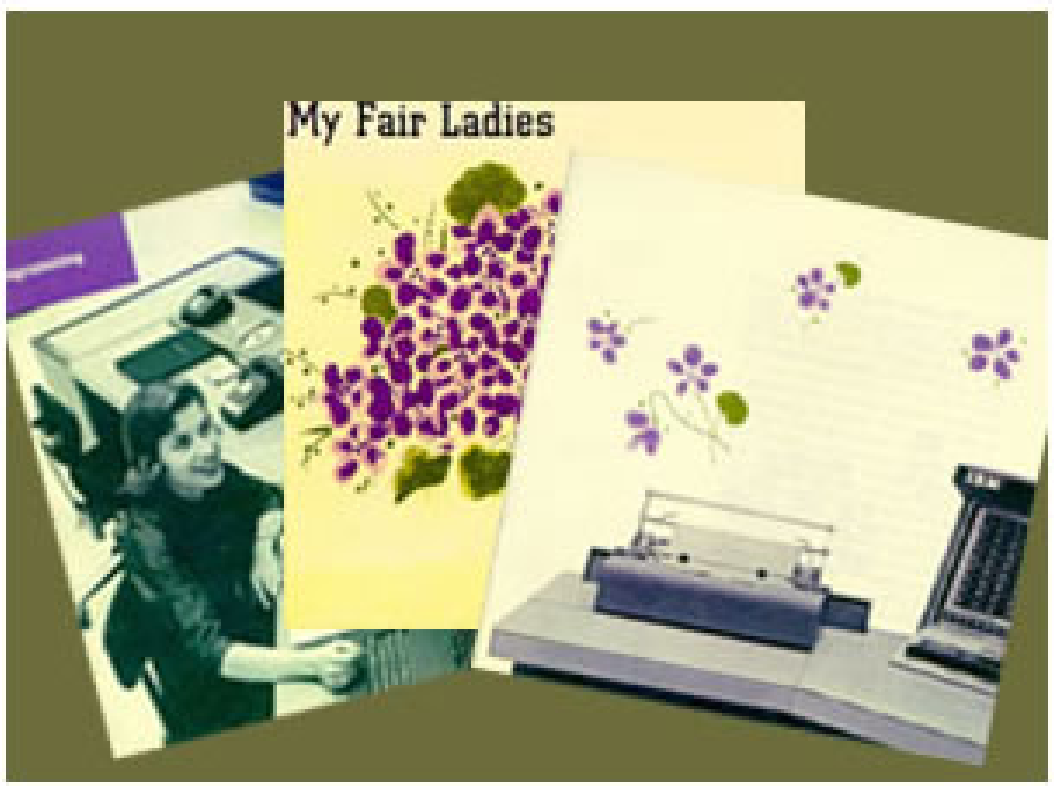

Source : unknown ${ }^{305}$.

\footnotetext{
${ }^{304}$ http://sysrun.haifa.il.ibm.com/ibm/history/witexhibit/wit_decade_1950.html. ${ }^{305}$ http://globalnerdy.com/wordpress/wp-content/uploads/2007/02/my-fair-ladies. jpg
} 
Images : Digital Equipment Corporation's PDP-11 and 8 ads (1970s)

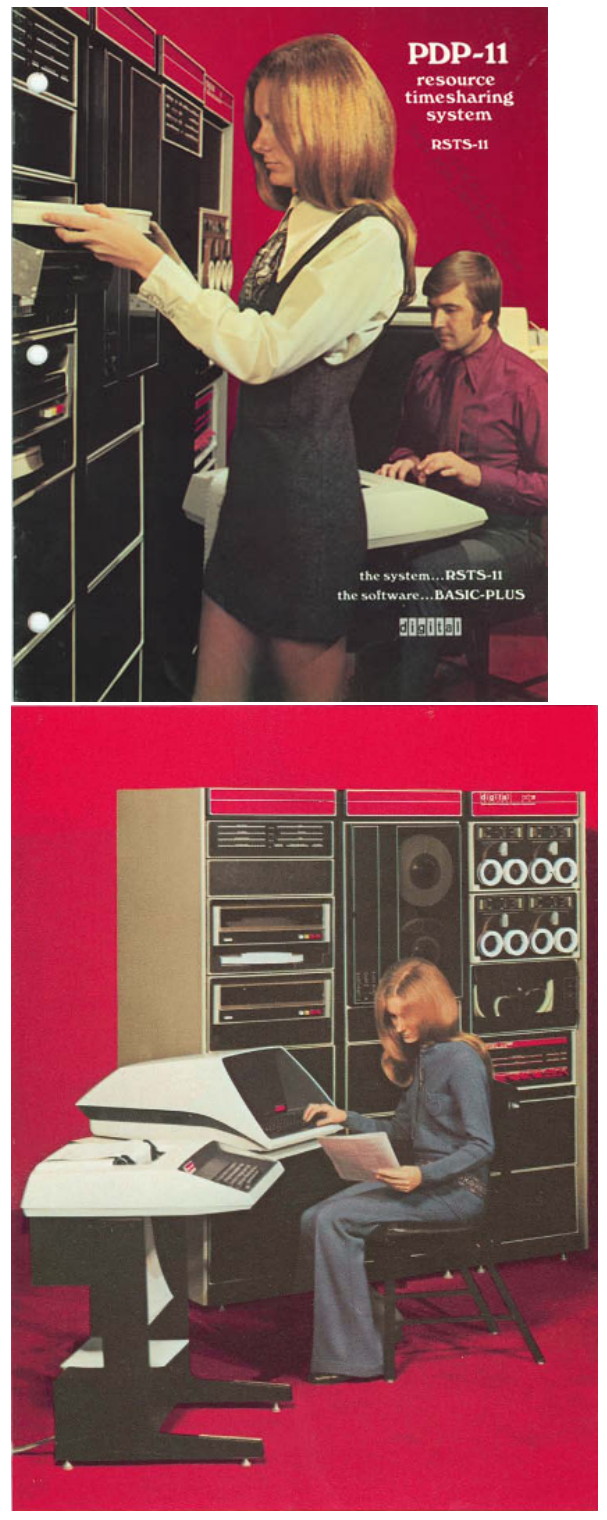

Source : 1970 PDP-11 brochure (top, front cover, bottom, p. 11) $)^{306}$

${ }^{306}$ Computer History Museum. http://archive.computerhistory.org/resources/text/ DEC/pdp-11/Digital.PDP-11.1970.102646128.pdf. 


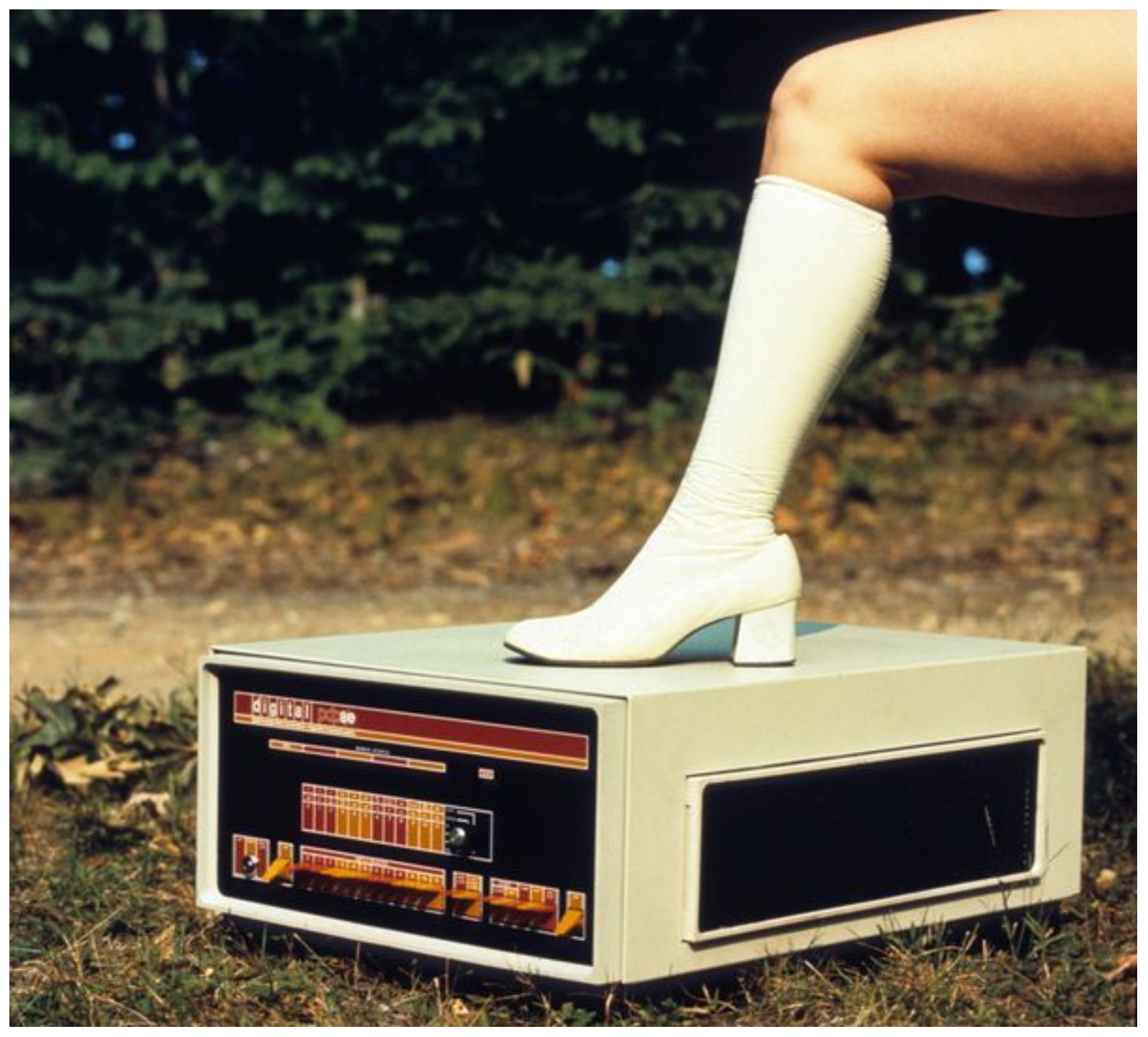

Source : ca. 1971 PDP-8 family advertisement ${ }^{307}$

${ }^{307}$ Computer History Museum. minicomputers/11/intro/1910. http://www. computerhistory.org/revolution/ 
Video captions : Alibaba recruitment campaign (2010s)

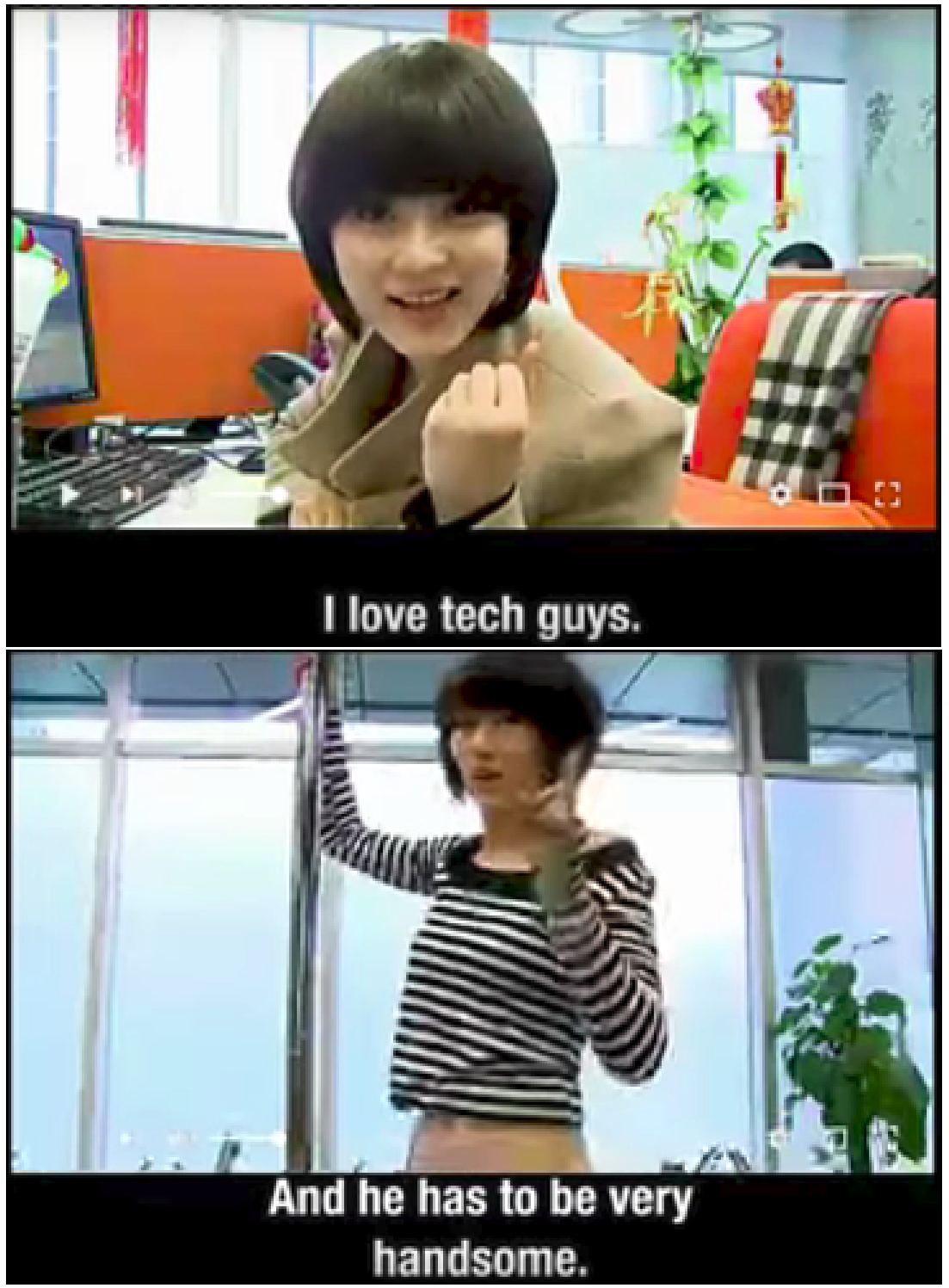

Source : Alibaba recruitment videos ${ }^{308}$

${ }^{308}$ Human Rights Watch 2018. 
Image : Matilda effect in computer science

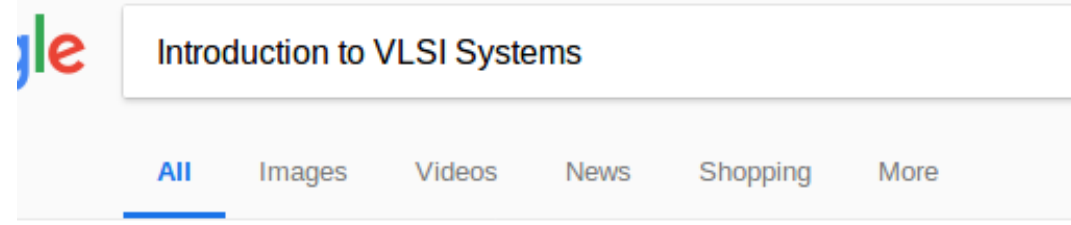

About 6150000 results $(0,38$ seconds)

\section{Introduction to VLSI systems}

Book by Carver Mead

Did you like this book?

Mos devices and circuits - Integrated system fabrication - Data and control flow in systematic structures - Implementing integrated system designs : from circuit topology to patterning geometry to wafer ... Google Books

Originally published: 1978

Author: Carver Mead

People also search for

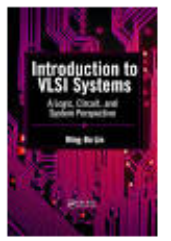

Introduction

to VLSI

Systems..

Ming-Bo Lin

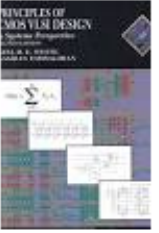

Principles of CMOS VLSI

Desi...

Kamran

Eshraghian

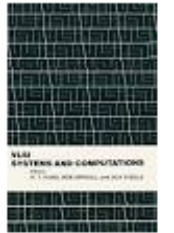

VLSI

Systems and Com.

View 25+ more

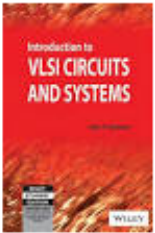

Introduction to VLSI

Circuits a...

John P.

Uyemura

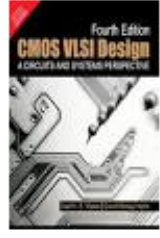

CMOS VLSI Design: A...

David Harris

Feedback

Accessed 05/2018. 
Table 55: Turing award winners by research topics

\begin{tabular}{|l|l|}
\hline Analysis of Algorithms & Hopcroft, John E (1986) \\
\hline & Knuth, Donald ("Don") Ervin (1974) \\
\hline & Lamport, Leslie (2013) \\
\hline & Pearl, Judea (2011) \\
\hline & Tarjan, Robert (Bob) Endre (1986) \\
\hline Artificial Intelligence & Feigenbaum, Edward A ("Ed") (1994) \\
\hline & Minsky, Marvin (1969) \\
\hline & Newell, Allen (1975) \\
\hline & Pearl, Judea (2011) \\
\hline & Reddy, Dabbala Rajagopal ("Raj") (1994) \\
\hline & Simon, Herbert ("Herb") Alexander (1975) \\
\hline Combinatorial Algorithms & Valiant, Leslie Gabriel (2010) \\
\hline Compilers & Karp, Richard ("Dick") Manning (1985) \\
\hline & Allen, Frances ("Fran") Elizabeth (2006) \\
\hline & Cocke, John (1987) \\
\hline Computational Complexity & Perlis, Alan J (1966) \\
\hline & Blum, Manuel (1995) \\
\hline & Cook, Stephen Arthur (1982) \\
\hline & Goldwasser, Shafi (2012) \\
\hline & Hartmanis, Juris (1993) \\
\hline & Micali, Silvio (2012) \\
\hline & Stearns, Richard ("Dick") Edwin (1993) \\
\hline & Taliant, Leslie Gabriel (2010) \\
\hline & Brooks, Frederick ( "Fred") (1999) \\
\hline & Cocke, John (1987) \\
\hline & Thacker, Charles P. (Chuck) (2009) \\
\hline & \\
\hline &
\end{tabular}




\begin{tabular}{|c|c|}
\hline Computer Hardware & Wilkes, Maurice V. (1967) \\
\hline Computer Systems & Corbato, Fernando J ("Corby") (1990) \\
\hline \multirow[t]{7}{*}{ Cryptography } & Adleman, Leonard (Len) Max (2002) \\
\hline & Blum, Manuel (1995) \\
\hline & Goldwasser, Shafi (2012) \\
\hline & Micali, Silvio (2012) \\
\hline & Rivest, Ronald (Ron) Linn (2002) \\
\hline & Shamir, Adi (2002) \\
\hline & Yao, Andrew Chi-Chih (2000) \\
\hline \multirow[t]{2}{*}{ Data Structures } & Hopcroft, John E (1986) \\
\hline & Tarjan, Robert (Bob) Endre (1986) \\
\hline \multirow[t]{4}{*}{ Databases } & Bachman, Charles William (1973) \\
\hline & Codd, Edgar F. ("Ted") (1981) \\
\hline & Gray, James ("Jim") Nicholas (1998) \\
\hline & Stonebraker, Michael (2014) \\
\hline Education & Wilkes, Maurice V. (1967) \\
\hline Error Correcting Codes & Hamming, Richard W (1968) \\
\hline \multirow[t]{2}{*}{ Finite Automata } & Rabin, Michael O. (1976) \\
\hline & Scott, Dana Stewart (1976) \\
\hline Graphics & Sutherland, Ivan (1988) \\
\hline Interactive Computing & Engelbart, Douglas (1997) \\
\hline \multirow[t]{2}{*}{ Internet Communications } & Cerf, Vinton ("Vint") Gray (2004) \\
\hline & Kahn, Robert ("Bob") Elliot (2004) \\
\hline \multirow[t]{2}{*}{ List Processing } & Newell, Allen (1975) \\
\hline & Simon, Herbert ("Herb") Alexander (1975) \\
\hline Machine Learning & Valiant, Leslie Gabriel (2010) \\
\hline \multirow[t]{2}{*}{ Numerical Analysis } & Kahan, William ("Velvel") Morton (1989) \\
\hline & Wilkinson, James Hardy ("Jim”) (1970) \\
\hline Numerical Methods & Hamming, Richard W (1968) \\
\hline
\end{tabular}




\begin{tabular}{|c|c|}
\hline \multirow[t]{2}{*}{ Objected Oriented Programming } & Dahl, Ole-Johan (2001) \\
\hline & Nygaard, Kristen (2001) \\
\hline \multirow[t]{4}{*}{ Operating Systems } & Brooks, Frederick ("Fred") (1999) \\
\hline & Liskov, Barbara (2008) \\
\hline & Ritchie, Dennis M. (1983) \\
\hline & Thompson, Kenneth Lane (1983) \\
\hline Parallel Computation & Valiant, Leslie Gabriel (2010) \\
\hline \multirow[t]{3}{*}{ Personal Computing } & Kay, Alan (2003) \\
\hline & Lampson, Butler W (1992) \\
\hline & Thacker, Charles P. (Chuck) (2009) \\
\hline \multirow[t]{2}{*}{ Program Verification } & Dijkstra, Edsger Wybe (1972) \\
\hline & Pnueli, Amir (1996) \\
\hline \multirow[t]{4}{*}{ Programming } & Backus, John (1977) \\
\hline & Dijkstra, Edsger Wybe (1972) \\
\hline & Knuth, Donald ("Don") Ervin (1974) \\
\hline & Perlis, Alan J (1966) \\
\hline \multirow[t]{9}{*}{ Programming Languages } & Backus, John (1977) \\
\hline & Hoare, C. Antony ("Tony") R. (1980) \\
\hline & Iverson, Kenneth E. ("Ken") (1979) \\
\hline & Kay, Alan (2003) \\
\hline & Lamport, Leslie (2013) \\
\hline & Liskov, Barbara (2008) \\
\hline & Milner, Arthur John Robin Gorell ("Robin") (1991) \\
\hline & Naur, Peter (2005) \\
\hline & Wirth, Niklaus E (1984) \\
\hline \multirow[t]{2}{*}{ Proof Construction } & Lamport, Leslie (2013) \\
\hline & Milner, Arthur John Robin Gorell ("Robin") (1991) \\
\hline \multirow[t]{2}{*}{ Software } & Floyd, Robert (Bob) W (1978) \\
\hline & Stonebraker, Michael (2014) \\
\hline
\end{tabular}




\begin{tabular}{|l|l|}
\hline Software Engineering & Brooks, Frederick ("Fred") (1999) \\
\hline $\begin{array}{l}\text { Verification of Hardware and } \\
\text { Software Models }\end{array}$ & Clarke, Edmund Melson (2007) \\
\hline & Emerson, E. Allen (2007) \\
\hline & Sifakis, Joseph (2007) \\
\hline
\end{tabular}

Source : $\mathrm{ACM}^{309}$. The categories are ACM's own.

309 "A.M. Turing Award Winner Research Subjects. https://amturing. acm. org/bysubject. cfm 
US states with colleges attended by Turing laureates (bachelor)

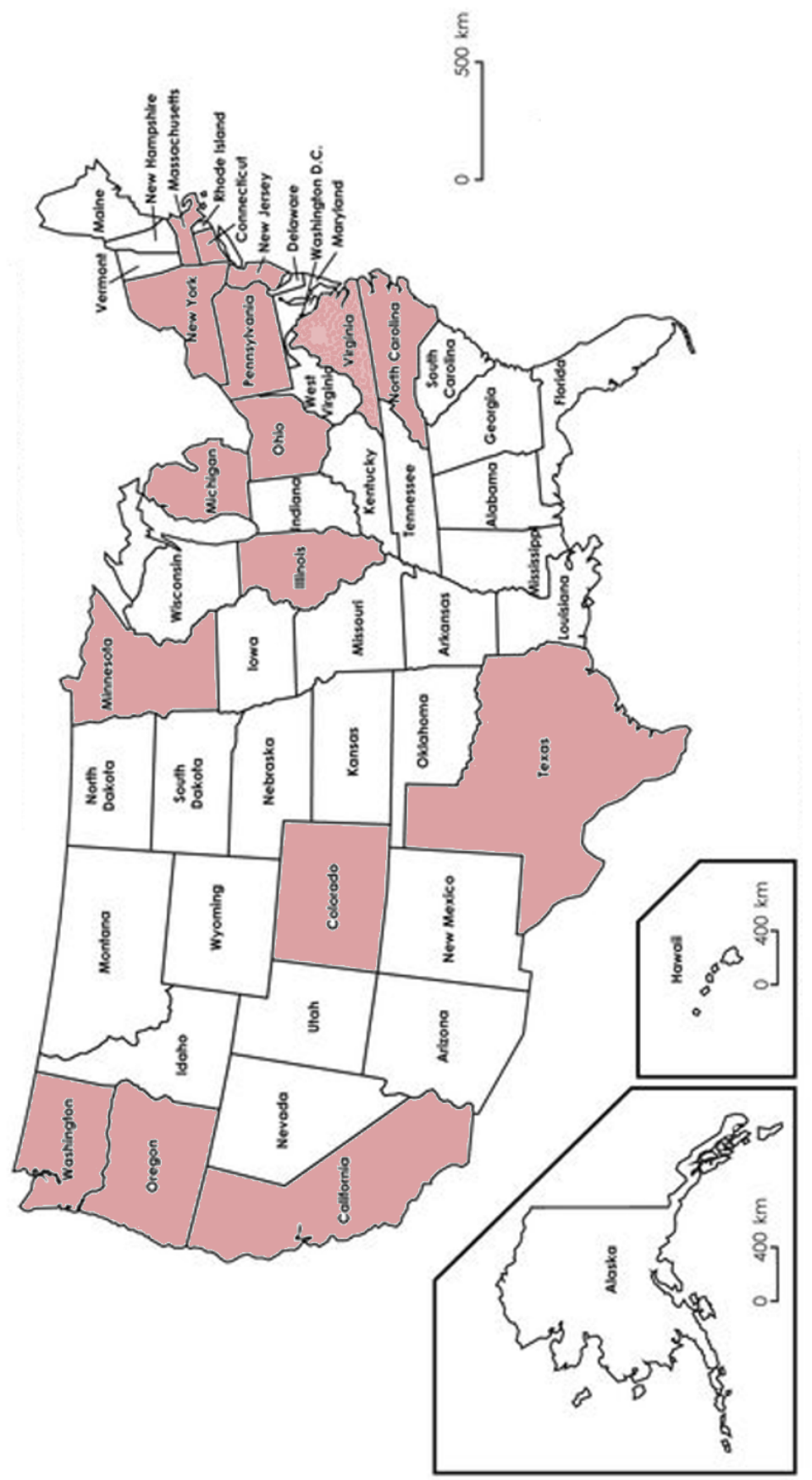


US states with colleges attended by Turing laureates (Master of PhD)

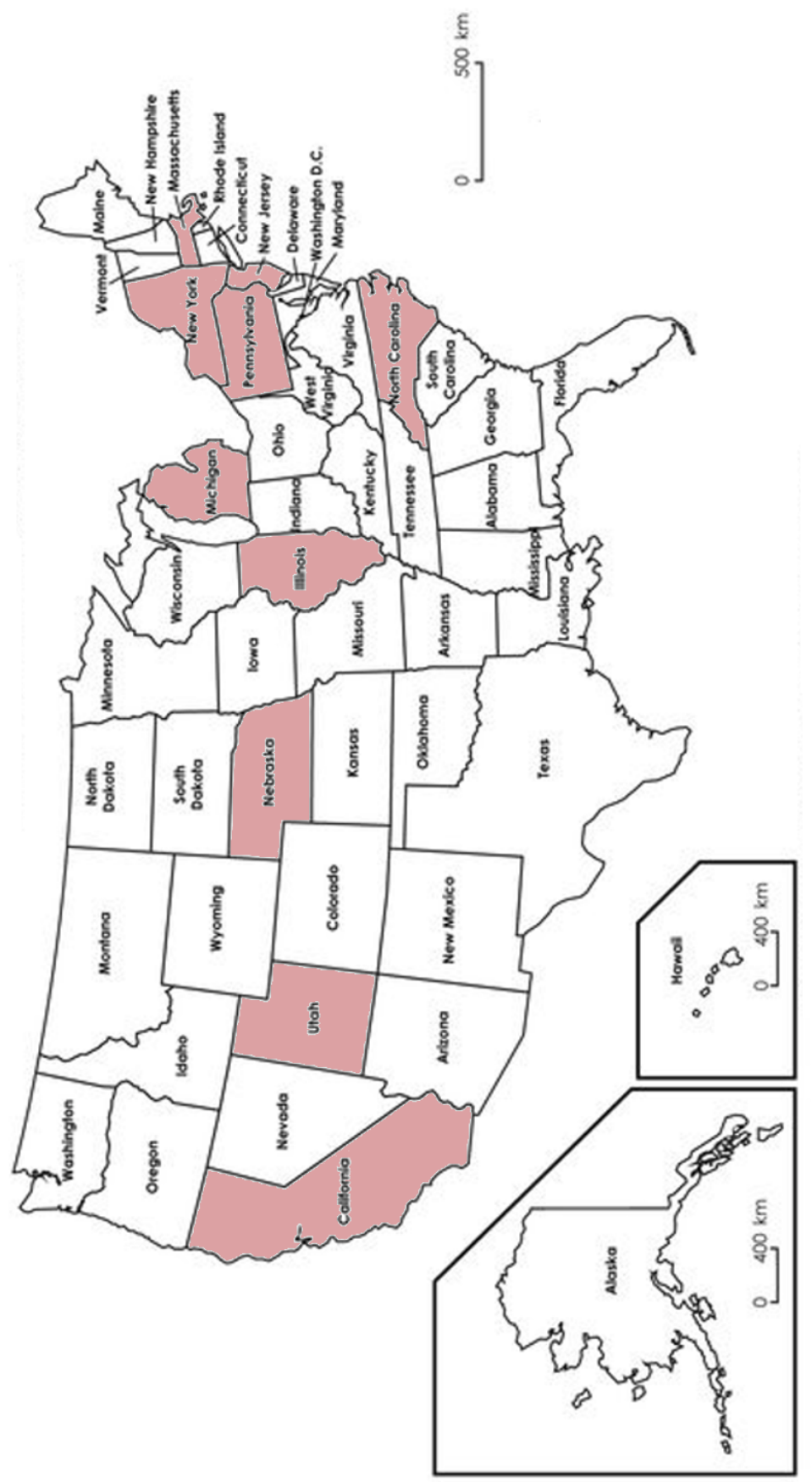




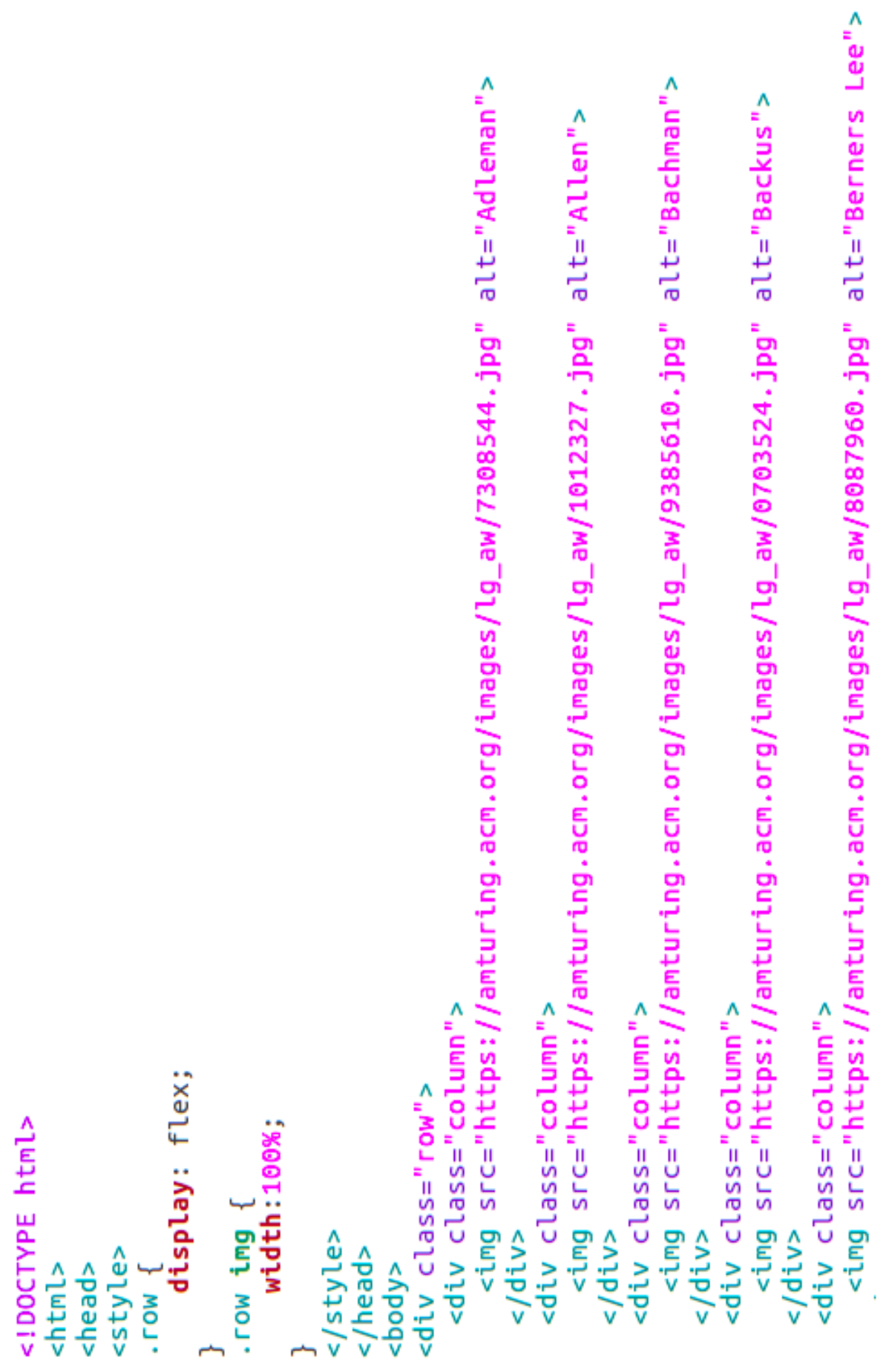


Table 56: IEEE Computer Pioneer award winners (1981-2018)

\begin{tabular}{|l|l|}
\hline Year & Winner \\
\hline $\mathbf{1 9 8 1}$ & Jeffrey Chuan Chu \\
\hline $\mathbf{1 9 8 2}$ & Arthur Burks \\
\hline $\mathbf{1 9 8 2}$ & Harry D. Huskey \\
\hline $\mathbf{1 9 8 4}$ & Willem L. van der Poel \\
\hline $\mathbf{1 9 8 4}$ & Nathaniel Rochester \\
\hline $\mathbf{1 9 8 4}$ & Nicholas C. Metropolis \\
\hline $\mathbf{1 9 8 4}$ & Jerrier A. Haddad \\
\hline $\mathbf{1 9 8 4}$ & John Vincent Atanasoff \\
\hline $\mathbf{1 9 8 5}$ & Heinz Zemanek \\
\hline $\mathbf{1 9 8 5}$ & David J. Wheeler \\
\hline $\mathbf{1 9 8 5}$ & Ivan Sutherland \\
\hline $\mathbf{1 9 8 5}$ & Alan Perlis \\
\hline $\mathbf{1 9 8 5}$ & John McCarthy \\
\hline $\mathbf{1 9 8 5}$ & John G. Kemeny \\
\hline $\mathbf{1 9 8 6}$ & Adriann van Wijngaarden \\
\hline $\mathbf{1 9 8 6}$ & James H. Pomerene \\
\hline $\mathbf{1 9 8 6}$ & Peter Naur \\
\hline $\mathbf{1 9 8 6}$ & Cuthbert C. Hurd \\
\hline $\mathbf{1 9 8 7}$ & Nicklaus E. Wirth \\
\hline $\mathbf{1 9 8 7}$ & Arthur L. Samuel \\
\hline $\mathbf{1 9 8 7}$ & Reynold B. Johnson \\
\hline $\mathbf{1 9 8 7}$ & Robert R. Everett \\
\hline $\mathbf{1 9 8 8}$ & Marcian E. Hoff, Jr. \\
\hline $\mathbf{1 9 8 8}$ & Freidrich L. Bauer \\
\hline $\mathbf{1 9 8 9}$ & Gordon D. Goldstein \\
\hline $\mathbf{1 9 8 9}$ & F. Joachim Weyl \\
\hline $\mathbf{1 9 8 9}$ & Marshall C. Yovits \\
\hline
\end{tabular}




\begin{tabular}{|l|l|}
\hline $\mathbf{1 9 8 9}$ & Mina S. Rees \\
\hline $\mathbf{1 9 8 9}$ & Ralph L. Palmer \\
\hline $\mathbf{1 9 8 9}$ & James A. Weidenhammer \\
\hline $\mathbf{1 9 8 9}$ & John Cocke \\
\hline $\mathbf{1 9 9 0}$ & C.A.R. Hoare \\
\hline $\mathbf{1 9 9 1}$ & Thomas E. Buchholz \\
\hline $\mathbf{1 9 9 1}$ & Thomas E. Kurtz \\
\hline $\mathbf{1 9 9 1}$ & Robert W. Floyd \\
\hline $\mathbf{1 9 9 1}$ & Bob O. Evans \\
\hline $\mathbf{1 9 9 2}$ & Douglas C. Engelbart \\
\hline $\mathbf{1 9 9 2}$ & Stephen W. Dunwell \\
\hline $\mathbf{1 9 9 3}$ & Willis H. Ware \\
\hline $\mathbf{1 9 9 3}$ & Jack S. Kilby \\
\hline $\mathbf{1 9 9 3}$ & Erich Bloch \\
\hline $\mathbf{1 9 9 4}$ & Ken L. Thompson \\
\hline $\mathbf{1 9 9 4}$ & Dennis M. Ritchie \\
\hline $\mathbf{1 9 9 4}$ & Harlan D. Mills \\
\hline $\mathbf{1 9 9 4}$ & Gerrit A. Blaauw \\
\hline $\mathbf{1 9 9 5}$ & Kenneth Olsen \\
\hline $\mathbf{1 9 9 5}$ & Marvin Minsky \\
\hline $\mathbf{1 9 9 5}$ & Butler Lampson \\
\hline $\mathbf{1 9 9 5}$ & David Evans \\
\hline $\mathbf{1 9 9 5}$ & Gerald Estrin \\
\hline $\mathbf{1 9 9 6}$ & Antonin Svoboda \\
\hline $\mathbf{1 9 9 6}$ & Arnols Reitsakas \\
\hline $\mathbf{1 9 9 6}$ & Ivan Plander \\
\hline $\mathbf{1 9 9 6}$ & Grigore C. Moisil \\
\hline $\mathbf{1 9 9 6}$ & Romuald W. Marczynski \\
\hline $\mathbf{1 9 9 6}$ & Alexey A. Lyapunov \\
\hline & \\
\hline
\end{tabular}




\begin{tabular}{|l|l|}
\hline $\mathbf{1 9 9 6}$ & Sergey A. Lebedev \\
\hline $\mathbf{1 9 9 6}$ & Laszlo Kozma \\
\hline $\mathbf{1 9 9 6}$ & Antoni Kilinski \\
\hline $\mathbf{1 9 9 6}$ & Laszlo Kalmar \\
\hline $\mathbf{1 9 9 6}$ & Robert E. Kahn \\
\hline $\mathbf{1 9 9 6}$ & Lubomir Georgiev Iliev \\
\hline $\mathbf{1 9 9 6}$ & Jiri Horejs \\
\hline $\mathbf{1 9 9 6}$ & Jozef Gruska \\
\hline $\mathbf{1 9 9 6}$ & Victor M. Glushkov \\
\hline $\mathbf{1 9 9 6}$ & Norbert Fristacky \\
\hline $\mathbf{1 9 9 6}$ & Edgar Frank Codd \\
\hline $\mathbf{1 9 9 6}$ & Richard F. Clippinger \\
\hline $\mathbf{1 9 9 6}$ & Angel Angelov \\
\hline $\mathbf{1 9 9 7}$ & Frances Elizabeth (Betty) Snyder-Holberton \\
\hline $\mathbf{1 9 9 7}$ & Homer (Barney) Oldfield \\
\hline $\mathbf{1 9 9 8}$ & Irving John (Jack) Good \\
\hline $\mathbf{1 9 9 9}$ & Herbert Freeman \\
\hline $\mathbf{2 0 0 0}$ & Georgiy Lopato \\
\hline $\mathbf{2 0 0 0}$ & Gennady Stolyarov \\
\hline $\mathbf{2 0 0 0}$ & Harold W. Lawson \\
\hline $\mathbf{2 0 0 1}$ & William H. Bridge \\
\hline $\mathbf{2 0 0 1}$ & Vernon L. Schatz \\
\hline $\mathbf{2 0 0 2}$ & Robert W. Bemer \\
\hline $\mathbf{2 0 0 2}$ & Per Brinch Hansen \\
\hline $\mathbf{2 0 0 3}$ & Martin Richards \\
\hline $\mathbf{2 0 0 4}$ & Frances (Fran) E. Allen \\
\hline $\mathbf{2 0 0 6}$ & Arnold M. Spielberg \\
\hline $\mathbf{2 0 0 6}$ & Mamoru Hosaka \\
\hline $\mathbf{2 0 0 8}$ & Carl A. Petri \\
\hline & \\
\hline
\end{tabular}




\begin{tabular}{|l|l|}
\hline $\mathbf{2 0 0 8}$ & Edward J. McCluskey \\
\hline $\mathbf{2 0 0 8}$ & Betty Jean Jennings Bartik \\
\hline $\mathbf{2 0 0 9}$ & Lynn Conway \\
\hline $\mathbf{2 0 0 9}$ & Jean Sammet \\
\hline $\mathbf{2 0 1 1}$ & David Kuck \\
\hline $\mathbf{2 0 1 2}$ & Cleve Moler \\
\hline $\mathbf{2 0 1 3}$ & Edward Feigenbaum \\
\hline $\mathbf{2 0 1 3}$ & Stephen B. Furber \\
\hline $\mathbf{2 0 1 4}$ & Linus Torvalds \\
\hline $\mathbf{2 0 1 5}$ & Peter M. Kogge \\
\hline $\mathbf{2 0 1 5}$ & Michael J. Flynn \\
\hline $\mathbf{2 0 1 6}$ & E. Grady Booch \\
\hline $\mathbf{2 0 1 8}$ & Bjarne Stroustrup \\
\hline $\mathbf{2 0 1 8}$ & Barbara Liskov \\
\hline
\end{tabular}

Source : IEEE Computer Pioneer Award ${ }^{310}$.

310https://www. computer.org/web/awards/pioneer 



\title{
A well of loneliness : diversity among leading Linux kernel developers (2005-2020)
}

\author{
Camille Akmut
}

February 5, 2020

\begin{abstract}
Fifteen years of Linux kernel development are reviewed from the point of view of gender diversity. Study based on total commits (as opposed to e.g. mailing list participation) $: \geq 1,400$, corresponding to top 50 Linux kernel developers (including Linus Torvalds).
\end{abstract}


Table 1 - Diversity among Linux kernel developers (2005-2020)

\begin{tabular}{|c|c|c|c|c|}
\hline & & commits & & \\
\hline 1 & tiwai & 6,207 & Takashi Iwai & $\mathrm{m}$ \\
\hline 2 & ickle & 5,401 & $?$ & $?$ \\
\hline 3 & arndb & 4,633 & Arnd Bergmann (?) & $\mathrm{m}(?)$ \\
\hline 4 & jmberg & 4,435 & Johannes Berg (?) & $\mathrm{m}(?)$ \\
\hline 5 & gregkh & 4,344 & Greg Kroah-Hartman & $\mathrm{m}$ \\
\hline 6 & bigguiness & 4,196 & H Hartley Sweeten & $\mathrm{m}$ \\
\hline 7 & htejun & 4,132 & Tejun Heo & $\mathrm{m}$ \\
\hline 8 & broonie & 4,060 & Mark Brown & $\mathrm{m}$ \\
\hline 9 & mchehab & 3,988 & Mauro Carvalho Chehab & $\mathrm{m}$ \\
\hline 10 & morimoto & 3,387 & Kuninori Morimoto & $\mathrm{m}$ \\
\hline 11 & davem330 & 3,217 & David S. Miller & $\mathrm{m}$ \\
\hline 12 & danvet & 3,187 & Daniel Vetter & $\mathrm{m}$ \\
\hline 13 & JoePerches & 3,131 & Joe Perches (?) & $\mathrm{m}(?)$ \\
\hline 14 & skeggsb & 3,115 & Ben Skeggs (?) & $\mathrm{m}(?)$ \\
\hline 15 & vsyrjala & 3,102 & Ville Syrjala (?) & $\mathrm{m}(?)$ \\
\hline 16 & linusw & 2,971 & Linus Walleij & $\mathrm{m}$ \\
\hline 17 & AxelLin & 2,929 & Axel Lin & $\mathrm{m}$ \\
\hline 18 & ColinIanKing & 2,676 & Colin Ian King & $\mathrm{m}$ \\
\hline 19 & dhowells & 2,452 & David Howells (?) & $\mathrm{m}(?)$ \\
\hline 20 & bzolnier & 2,424 & Bartlomiej Zolnierkiewicz (?) & $\mathrm{m}(?)$ \\
\hline 21 & jwrdegoede & 2,316 & Hans de Goede & $\mathrm{m}$ \\
\hline 22 & larsclausen & 2,302 & Lars-Peter Clausen & $\mathrm{m}$ \\
\hline 23 & andy-shev & 2,288 & Andy Shevchenko & $\mathrm{m}$ \\
\hline 24 & jhovold & 2,146 & Johan Hovold & $\mathrm{m}$ \\
\hline 25 & ralfbaechle & 2,123 & Ralf Baechle & $\mathrm{m}$ \\
\hline 26 & masahir0y & 2,060 & Masahiro Yamada & $\mathrm{m}$ \\
\hline 27 & ebiederm & 1,934 & Eric Biederman (?) & $\mathrm{m}(?)$ \\
\hline 28 & AdrianBunk & 1,914 & Adrian Bunk & $\mathrm{m}$ \\
\hline 29 & paulmck & 1,847 & Paul E. McKenney & $\mathrm{m}$ \\
\hline 30 & heicarst & 1,819 & Heiko Carstens (?) & $\mathrm{m}(?)$ \\
\hline 31 & vireshk & 1,752 & Viresh Kumar & $\mathrm{m}$ \\
\hline 32 & herbertx & 1,732 & Herbert Xu & $\mathrm{m}$ \\
\hline 33 & ffainelli & 1,730 & Florian Fainelli & $\mathrm{m}$ \\
\hline 34 & groeck & 1,691 & Guenter Roeck & $\mathrm{m}$ \\
\hline 35 & hverkuil & 1,676 & Hans Verkuil (?) & $\mathrm{m}(?)$ \\
\hline 36 & tmlind & 1,656 & Tony Lindgren & $\mathrm{m}$ \\
\hline 37 & torvalds & 1,595 & Linus Torvalds & $\mathrm{m}$ \\
\hline 38 & kees & 1,575 & Kees Cook & $\mathrm{m}$ \\
\hline 39 & jankara & 1,554 & Jan Kara & $\mathrm{m}$ \\
\hline 40 & ozbenh & 1,543 & Benjamin Herrenschmidt & $\mathrm{m}$ \\
\hline 41 & chucklever & 1,507 & Chuck Lever & $\mathrm{m}$ \\
\hline
\end{tabular}




\begin{tabular}{|l|l|l|l|l|}
\hline 42 & neilbrown & 1,501 & Neil Brown & $\mathrm{m}$ \\
\hline 43 & mripard & 1,473 & Maxime Ripard & $\mathrm{m}$ \\
\hline 44 & mpe & 1,471 & Michael Ellerman & $\mathrm{m}$ \\
\hline 45 & pinchartl & 1,456 & Laurent Pinchart (?) & $\mathrm{m}(?)$ \\
\hline 46 & krzk & 1,456 & Krzysztof Kozlowski & $\mathrm{m}$ \\
\hline 47 & ian-abbott & 1,444 & Ian Abbott & $\mathrm{m}$ \\
\hline 48 & kaber & 1,427 & Patrick McHardy & $\mathrm{m}$ \\
\hline 49 & GustavoARSilva & 1,426 & Gustavo A. R. Silva & $\mathrm{m}$ \\
\hline 50 & djbw & 1,416 & Dan Williams & $\mathrm{m}$ \\
\hline
\end{tabular}

Table 1: "...to master, excluding merge commits" /torvalds/linux/

\section{Measured 05/02/20 c. 9.40 am (no refresh)}

Gender was identified based on names, photos, user names, 'Linux kernel report', mailing lists, commit messages...

An error would have consisted to give for time period "2002-2020" — otherwise indicated by Github. As the Linux kernel developer report makes additionally clear : the "git era" of Linux kernel development starts in $2005^{1}$ (git was released that year...).

\section{Table 2 - Aggregated results}

\begin{tabular}{|l|l|l|}
\hline Gender & $\mathrm{n}$ & Percentage \\
\hline Female & 0 & $0 \%$ \\
\hline Male & 50 & $100 \%$ \\
\hline
\end{tabular}

Table 2: Diversity among top 50 Linux kernel developers (2005-20)

\footnotetext{
1" the beginning of the git era (the 2.6.11 release in 2005)". Linux Foundation 2017 : 11.
} 
Table 3 - Diversity among Linux kernel developers (2005-2017)

\begin{tabular}{|l|l|l|}
\hline Name & "Changes" / \% & \\
\hline H Hartley Sweeten & $6,0340.9 \%$ & $\mathrm{~m}$ \\
\hline Al Viro & $5,9040.9 \%$ & $\mathrm{~m}$ \\
\hline Takashi Iwai & $5,0890.8 \%$ & $\mathrm{~m}$ \\
\hline Mauro Carvalho Chehab & $5,0390.8 \%$ & $\mathrm{~m}$ \\
\hline David S. Miller & $4,0440.6 \%$ & $\mathrm{~m}$ \\
\hline Johannes Berg & $4,0140.6 \%$ & $\mathrm{~m}$ \\
\hline Mark Brown & $3,9780.6 \%$ & $\mathrm{~m}$ \\
\hline Tejun Heo & $3,9510.6 \%$ & $\mathrm{~m}$ \\
\hline Russell King & $3,6920.6 \%$ & $\mathrm{~m}$ \\
\hline Greg Kroah-Hartman & $3,5930.6 \%$ & $\mathrm{~m}$ \\
\hline Thomas Gleixner & $3,5820.6 \%$ & $\mathrm{~m}$ \\
\hline Christoph Hellwig & $3,4980.5 \%$ & $\mathrm{~m}$ \\
\hline Hans Verkuil & $3,4190.5 \%$ & $\mathrm{~m}$ \\
\hline Ingo Molnár & $3,1280.5 \%$ & $\mathrm{~m}$ \\
\hline Chris Wilson & $3,0900.5 \%$ & $\mathrm{~m}$ \\
\hline Arnd Bergmann & $3,0710.5 \%$ & $\mathrm{~m}$ \\
\hline Geert Uytterhoeven & $3,0110.5 \%$ & $\mathrm{~m}$ \\
\hline Dan Carpenter & $2,9940.5 \%$ & $\mathrm{~m}$ \\
\hline Eric Dumazet & $2,9880.5 \%$ & $\mathrm{~m}$ \\
\hline Joe Perches & $2,9370.5 \%$ & $\mathrm{~m}$ \\
\hline Alex Deucher & $2,7570.4 \%$ & $\mathrm{~m}$ \\
\hline Daniel Vetter & $2,6880.4 \%$ & $\mathrm{~m}$ \\
\hline Laurent Pinchart & $2,6870.4 \%$ & $\mathrm{~m}$ \\
\hline Axel Lin & $2,6700.4 \%$ & $\mathrm{~m}$ \\
\hline Trond Myklebust & $2,5540.4 \%$ & $\mathrm{~m}$ \\
\hline Ben Skeggs & $2,5160.4 \%$ & $\mathrm{~m}$ \\
\hline Arnaldo Carvalho de Melo & $2,4560.4 \%$ & $\mathrm{~m}$ \\
\hline Bartlomiej Zolnierkiewicz & $2,3310.4 \%$ & $\mathrm{~m}$ \\
\hline Kuninori Morimoto & $2,3000.4 \%$ & $\mathrm{~m}$ \\
\hline Linus Walleij & $2,2810.4 \%$ & \\
\hline & & \\
\hline
\end{tabular}

Source (except gender) : "Top 30 kernel developers, 2.6.11-4.13" Linux Foundation 2017

Table 4 - Aggregated results

\begin{tabular}{|l|l|l|}
\hline Gender & $\mathrm{n}$ & Percentage \\
\hline Female & 0 & $0 \%$ \\
\hline Male & 30 & $100 \%$ \\
\hline
\end{tabular}

Table 4: Diversity among top 30 Linux kernel developers (2005-17) 


\section{References}

- "Linux kernel source tree". https://github.com/torvalds/linux/graphs/contributors ("Contributions to master, excluding merge commits")

- Linux Foundation. 2017. "Linux kernel development report". 


\title{
More data on an exclusive group : Linux kernel developers and diversity (2005-2020)
}

\author{
Camille Akmut
}

February 5, 2020

abstract One hundred Linux kernel developers were reviewed, in total. Commits : $\geq 935$. (This group shares similar traits with early 20th c. college culture.)

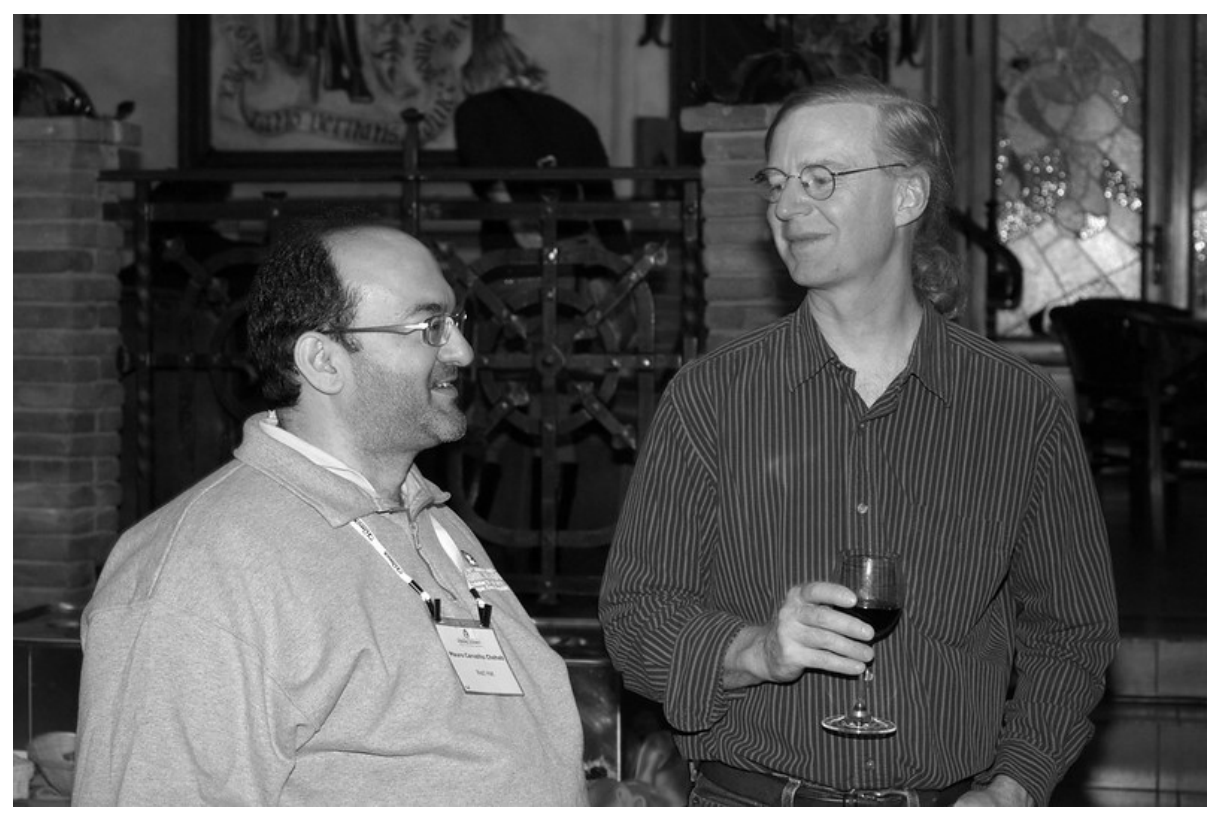

Figure 1: Linux kernel summit 2011 (Linux foundation) 
Table 1 - Diversity and Linux kernel developers, \#51-100 (2005-2020)

\begin{tabular}{|l|l|l|l|l|}
\hline$\ldots$ & & commits & & \\
\hline 51 & rostedt & 1,382 & Steven Rostedt & $\mathrm{m}$ \\
\hline 52 & geertu & 1,382 & Geert Uytterhoeven & $\mathrm{m}$ \\
\hline 53 & lwfinger & 1,362 & Larry.Finger (?) & $\mathrm{m}(?)$ \\
\hline 54 & alexandrebelloni & 1,354 & Alexandre Belloni & $\mathrm{m}$ \\
\hline 55 & JuliaLawall & 1,349 & Julia Lawall (?) & $\mathrm{f}(?)$ \\
\hline 56 & tomba & 1,340 & Tomi Valkeinen & $\mathrm{m}(?)$ \\
\hline 57 & olsajiri & 1,332 & Jiri Olsa (?) & $\mathrm{m}(?)$ \\
\hline 58 & bebarino & 1,315 & Stephen Boyd & $\mathrm{m}$ \\
\hline 59 & AlanStern & 1,300 & Alan Stern (?) & $\mathrm{m}(?)$ \\
\hline 60 & ujfalusi & 1,299 & Péter Ujfalusi & $\mathrm{m}$ \\
\hline 61 & ukleinek & 1,271 & Uwe Kleine-König & $\mathrm{m}$ \\
\hline 62 & wildea01 & 1,243 & Will Deacon (?) & $\mathrm{m}(?)$ \\
\hline 63 & jtlayton & 1,235 & Jeff Layton (?) & $\mathrm{m}$ \\
\hline 64 & dtor & 1,222 & Dmitry Torokhov & $\mathrm{m}$ \\
\hline 65 & palosaari & 1,206 & Antti Palosaari & $\mathrm{m}$ \\
\hline 66 & jnikula & 1,183 & Jani Nikula & $\mathrm{m}$ \\
\hline 67 & elfring & 1,170 & Markus Elfring & $\mathrm{m}$ \\
\hline 68 & egrumbach & 1,170 & Emmanuel Grumbach $(?)$ & $\mathrm{m}(?)$ \\
\hline 69 & paulgortmaker & 1,160 & Paul Gortmaker & $\mathrm{m}$ \\
\hline 70 & dwmw2 & 1,154 & David Woodhouse & $\mathrm{m}$ \\
\hline 71 & holtmann & 1,138 & Marcel Holtmann & $\mathrm{m}$ \\
\hline 72 & kuba-moo & 1,135 & Jakub Kicinski & $\mathrm{m}$ \\
\hline 73 & lag-linaro & 1,096 & Lee Jones & $\mathrm{m}$ \\
\hline 74 & jhedberg & 1,095 & Johan Hedberg & $\mathrm{m}$ \\
\hline 75 & paulusmack & 1,088 & Paul Mackerras & $\mathrm{m}$ \\
\hline 76 & rustyrussell & 1,083 & Rusty Russell & $\mathrm{m}$ \\
\hline 77 & martinezjavier & 1,057 & Javier Martinez Canillas & $\mathrm{m}$ \\
\hline 78 & bjorn-helgaas & 1,050 & Bjorn Helgaas & $\mathrm{m}$ \\
\hline 79 & rmilecki & 1,038 & Rafał Miłecki & $\mathrm{m}$ \\
\hline 80 & airlied & 1,035 & Dave Airlie & $\mathrm{m}$ \\
\hline 81 & borkmann & 1,027 & Daniel Borkmann & $\mathrm{m}$ \\
\hline 82 & fweisbec & 1,025 & Frederic Weisbecker & $\mathrm{m}$ \\
\hline 83 & akpm00 & 1,021 & Andrew Morton (?) & $\mathrm{m}(?)$ \\
\hline 84 & lyakh & 1,020 & Guennadi Liakhovetski & $\mathrm{m}$ \\
\hline 85 & jpirko & 1,018 & Jiri Pirko & $\mathrm{m}$ \\
\hline 86 & rjwysocki & 1,015 & Rafael J. Wysocki & $\mathrm{m}$ \\
\hline 87 & somasbw & 1,012 & Tomas Winkler & $\mathrm{m}$ \\
\hline 88 & 1,011 & Stephen Rothwell & $\mathrm{m}$ \\
\hline 89 & 1,008 & Oleg Nesterov (?) & $\mathrm{m}(?)$ \\
\hline 90 & 1,005 & David Sterba (?) & $?$ \\
\hline 91 & 999 & K. Y. Srinivasan (?) & \\
\hline & & & \\
\hline
\end{tabular}




\begin{tabular}{|l|l|l|l|l|}
\hline 92 & ardbiesheuvel & 998 & Ard Biesheuvel & $\mathrm{m}$ \\
\hline 93 & acpibob & 995 & Robert Moore & $\mathrm{m}$ \\
\hline 94 & dsahern & 982 & David Ahern & $\mathrm{m}$ \\
\hline 95 & tytso & 969 & Theodore Ts'o & $\mathrm{m}$ \\
\hline 96 & ebiggers & 968 & Eric Biggers & $\mathrm{m}$ \\
\hline 97 & michalsimek & 957 & Michal Simek & $\mathrm{m}$ \\
\hline 98 & wens & 955 & Chen-Yu Tsai & $\mathrm{m}$ \\
\hline 99 & aakoskin & 935 & Aaro Koskinen & $\mathrm{m}$ \\
\hline 100 & ummakynes & 931 & Pablo Neira Ayuso (?) & $\mathrm{m}(?)$ \\
\hline
\end{tabular}

Table 1: "...to master, excluding merge commits" /torvalds/linux/

Measured 05/02/20 c. 9.40 am (no refresh)

We continue to indicate information not directly derived from Github profiles with (?)

Table 2 - Aggregated data

\begin{tabular}{|l|l|l|}
\hline Gender & $\mathrm{n}$ & Percentage \\
\hline Female & 1 & $2 \%$ \\
\hline Male & 49 & $98 \%$ \\
\hline
\end{tabular}

Table 2: Diversity : Linux kernel developers, \#51-100 (2005-2020)

Table 3 - Total aggregated data

\begin{tabular}{|l|l|l|}
\hline Gender & $\mathrm{n}$ & Percentage \\
\hline Female & 1 & $1 \%$ \\
\hline Male & 99 & $99 \%$ \\
\hline
\end{tabular}

Table 3: Diversity, top 100 linux kernel developers (2005-2020) 


\section{References}

- "Linux kernel source tree". https://github.com/torvalds/linux/graphs/contributors

("Contributions to master, excluding merge commits")

- Linux Foundation photographies https://www.flickr.com/photos/linuxfoundation/22747710852/in/album-72157660376885370/

https://www.flickr.com/photos/linuxfoundation/6306036922/in/album-72157627910931679/

https://www.flickr.com/photos/linuxfoundation/6305975680/in/album-72157627910931679/

https://www.flickr.com/photos/linuxfoundation/5182564838/in/album-72157625402551490/

https://www.flickr.com/photos/linuxfoundation/30804670406/in/album-72157676268395315/

https://www.flickr.com/photos/linuxfoundation/30724804272/in/album-72157676268395315/

CC BY 2.0 (creativecommons.org)

\section{Addition to previous study}

Chris Wilson is ickle (based on "Signed-off-by" information in their commits)?

While we did our best, we may not have been able to identify all non-binary identities, just as binary ones. Sorry! 


\section{Annex}

- Linux kernel summit 2010 - group photo

- Linux kernel summit 2011 - group photo

- Linux kernel summit 2015 - group photo

- Linux kernel summit 2016 - group photo

- Linux kernel summit 2016 - gentlemen eating*

— Linux kernel summit 2011 - two gentlemen talk [front cover]

(*a woman is seen in the background) 


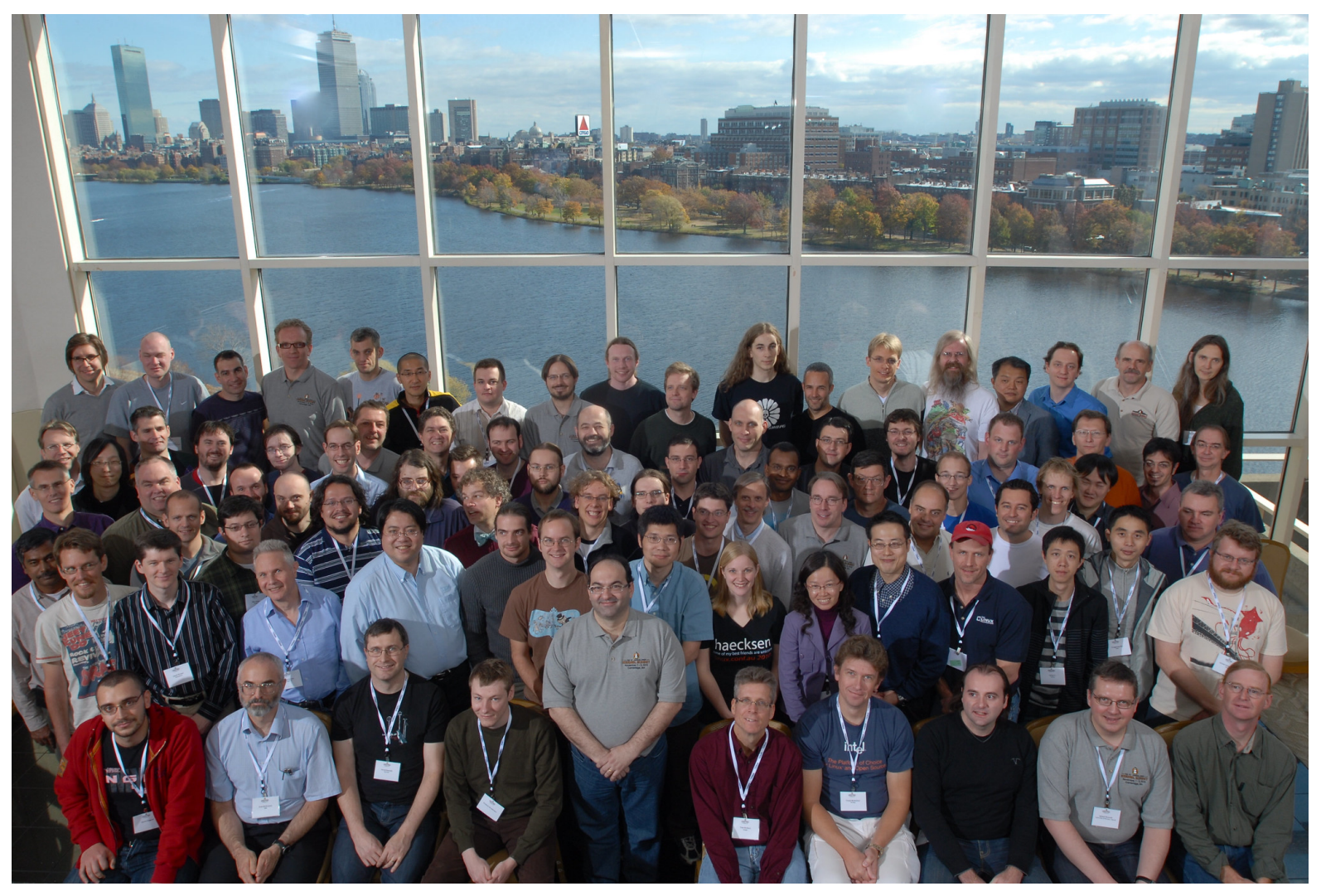

Figure 2: Linux kernel summit 2010 (Linux foundation) 


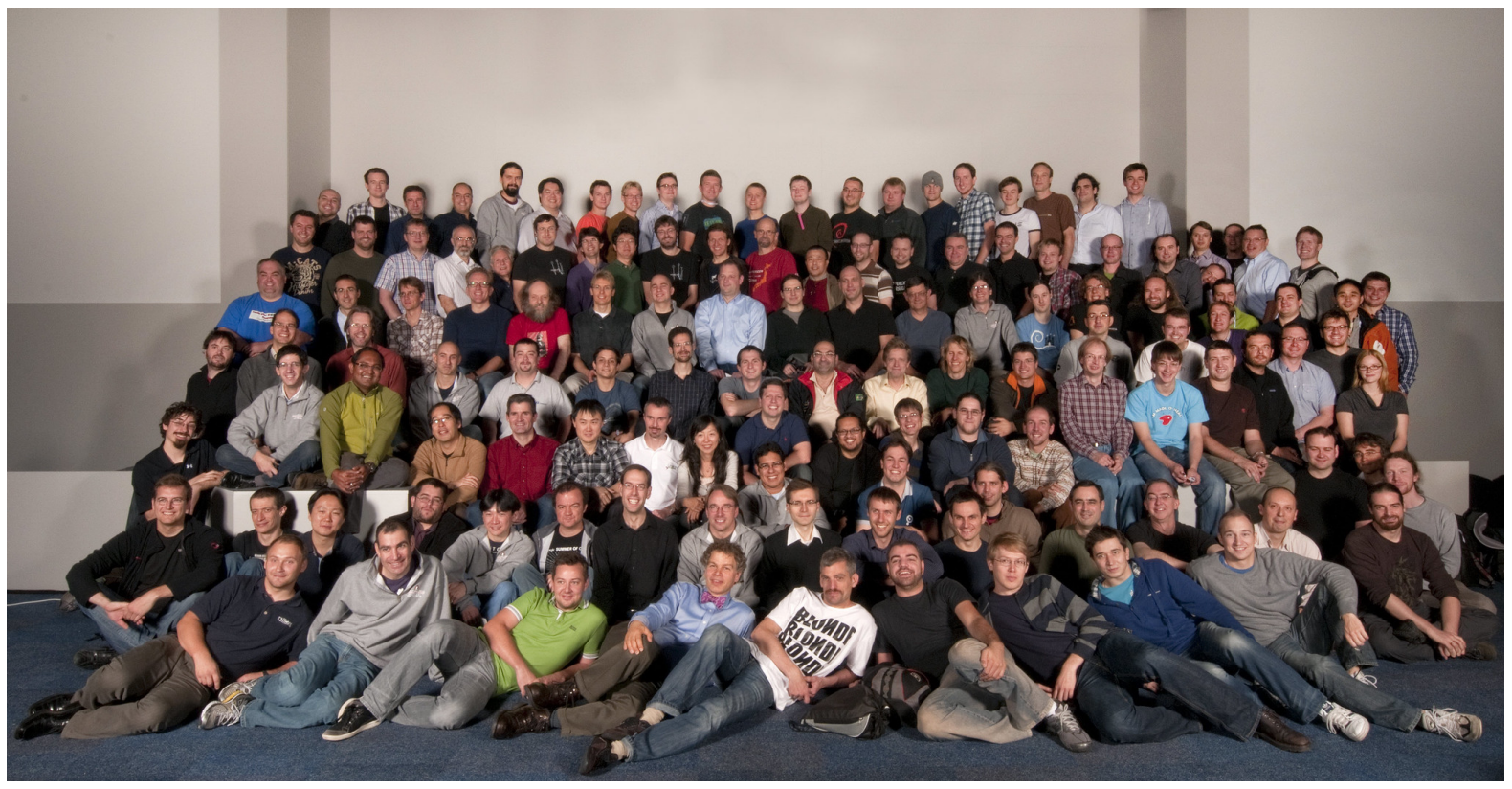

Figure 3: Linux kernel summit 2011 (Linux foundation) 


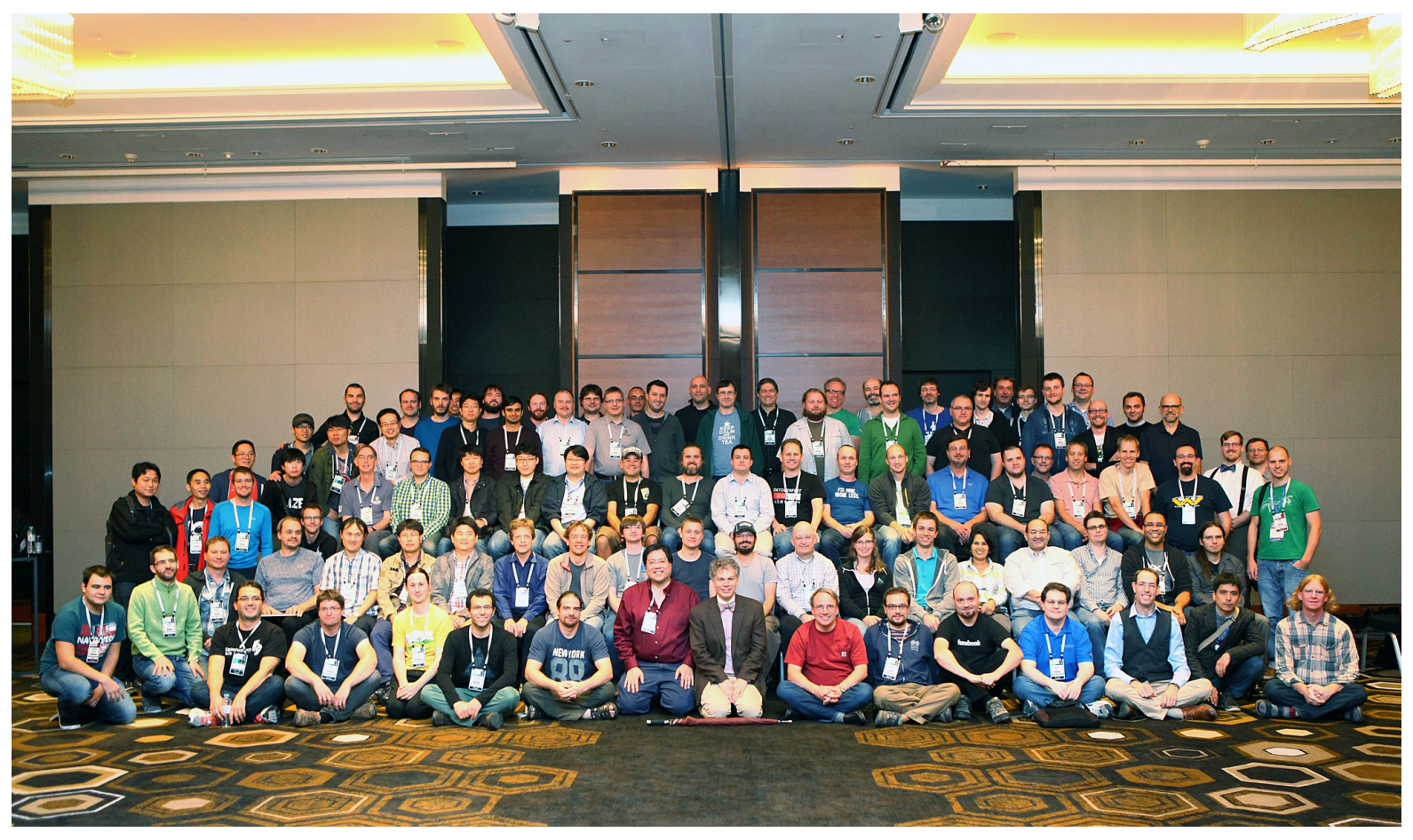

Figure 4: Linux kernel summit 2015, Seoul (Linux foundation) 


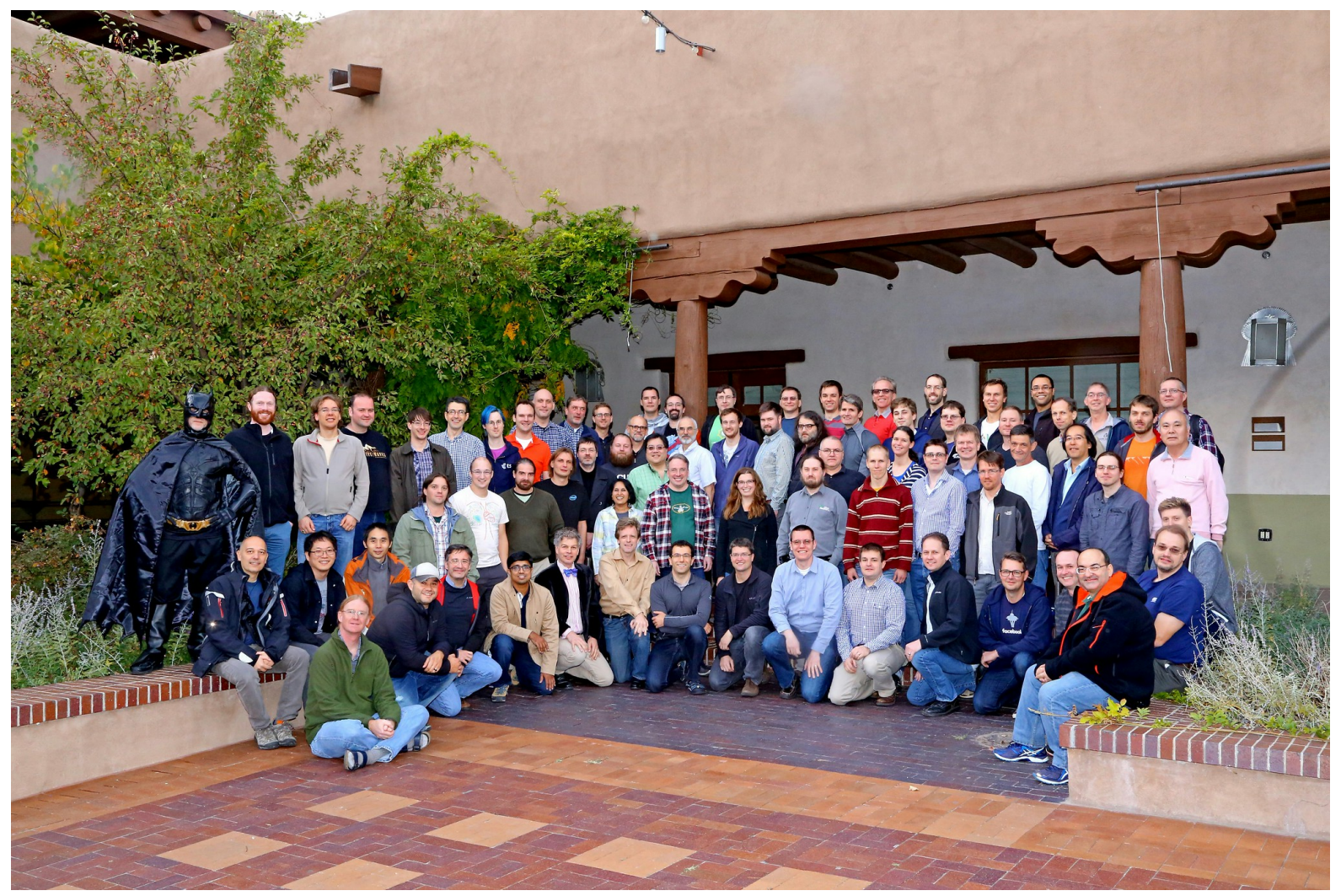

Figure 5: Linux kernel summit 2016, Santa Fe (Linux foundation) 


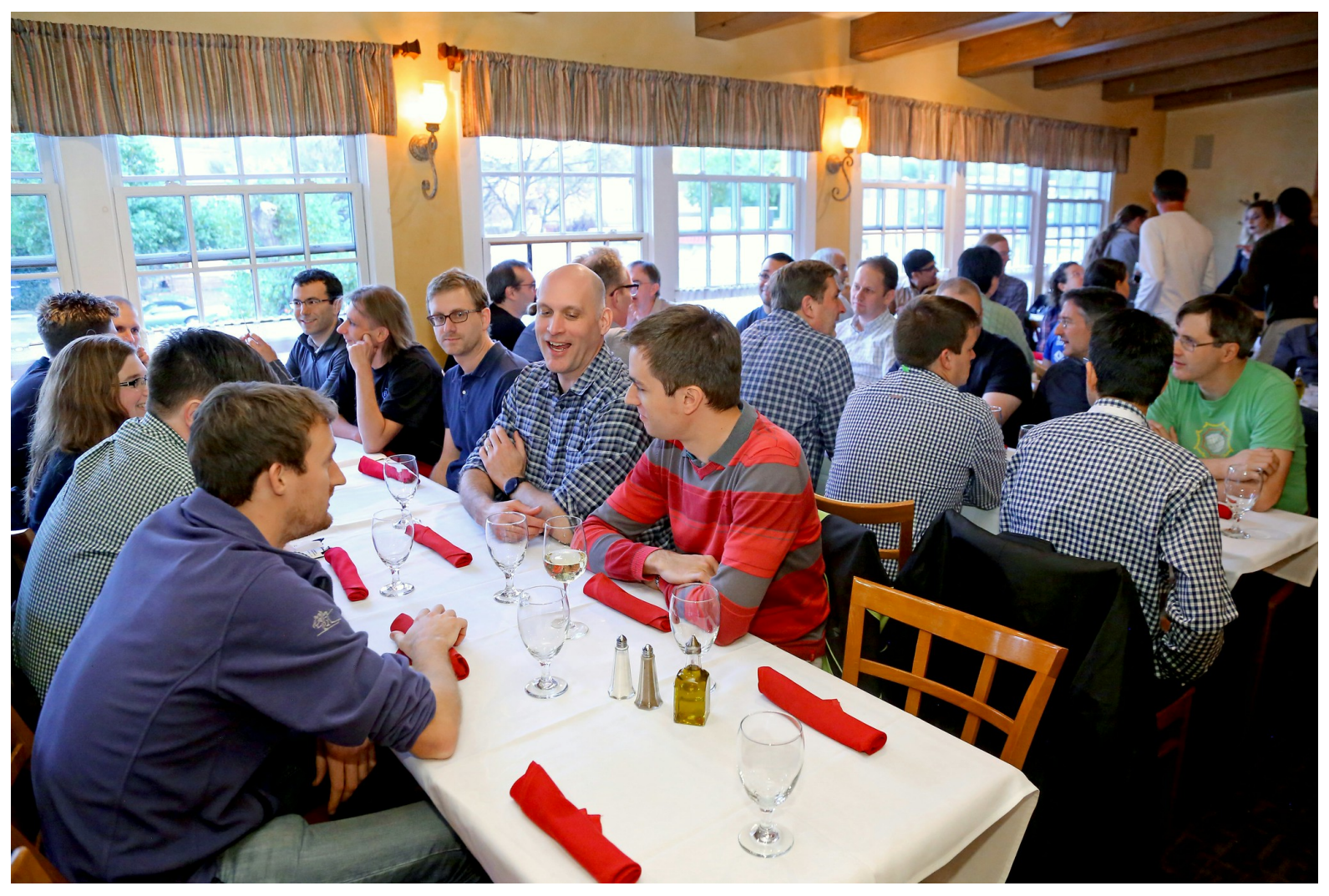

Figure 6: Linux kernel summit 2016, Santa Fe \#2 (Linux foundation) 


\title{
Just us boys : diversity in the GNU project as measured by mailing list activity.
}

\author{
Camille Akmut
}

October 4, 2019

\begin{abstract}
Structure and patterns of a male-dominated culture. Statistics measured over a period of one year (leading up to, including September 2019).
\end{abstract}




\section{Introduction : GNU is not...}

In the following we measure diversity in the GNU project by using mailing list activity, as proxy ${ }^{1}$.

Specifically, we chose info-gnu, where announcements relating to the GNU project are posted.

All the major figures (e.g. Richard Stallman, Werner Koch, Alexandre Oliva...) of this free software project - arguably the most important of all - make regular appearances here and release information regarding their respective areas, or software.

These encompass the well-known ones : GNU itself, GPG, Linux-Libre, GCC, GDB, coreutils, etc.

GNU is not for women - such would be the conclusion of anyone going through our statistics.

And, if the mostly passive attitudes adopted so far have led to such results, surely they can no longer be considered enough.

At the turn of the last century, men formed peculiar circles, still, in and around universities.

The more prestigious these places, the longer it took them to admit women inside their walls - and longer still to admit them as equals. ${ }^{2}$

In the novels of Waugh and Forster, where the old, male-exclusive university system still exists, undisturbed by the advances of times, the absence of women goes largely unnoticed : unproblematic.

"This is just how things are", "They've always been this way" - so went their inner lives.

Lise Meitner (who ended up finding a place within academia) or Emmy Noether had no place in these novels, no more than they had in the times they depict...

As to the satisfaction of their pleasures, these gentlemen, knowledgeable as they were about ancient Greek texts, had long found solutions of their own.

To heterosexual casuistics ${ }^{3}$ of old days correspond now intricate rationalizations to make up for the absence of women and minorities of various kinds :

They blame schools, they blame society, even the weather or the stars if they could - so long as not themselves.

And, so, they continue to live peaceful lives, not unlike the eternal Cambridge and Oxford of aforementioned novels... "Just us boys" is their motto - now as it was then.

\footnotetext{
${ }^{1}$ Other proxies (i.e. approximations) can be used.

${ }^{2}$ This is consistent with phenomena in other areas; the greatest inequalities are usually found at the top, never at the bottom : board of directors, executives and CEO's, software engineer positions, etc.. Or project leaders, as in this case.

${ }^{3}$ Casuistics were (largely obscure, if not irrational) conditional statements that formed complex moral and philosophical systems amongst Medieval scholars such as those of Christianity - though, certainly, not only them.
} 


\section{Raw data}

\begin{tabular}{|c|c|c|}
\hline Project & Author & Gender \\
\hline - September 2019 & & \\
\hline $\begin{array}{l}\text { GNU Project } \\
\text { Texinfo } \\
\text { GDB } \\
\text { GNU Datamash } \\
\text { GNU Linux-libre } \\
\text { Bison } \\
\text { GNU Mes } \\
\text { GNU Wget } 2 \\
\text { GNU gama }\end{array}$ & $\begin{array}{l}\text { Richard Stallman } \\
\text { Gavin Smith } \\
\text { Joel Brobecker } \\
\text { Assaf Gordon } \\
\text { Alexandre Oliva } \\
\text { Akim Demaille } \\
\text { Jan Nieuwenhuizen } \\
\text { Tim Ruhsen } \\
\text { Ales Cepek }\end{array}$ & $\begin{array}{l}\mathrm{m} \\
\mathrm{m} \\
\mathrm{m} \\
\mathrm{m} \\
\mathrm{m} \\
\mathrm{m} \\
\mathrm{m} \\
\mathrm{m} \\
\mathrm{m}\end{array}$ \\
\hline - August & & \\
\hline $\begin{array}{l}\text { GNU findutils } \\
\text { Libgcrypt } \\
\text { Emacs } \\
\text { nano } \\
\text { FreeIPMI } \\
\text { GNU Scientific Library } \\
\text { GCC } \\
\text { Unifont } \\
\text { Gnuastro } \\
\text { GNU C Library }\end{array}$ & $\begin{array}{l}\text { Bernhard Voelker } \\
\text { Werner Koch } \\
\text { Nicolas Petton } \\
\text { Benno Schulenberg } \\
\text { Albert Chu } \\
\text { Patrick Alken } \\
\text { Jakub Jelinek } \\
\text { Paul Hardy } \\
\text { Mohammad Akhlaghi } \\
\text { Carlos O'Donell }\end{array}$ & $\begin{array}{l}\mathrm{m} \\
\mathrm{m} \\
\mathrm{m} \\
\mathrm{m} \\
\mathrm{m} \\
\mathrm{m} \\
\mathrm{m} \\
\mathrm{m} \\
\mathrm{m} \\
\mathrm{m}\end{array}$ \\
\hline- July & & \\
\hline $\begin{array}{l}\text { GNU Stow } \\
\text { Denemo } \\
\text { GNU direvent } \\
\text { rush } \\
\text { GnuPG } \\
\text { GNU Linux-libre } \\
\text { GNU gama } \\
\text { pies } \\
\text { rush }\end{array}$ & $\begin{array}{l}\text { Adam Spiers } \\
\text { Richard Shann } \\
\text { Sergey Poznyakoff } \\
\text { Sergey Poznyakoff } \\
\text { Werner Koch } \\
\text { Alexandre Oliva } \\
\text { Ales Cepek } \\
\text { Sergey Poznyakoff } \\
\text { Sergey Poznyakoff }\end{array}$ & $\begin{array}{l}\mathrm{m} \\
\mathrm{m} \\
\mathrm{m} \\
\mathrm{m} \\
\mathrm{m} \\
\mathrm{m} \\
\mathrm{m} \\
\mathrm{m} \\
\mathrm{m}\end{array}$ \\
\hline - June & & \\
\hline $\begin{array}{l}\text { GNU Guile } \\
\text { GNU Stow } \\
\text { Nettle } \\
\text { Nettle }\end{array}$ & $\begin{array}{l}\text { Ludovic Courtes } \\
\text { Adam Spiers } \\
\text { Niels Moller } \\
\text { Niels Moller }\end{array}$ & $\begin{array}{l}\mathrm{m} \\
\mathrm{m} \\
\mathrm{m} \\
\mathrm{m}\end{array}$ \\
\hline
\end{tabular}


GNU APL

mailutils

GNU Guile

Gawk

nano

Dr. Geo

GNU Artanis

IceCat

Unifont

- May

GnuPG

GNU OrgaDoc

GNU libidn2

Bison

GNU Guix

Bison

GNU gettext

GNU Mcron

Unifont

GNU Shepherd

GDB

GNU gettext

GNU CSSC

LibreJS

GNU Linux-libre

GCC

GNU Guix

Emms

\section{- April}

dico

nano

rush

GNU Shepherd

Gnuastro

nano

Emacs

Gawk

wget

wget

- March

GnuPG

nano

GnuPG

LibreJS
Dr. Jurgen Sauermann m

Sergey Poznyakoff m

Ludovic Courtes m

Arnold Robbins m

Benno Schulenberg m

Hilaire Fernandes m

Nala Ginrut [Lei Mu] (?)

Ruben Rodriguez m

Paul Hardy m

Werner Koch m

Adam Bilbrough m

Tim Ruhsen m

Akim Demaille m

Ludovic Courtes m

Akim Demaille m

Bruno Haible m

Adam Bilbrough m

Paul Hardy m

Ludovic Courtes m

Joel Brobecker m

Bruno Haible m

James Youngman m

Ruben Rodriguez m

Alexandre Oliva m

Jakub Jelinek m

Ludovic Courtes m

Yoni Rabkin m

Sergey Poznyakoff m

Benno Schulenberg m

Sergey Poznyakoff m

Ludovic Courtes m

Mohammad Akhlaghi m

Benno Schulenberg m

Nicolas Petton m

Arnold Robbins m

Darshit Shah m

Darshit Shah m

Werner Koch m

Benno Schulenberg m

Werner Koch m

Ruben Rodriguez m 


coreutils
Unifont
GNU Linux-libre
GNU Octave
- February
GNU Dr. Geo
GNU ddrescue
dico
tar
mailutils
cflow
GCC
GNU MCSim
FreeDink
Texinfo
GnuPG
GNU libidn 2
GNU gama
GNU Binutils
- January

Padraig Brady m

Paul Hardy m

Alexandre Oliva m

John W. Eaton m

Hilaire Fernandes m

Antonio Diaz Diaz m

Sergey Poznyakoff m

Sergey Poznyakoff m

Sergey Poznyakoff m

Sergey Poznyakoff m

Jakub Jelinek m

fredomatic [Frederic Bois?] m

Sylvain Beucler m

Gavin Smith m

Werner Koch m

Tim Ruhsen m

Ales Cepek m

Nick Clifton m

$\begin{array}{lll}\text { GNU MPFR } & \text { Vincent Lefevre } & \mathrm{m} \\ \text { GNU C Library } & \text { Siddhesh Poyarekar } & \mathrm{m} \\ \text { Bison } & \text { Akim Demaille } & \mathrm{m} \\ \text { Bison } & \text { Akim Demaille } & \mathrm{m} \\ \text { FreeIPMI } & \text { Albert Chu } & \mathrm{m} \\ \text { FreeDink } & \text { beuc [Sylvain Beucler ] } & \mathrm{m} \\ \text { GNU Ocrad } & \text { Antonio Diaz Diaz } & \mathrm{m} \\ \text { GNU MDK } & \text { Jose A. Ortega Ruiz } & \mathrm{m} \\ \text { Readline } & \text { Chet Ramey } & \mathrm{m} \\ \text { Bash } & \text { Chet Ramey } & \mathrm{m} \\ \text { GNUstep } & \text { Ivan Vucica } & \mathrm{m} \\ \text { GNUstep } & \text { Ivan Vucica } & \mathrm{m} \\ \text { GNUstep } & \text { Ivan Vucica } & \mathrm{m} \\ \text { autoconf } & \text { Peter Simons } & \mathrm{m} \\ \text { GNU libidn } & \text { Tim Ruhsen } & \mathrm{m} \\ \text { GNU moe } & \text { Antonio Diaz Diaz } & \mathrm{m} \\ \text { GNU ed } & \text { Antonio Diaz Diaz } & \mathrm{m} \\ \text { recutils } & \text { Jose E. Marchesi } & \mathrm{m} \\ \text { tar } & \text { Sergey Poznyakoff } & \mathrm{m} \\ \text { diffutils } & \text { Jim Meyering } & \mathrm{m}\end{array}$

[Note : Lei is given to both men and women] 


\section{Statistics}

\begin{tabular}{|c|c|c|}
\hline Month (2019) & Male participants & Female participants \\
Sep. & $100 \%$ & $0 \%$ \\
Aug. & $100 \%$ & $0 \%$ \\
July & $100 \%$ & $0 \%$ \\
June & $100 \%(?)$ & $0 \%(?)$ \\
May & $100 \%$ & $0 \%$ \\
Apr. & $100 \%$ & $0 \%$ \\
Mar. & $100 \%$ & $0 \%$ \\
Feb. & $100 \%$ & $0 \%$ \\
Jan. & $100 \%$ & $0 \%$ \\
\hline
\end{tabular}

Table 1: Diversity in the GNU project and gnu-info mailing list participation.

\section{Bibliography}

info-gnu. https://lists.gnu.org/mailman/listinfo

\section{Announcing future research}

-. (upcoming). "Yann Le Cun : portrait of a small-time engineer."

Note : from the very bottom of French engineer schools crochetted his way to the top of international scientific society!

-. (upcoming). "Danah Boyd never bothered anyone. Science in the interest of the rich and mighty."

Note : celebrated by the EFF and employed by Microsoft, but "famous artists are quickly forgotten" according to Peter Doig.

-. (upcoming). "Saint Sheryl."

Note : on Sheryl Sandberg, and more on corporate diversity. Dumb like her barbies - said someone I know... 



\title{
Becoming professional tech journalists - beginnings of a new social category. From Reality Hackers to a reality check: Origins of Wired (1984-2003)
}

\author{
Camille Akmut
}

February 18, 2022

\begin{abstract}
brief
Technology journalists transitioned from fairly obscure figures to in demand stars of the news and publishing world. This work retraces the origins and ascension of this now dominant social group, producers of ruling discourses; based on largely forgotten publications of the 1980s as well as better known, experimental magazine Mondo 2000. Up to St. Jude's death.
\end{abstract}




\section{I high frontiers a drug, science, art newspaper of the $1980 \mathrm{~s}$}

In the beginning there was a modest newspaper called High Frontiers that covered "Psychedelics, Science, Human Potential, Irreverence \& Modern Art". "A S.F. Bay Area Publication" of about 30 pages, sold for - then 1 dollar. ${ }^{1}$

\section{1 drugs + science : mckenna, leary and the fundamental fysiks group}

Stylistically, High Frontiers set the tone for the entire series: Presented as "the Space Age Newspaper" for the topics of drugs, science and art, it would be critical of others but only so much as critical of itself, and self-derisive.

Among later features of note of Mondo 2000 were for example the publication of, often very explicit, negative, reader feedback (along the lines of about "you complete fuckers, idiots"...), as well as various linguistic shenanigans that resembled or were derived from elite academic culture or hacker tradition : e.g. circles like the Fundamental Fysiks Group, associated with Berkeley, or early hackers as found at MIT.

To give a few examples only : the usual "table of contents" is replaced by a "table of contexts" in one of the issues, and by "offerings" in $\mathrm{R} 6$, readers writing letters to Reality Hackers were in turn called "reality hecklers", etc. The staff addressed readers with the uncertain, affectionate "Dear Mondoids" (e.g. \#4)

In High Frontiers's "premier issue", members of those societies were represented such as in particular in the person of Jack Sarfatti.

Thematically, High Frontiers set the standard for at least two corner stones of later publications (like Mondo), drugs combined with science : Contributors of that first issue included Terence McKenna and Timothy Leary, musing about space and time, and sperm, and of course their topic of predilection, drugs were never far away.

However, in the case of Leary, drugs were a means to an end, namely research on intelligence increase which he felt was a pressing matter following his release from prison (as explained at the beginning of the 1987 issue). In Leary's mind, at least, drugs were a way "[of] turning yourself on, booting up your brain, activating new circuits in your mind."

For McKenna (who wrote a column-style "psychopharmacognosticon"), drugs seemed to be a way a way to break with deeply ingrained societal normal states, and established norms, as well as a means to understand human evolution as

\footnotetext{
${ }^{1}$ High Frontiers, "premier issue" cover.
} 
part of re-written history of mankind where drugs were according to him a key factor in the evolution of humans ${ }^{2}$.

Other writers close to them would later join in : Ram Dass in the next issue, for instance, Andrew Weil in this one.

Weil, another graduate of Harvard, "a medical doctor and nationally recognized pharmacologist", explained his introduction to the subject so :

I was to start my Freshman year ... and I was in a course called "Sociology in American Society." We had to write a term paper, and I wrote on the subject of "Drugs in Society." That gave me an excuse to read everything on the subject and I came upon Aldous Huxley's book The Doors of Perception. He was uo at M.I.T. that year, this was the fall of 1960, lecturing on visionary experience. I wrote him a letter and asked him where I could get some mescaline

3

As for the second corner stone of this publication - namely, science - it would be laid with the inaugural Nick Herbert "Fringe science" column in issue 2 of High Frontiers; a tradition that would endure throughout modifications all the way to Mondo's (symbolic) end.

Together with Sarfatti, and later Saul-Paul Sirag (Mondo), they would be constitutive of High Frontier's and then Mondo's science department. Their connection? The Fundamental Fysiks Group, an association of physicists that melted science and philosophy, around Berkeley.

Perhaps the best known historical antecedent was the, so-called, "School of Vienna"4.

Characteristic of such groups were the grouping of scientists together with philosophers and historians, and other like-minded people; they did not share the aversion for the humanities that unfortunately characterizes some of their successors. $^{5}$

\section{2 art and lifestyle: wilson, burroughs, and "durk and sandy"}

Finally, the art corner stone of this older publication was represented by such writers as Robert Anton Willson (\#2), Burroughs (\#3), both of which would re-appear in issues of Mondo.

Meanhile the "Human Potential" thematic was furthered, in addition to Leary's intelligence enhancement, by the appearance of long time collaborators Durk Pearson and Sandy Shaw, who wrote -and sold- a variety of "life extensions" tips and products, as well as "designer" solutions (e.g. food, lifestyle), often referred to as simply "Durk and Sandy".

\footnotetext{
${ }^{2}$ See his incalculably numerous lectures and talks, e.g. Alien Dreamtime, and his book Food...

3 issue 1, p. 8.

${ }^{4}$ See Jean Cavailles' review, of which we have produced a translation.

5 (we leave the question of whether this trait is to the detriment of their 'hard science' aside)
} 
Artists like Bę̧tie Boys and Todd Rundgren were interviewed, featured (\#4).

\section{3 fourth issue : introduction of "reality hackers"}

Thematically, still, the first two to three issues of High Frontiers were more reminiscent of 1960's counter-culture literature, despite their 1980's publication date, than the later explicit cyberpunk affiliations and leaning of Mondo 2000.

A significant changed occurred with issue 4 of High Frontiers, whose table of contents read :

\section{STEAL THIS DECADE: THE SIXTIES! \\ ... \\ INTO THE NINETIES: THE REALITY HACKERS TAKE OVER! \\ Illustration : section titles in High Frontiers' fourth issue}

The fourth issue of High Frontiers made it clear : keep the 1960's, if you want, here come the hackers - by which motto they meant to clarify their increasing interest in, and orientation towards electronics, computers and their counter-cultural uses.

On the occasion of issue 4 , a hacker convention was visited and became the location of an interview;

A special section was dedicated to new technologies;

Leary was interviewed as part of a piece echoing the format of the film $M y$ Dinner with Andre, including thoughts on nanotechnologies.

The allusion to My Dinner with Andre merits a detour, as this reference is quite representative for the magazine's later interests : the film's arguably most memorable segment is a mind experiment along the lines of contemporary adaptations of Cartesian doubt "What if this is all fake and we live in a simulation" (culminating in the popularity of 1990's mega-success The Matrix, and found since everywhere from entrepreneur tweets to hit animation Rick and Morty), applied to the specific issue of New Yorkers' apparent inability to leave their city despite much complaints and attempts to do so.

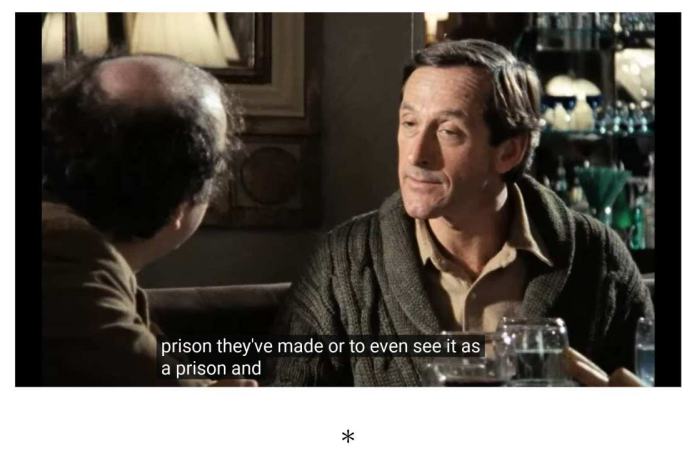

R.U. Sirius, Somerset Mau Mau and Queen Mu were publishers. 


\section{II reality hackers transition to the 1990 s}

A major contributor was still mostly missing from High Frontiers, to push its slightly outdated style towards modernity : the legendary hacker Jude Milhon, a.k.a. St. Jude, made a brief appearance in issue 4 under the "Proofreading" staff section but only became an editor in the follow-up magazine.

The 1987 High Frontiers issue announced a newsletter that would bring readers "new information from the frontiers of technology and consciousness" 6 , called Reality Hackers. Whereas the former was an annual publication, the latter would appear more frequently. It also reflected a shift in interests.

\section{1 thematic shift towards "information technologies"}

Issue 5 of Reality Hackers was a complete break with the former hippie-andspace newspaper, it now featured the following modern subtitle:

Information technologies \& Entertainment [for Those on the Brink]

It had now shed its former Beatnik culture meets space age enthusiasm for science origins, and understood its new mission to be the coverage of computer technologies.

However, Reality Hackers was not to be a mere straight-down-to-facts-andspecs publication (a la Byte),

As its revised subtitle made evident, the vision was of a cool tech magazine that should be different from what had existed. It proposed to do that by mixing new tech with sex and cultural tour de force writings, and the drug gurus' teachings (which could be kept).

\section{2 fortunate intuition : computers are sexy}

Another new orientation was the melange of suggestive imagery put in contrast with hard computer facts and heady essays.

The ever of issue 5 of Reality Hackers, in addition to a new thematic, also announced new aesthetics that would characterize Mondo's distinctive style, recognizable among thousand, namely the here born, fortunate intuition that mixing computers with sex was probably not such a bad idea.*

\footnotetext{
${ }^{6} \mathrm{H} 4$, Front page.
}

*Beyond the general idea that sex sells, the publishers of Mondo were not alone in this, but could look back on a long tradition of sexualized computer imagery (see in part. ad campaigns for systems such as Digital Equipment Corporation's PDP : miniskirts, boots, possibly inspired by Stark Trek costumes). For contemporary magazines : Amiga Magazine, Your Amiga (04/1990) .... from the same period. 


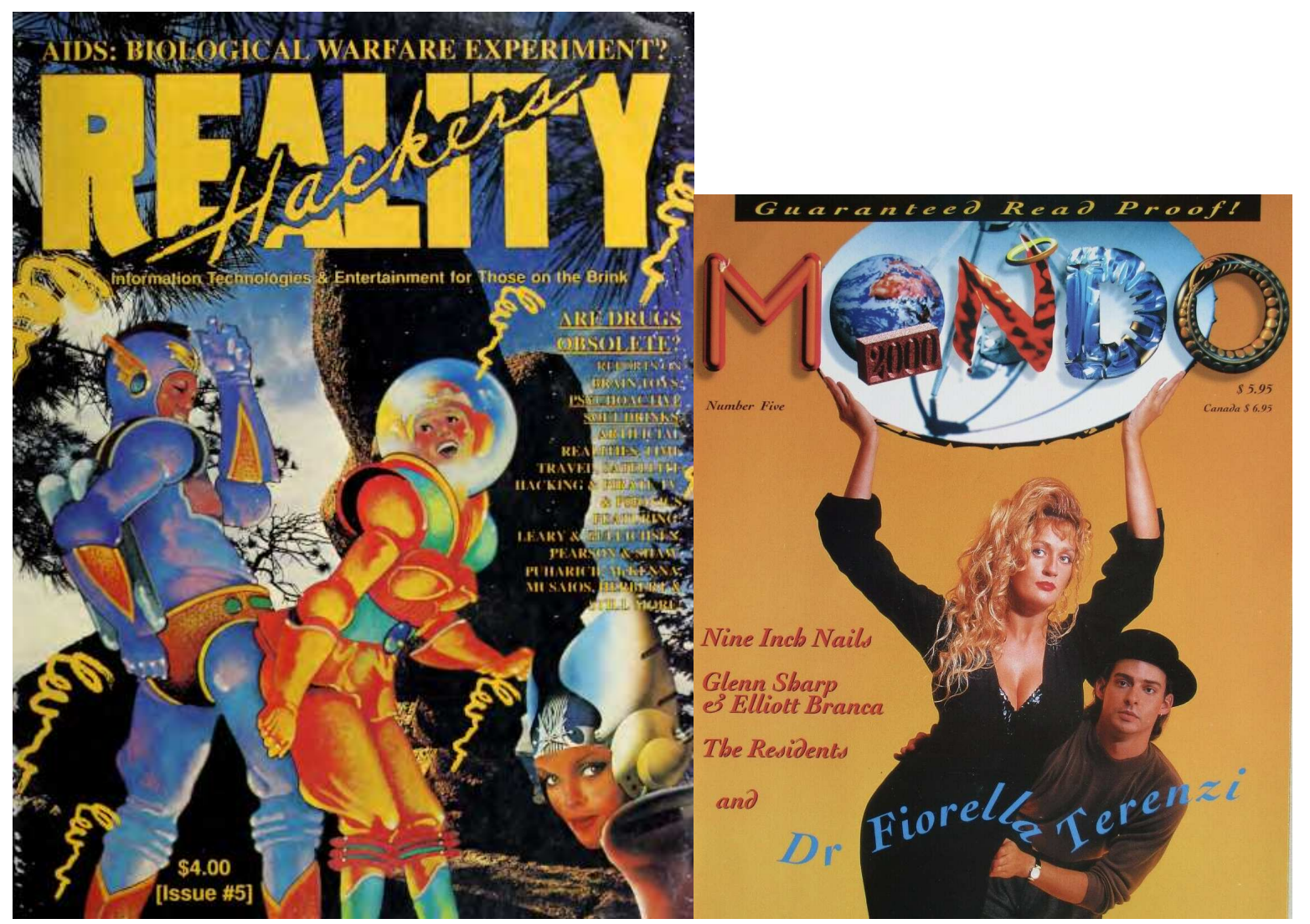

Illustration: issue 5 Reality Hackers cover (l), Mondo 5 (r) comparison

Mondo 2000's issues - systematically headed by women on their covers popped out from any kiosks and vendor racks, among otherwise mostly gray, uninspired IT tomes.

First experiments leading to this distinctive new genre of literature happened in Reality Hackers, issue 5 showed two space enthusiasts having a good time and rubbing and frotting (to unheard rhythms).

In issue 5 of Mondo, shown here for comparison purposes, the male and female cartoon characters were replaced by their human counterparts in similarenough positions (the subject of the cover being, real-life, astrophycist Fiorella Terenzi).

But, just who was Reality Hackers for? The fifth issue provided an answer, by clarifying who the so-called "reality hackers" were, in the first place.

1. USING HIGH TECHNOLOGY FOR

A LIFE BEYOND LIMITS.

2. EXPANDING THE EFFECTIVE- 
NESS \& ENJOYMENT OF THE

HUMAN BRAIN, MIND,

NERVOUS SYSTEM \& SENSES.

3. BLURRING THE DISTINCTION

BETWEEN SCIENCE FICTION

\& REALITY.

4. MAKING BIG BUREAUCRACY

IMPOSSIBLE.

5. ENTERTAINING ANY NOTION USING WHAT WORKS.

6. INFUSING NEW ENERGY INTO

POST-MODERN CULTURE.

7. USING HARDCORE ANTHRO-

POLOGY TO UNDERSTAND

HUMAN EVOLUTION.

8. USING MEDIA TO SEND OUT

MUTATIONAL MEMES

(THOUGHT VIRUSES).

9. BLURRING THE DISTINCTION

BETWEEN HIGH TECHNOLOGY

\& MAGIC.

10. REPLACING NERD MYTHOLOGY

WITH SEXY, HEALTHY, AESTHETIC \& ARTFUL TECHNO-

MAGICIANS OF BOTH GENDERS.

We reproduce this document in full due to, our perception of its importance : another such explicit exposition of objectives is not known to us. ${ }^{7}$

The answer they provided made once again clear that the publishers' and editors' interest lied not only with computers but their intelligent, useful, or weird or sensual applications (anything beyond dominant, commercial uses, essentially) : they wrote about "reality hackers" seeking joy, for themselves and others, aliewating pain, nuisances, threats (e.g. bureaucracy), knowledge (through their proposed revisions of anthropology and new interpretations of contemporary culture), against dogma ("using what works), etc..

\footnotetext{
${ }^{7} \mathrm{R} 5$, Front page.
} 
The reference to, specifically, "hardcore anthropology" to serve a new vision of human development seems to be a reference to fellow collaborator McKenna.

The next nearest document is a description of contents to expect, as it appeared at the end of issue 6 :

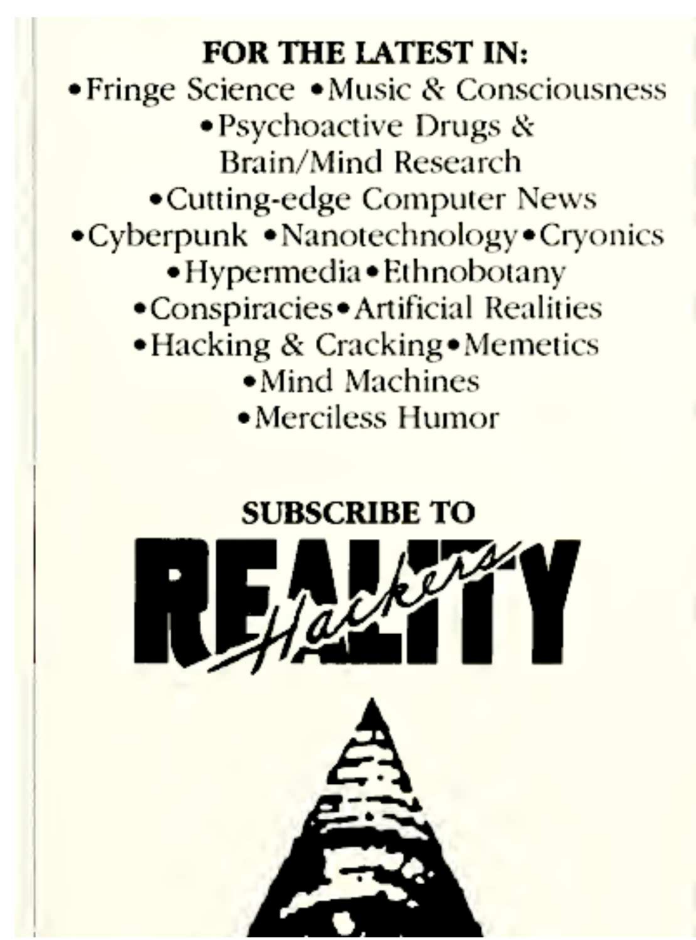

Illustration: issue 6 Reality Hackers end

\section{3 wider changes in society}

High Frontiers' succession by Reality Hackers, and ultimately Mondo 2000 can also be related to wider societal changes. The transition lied somewhere between :

i. computers, previously machines associated with academic labs and military installations as well as their belonging and property, had become within reach of the middle classes at the end of the previous decade (the close releases of popular Apple, Commodore, Tandy/Radio Shack offerings), both due to households friendly cheapening and living-room or even bedroom compatible miniaturization.*

ii. initiatives like the GNU operating systems, the liberation of the BSD code from AT\&T legacy parts, restrictive licensing and fees (the "Net" releases, in part.) in the 1980's.

iii. democratization of the internet outside university elites and expert, hacker circles - by roughly the mid-1990's, $5 \%$ of the World had now access to it - and the co-introduction of the web 
To sum up : the 'personal' computer extracted this new object from previous strongholds and put it in everyone's homes; free software was the translation of hacker culture ideals, and made it possible in the domain of computers; the internet and web created a massively-connected world;

The mythical T1-3 lines (e.g., mentioned in the more cyberpunk leaning episodes of X-Files) were replaced by relatively cheap, unspectacular $28 \mathrm{k} / 56 \mathrm{k} / \mathrm{ISDN}$ modems that made browsing and playing online games bearable, popular (before current high-speed). And while not everyone could transform their operating system, soon everyone could install a "Linux distribution" as found on the CDRoms of thick IT magazines;

issues previously only explored theoretically in science fiction had now crossed over to reality. Mondo was one of the publications that took them seriously, when few others would - then.

\section{4 increase in polish and professionalization}

In Reality Hackers issue 6 - almost twice as thick as the previous one - the table of contents sees the introduction of sub-topics (letters, columns, features) that would be kept in Mondo's organization, and can be regarded as a movement towards ever more professionalization.

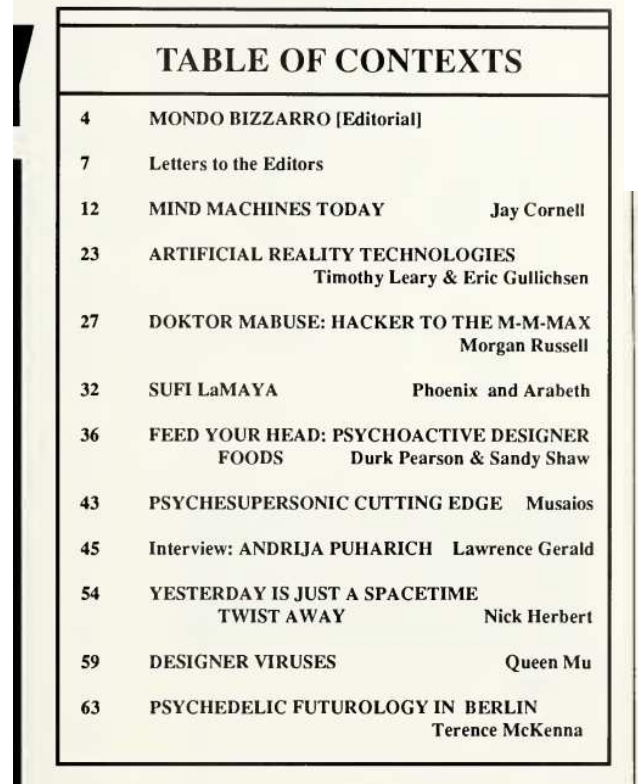

\section{editorial}

4 SOAPBOX

by Jas. Morgan and accomplices

\section{HACKER BIOS}

\section{REALITY HECKLERS}

Letters to the Editor

\section{columns}

\section{FRINGE SCIENCE}

by Nick Herhert

Illustration: issue 5 Reality Hackers, table of content / 6, the same

In terms of design, Reality Hackers had improved when compared to previous offering High Frontiers, and was more polished, and cool, while never reaching the heights of Mondo 2000 under Bart Nagel (although charming, on its own). 


\section{III mondo 2000}

"Mondo 2000 is published quarterly" its inside pages said ${ }^{8}$

During its existence, it managed to create a unique publication based on a formula steadily improved from iteration to iteration $-\mathrm{H}$, $\mathrm{R}$, now $\mathrm{M}-$ melding computers and elements of modern counter-cultures (drugs, sex, hip-hop)...

"More polish, less (of the) explosive" could be the formula behind Mondo 2000, when compared with its direct predecessor Reality Hackers.

\section{1 content focusing : more computer-centric material}

In one of the issues ${ }^{9}$ Mondo claimed to be 'the most subversive/dangerous new magazine'.

But, if this was true, the more risky articles were now to be a thing of the past. Instead more and more articles were computer-centric :

In fact, what turned out to be the first issue of Mondo 2000 was originally conceived as, supposed to be a cyberpunk special issue of Reality Hackers, and was announced so in its pages.

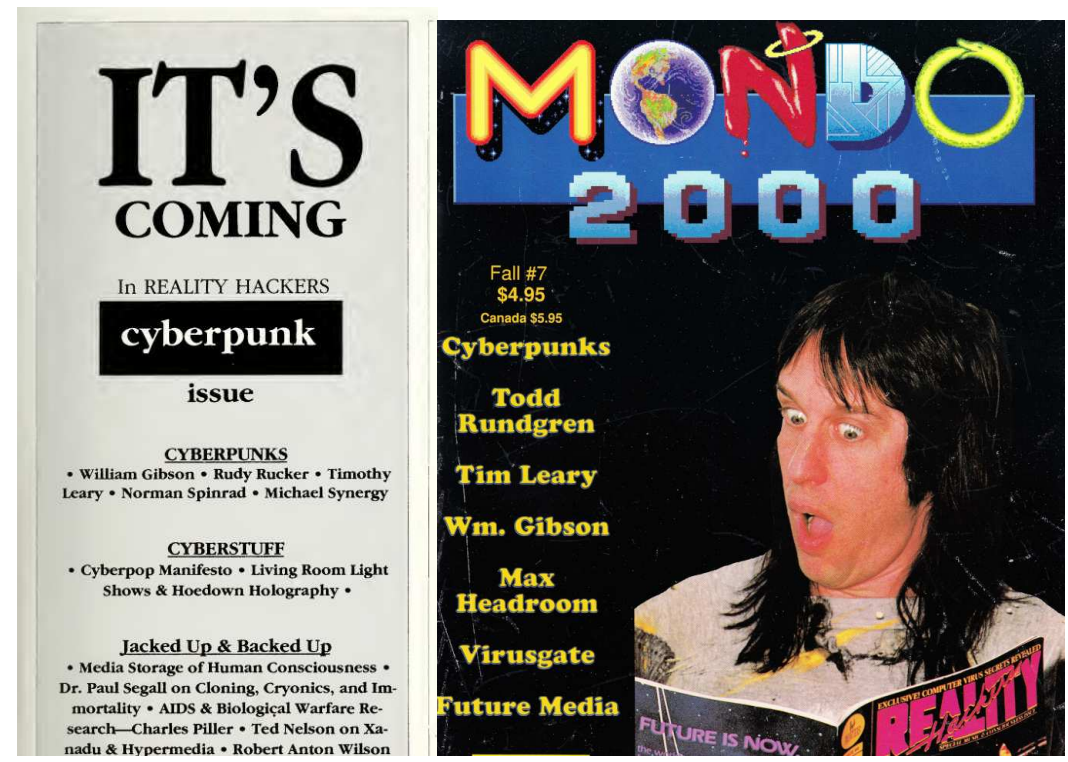

Illustration: issue 6 Reality Hackers end / issue 7,., - 1 of Mondo 2000

The cover even bears the mention of "issue \#7" and makes this lineage clear though the imagery of a reader holding a Reality Hackers issue (the previous issue, 6, with Sun Ra) despite the, new, "Mondo 2000" title.

\footnotetext{
${ }^{8} \mathrm{M} 4$ staff.

$9(5,9 ?)$
} 
Gone the articles on AIDS as a "designer virus" or "biological warfare experiment", relegated to yesteryear. ${ }^{10}$.

In later issues, when it came to technically sound articles, Norman French regularly provided some of the best coverage of this magazine : the most memorable of which probably the series of PGP articles ${ }^{11}$.

Mondo's claim to subversiveness was nonetheless serious

While we won't re-print the pictures of e.g. peeing babies, nude photos of Michael Jackson were shown (in a photo collage/montage?) with what appears to be female genitalia ${ }^{12}$. Meanwhile Oridge's icogonography blending gory, sexy, and the bizarre and obscure still provided plenty of material to be shocked or angry about, and would unlikely be published today (in Wired, or most other places elsewhere). Androgyny, gender-bending was also regularly included.

As for the sex appeal dimension of this publication, no changes were further made to this winning formula.
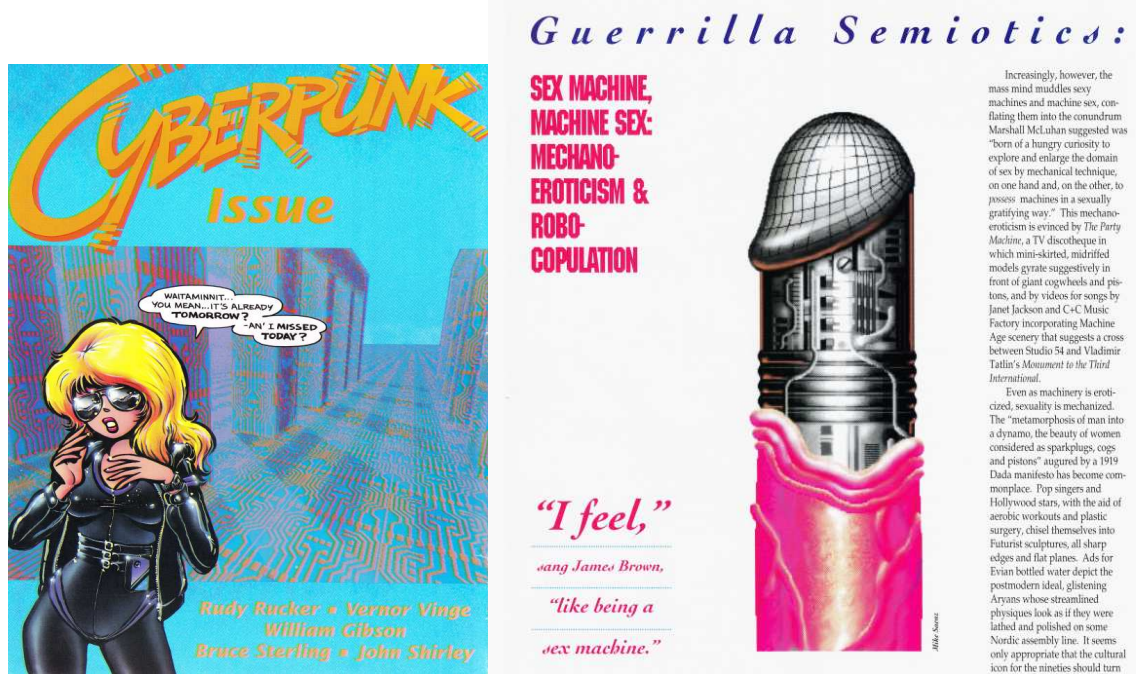

Illustration: issue 1 and 5 Mondo 2000

Cyber-Babe: "YOU MEAN... IT's ALREADY TOMORROW?"

\section{2 experienced staff and long-time collaborators}

Contrary to previous iterations, which sometimes could be very rough (HF's "premier issue") or relied on fairly new personnel, Mondo 2000 enjoyed now a mostly experienced staff assembled over half-a-decade of prior errors and trials.

\footnotetext{
${ }^{10}$ For example, R 5. The reader would search in vain trying to find anything even remotely close or comparable in their latest issue of, supposedly subversive, Wired magazine...

${ }^{11} \mathrm{M} 5,9$.

122102
} 
The core members of staff of Mondo emerged as :

- R. U. Siruius (editor-in-chief),

- Queen $\mathrm{Mu}$ (in a neology rank above everyone else's),

- St. Jude (senior editor),

- Bart Nagel (art director),

- Jas. Morgan (as music/arts editor),

Many others contributed over the years, some disappearing along the way, others rising in rank, e.g. publishers and editors Morgan Russell, Michael Synergy, Hultkrans, art director Foley...

They received continued support and cooperation from long term collaborators McKenna, Herbert, Leary, Durk and Sandy, Robert Anton Wilson... - to which was now added heavyweight John Barlow (a contributing editor from issue 4 on).

Joi Ito was listed as a Tokyo correspondent (due to Leary?). The latest trends from Japan regularly appeared in the magazine (by other people).

\section{3 golden age}

During its existence, Mondo managed to create a unique publication based on a formula steadily improved from iteration to iteration $-\mathrm{H}, \mathrm{R}$, now $\mathrm{M}-$ where cyber age pin-ups (covers), avant garde cultural criticism (e.g. Dery ), the best of current science fiction (Gibson, Vinge, Stephenson...) encountered solid technical exposes (on e.g. then-just-released encryption solutions), always elevated by philosophical texts provided by members of the Fundamental Fysiks Group and political discussions of latest legal threats and soon to be passed laws (prison, patents, etc, ${ }^{13}$ ).

Issue 1 brought together the original hackers Lee Felsenstein and Richard Stallman : respectively a second generation (hardware) hacker from California, and the 'last true hacker' whose profile concludes the reference book Hackers.

Felsenstein had been involved in the Homebrew Computer Club (where Apple's founders found much inspiration, before hastely closing their systems despite having greatly benefited previously from the exchange of knowledge that characterized this group of tinkerers), and the Community Memory Project, a democratic initiative aiming to give everyone access to a -digital-forum.*

\footnotetext{
${ }^{13}$ e.g. HR4079 in \#3, Stallman's "UN Treaty" in $4 \ldots$
}

*Computers were put in everyday places and people could add items and find items written by others based on keywords. Cf. Colstad/Lipkin 1975, ACM Computer and Society 6(4) 


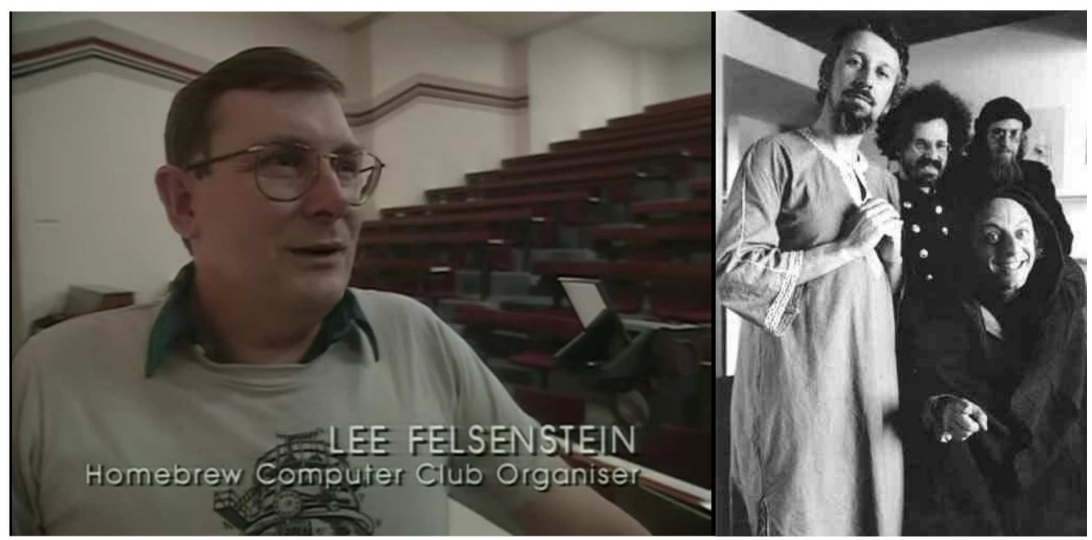

Il. : Felsenstein in Triumph of the Nerds (1996); Fundamental Fysiks Group

Stallman, then unburdened by the pro-corporate think tank Open Source Initiative, was able to express his full views on software and property, which he has since then never done with such ardor, partly due to the influence of the OSI as a "more flexible" representation of free software... :

Interviewed by R.U. Sirius, he concluded in quasi-Marxist terms :

\section{"PEOPLE WHO SELL SOFTWARE ARE CRIMINALS"}

M2: Your value system would not necessarily prevent you from taking from people who are trying to be proprietary, from grabbing it, using it, and making your own changes.

RS: Right. Software hoarding is a crime. If I can thwart that crime successfully, protect its victims, then I will do it.

All the people who sell software are guilty of this crime.

M2: This idea that information should be free, is this something that is specific to computers? What about works of art or bootlegging records...

RS : I would say that whenever something can be copied by the general public, the general public has a right to do so. The more society becomes information instead of material objects, this question of whether a person can copy things will make the difference between a world of universal prosperity or a world of constant rat race. You can create so much artificial scarcity by owning information. Once the great bulk of the things we value is information, the only thing to do is eliminating ownership.

14

\footnotetext{
${ }^{14}$ Compare with current day Richard Stallman's defense of some aspects of capitalism, such as having nice specialty food products, etc. He opposes what he calls "out-and-out socialism" Old age does not bring wisdom, always, and perhaps young Richard can teach old RMS something. [news item 14 feb. 22]
} 
Issue 3 covered the, nascent, EFF (interview with Barlow, among others).

Nick Herbert regularly contributed thought-provoking, interesting essays (e.g. "when metaphysics will be outlawed, only outlaws will do metaphysics"). In that same issue he wrote, for instance:

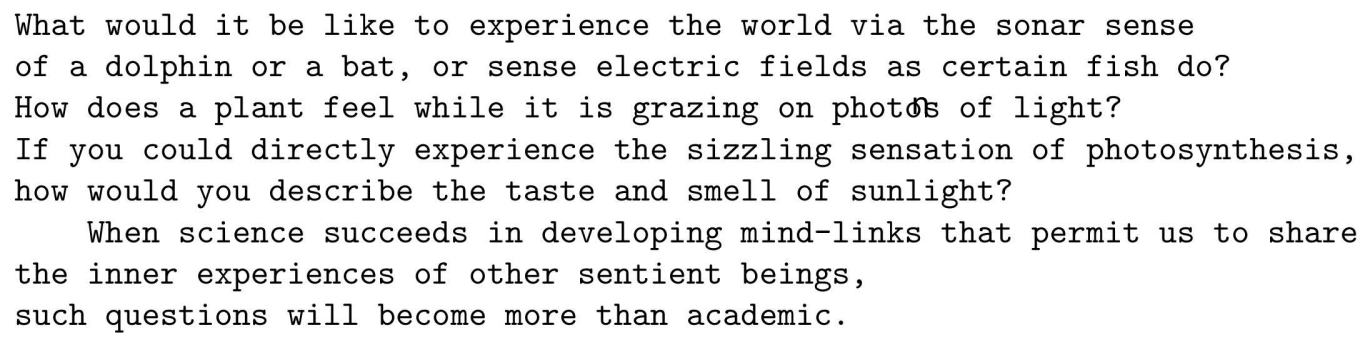

Issue 3 was also the occasion of an ethnographic-style excursion to SIGGRAPH (one of the ACM special interest groups); where cool computer animations can, sometimes, be seen.

Issue 4 featured a conversation with Hip-hop group Digital Underground, including critics of the label system (which Cornel West would no doubt call "back on the plantation").

Issue 5 had the excellent articles on Phil Zimmerman's fight against upcoming legislation as context for the creation of PGP (followed up in issue 9).

6 contains an article on Peter Chung. Aeon Flux has philosophical themes in common with Ghost in the Shell, e.g. the issue of memory and personality persistence across multiple/artificial bodies. Hence also its succession by an article on cyborg (bodies) makes sense, in this context.

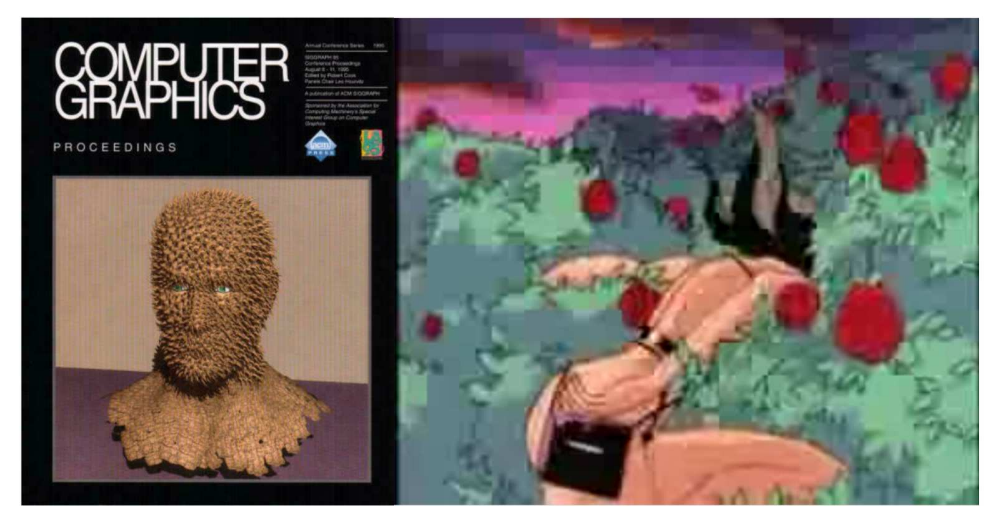

Illustration : SIGGRAPH Proceedings 1995; Aeon Flux (1991-1995)

One part of their publishing activity consisted in re-publishing and bringing to a new audience and generation classic pieces of hacker literature (such as in part. "Hacker Conscience" by The Mentor, from magazine Phrack); 
At other times it published excerpts from works it thought interesting (such as Cronenberg on Cronenberg in 8)

Issue 7 was short (110 pages, compared with over 130 for both preceding issues) and belongs to the weakest. It marked a first sign of decline.

Issue 8 was better : Sarfatti and Herbert were in conversation, exerts of a book on Cronenberg...

Issue 9 was arguably the last bang before the end : it included the second article on PGP, Linklater...

Issue 10 had old guests among whom Terence Mckenna (as if to say goodbye).

\section{4 symbolic end}

In issue 11, R. U. Sirius became an "Icon-at-Large", Jude Milhon was downgraded to "Cyberpranx" editor. ${ }^{15}$

Issue 12 was the infamous Paul McEnery issue : Paul McEnery speaks. Paul McEnery on Paul McEnery. Paul McEnery on the importance of Paul McEnery... ${ }^{16}$

Meanwhile, remaining long-time staff Wes Thomas and Jas. Morgan attempted to maintain the old editorial line. But, no St. Jude, no R.U. Sirius, the magazine is dead. is mentioned

In issue 11, already, Wired $I$ and the new Mondo seems to associate themselves with them, as if equals. ${ }^{17}$

In 1992, the magazine published its first book ( $A$ User's Guide to the New Edge.

The same year Boing Boing published a parody of the magazine's -now recognizable- format and style.

In 1993, a weak Mondo issue appeared with mostly forgettable pieces (10).

Mondo had done so well (in the genre it had created for itself) that it outdid itself and made itself useless. Now every magazine was a "mondozine". The most baffling example being Time Magazin'es february 1993 issue on... "Cyberpunk" (realized by some of Mondo's staff).

In 1995, the Cyberpunk Handbook: The Real Cyberpunk Fakebook was published at Random House (ed. R.U. Sirius).

A few years later Mondo stopped publication altogether.

\section{5 final stages of professionalization}

The design of Mondo reached new heights with art director Bart Nagel.

The table of contents of issue 2 - in which he appears credited - becomes notably more stylized (compare with the first issue).

\footnotetext{
${ }^{15}$ By 1995, R. U. Sirius had still the emeritus status of "icon at large" while Jude Milhon leaned way as "contributor editor" (14?).

${ }^{16}$ In case some readers wondered also "whoever that is, and whatever hole he crawled out of" : he was in 10-11.

17 p. 35
} 
When Milhon is promoted to Senior Editor in issue 5 she uses "Jude Milhon" for credits, rather than St. Jude.

Issue 9's most profound change is the introduction of the category of 'tech editor' (given to early collaborator Wes Thomas (writer and publicity for the first two issues). Another sign of many, of professionalism displayed outwardly.

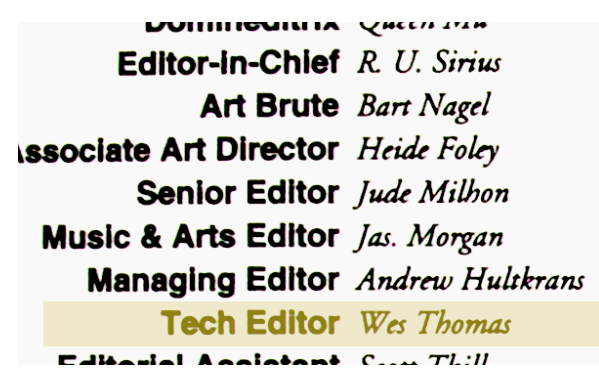

Illustration : issue 9 Mondo 2000 (staff section) 


\title{
4 wired : into the 2000s
}

Early articles were written by former Mondo 2000 staff or contributors.

Its style was clearly inspired by Mondo's (formatting table of contents, reader feedback, sections and columns e.g. "Electrosphere"...).

WIred marked yet another step towards professionalization : it emerged as a publication where cool ads - as seen prev. in Mondo ${ }^{18}$ - were becoming aggressively omnipresent almost indistinguishable from the edgy articles that appeared in-between them. Ads such as by Intel, Digital DEC (comparing themselves to a high-speed train...), HP, luxury cars, CK, Guess jeans, drinks etc. could be found ad nauseam on the inside.

\section{1 the first five years}

While already much more mainstream than Mondo 2000, Wired continued at least in the first 5 to 7 years to publish uneasy pieces : Among them were now classics, many due to Mondo's collaborators :

In 1993, Gibson's "Disneyland with the death penality" appeared, describing his impressions of Singapore as a mix of super sophisticated tech and very strict laws, customs.

In 1994, R. U. Sirius and St. Jude could be found among few writers.

\section{The Medium is the Message and the Message is Voyeurism}

\author{
By R.U. Sirius with St. Jude \\ he's permed, chubby, hose 'n' heels... Mom. She stands and girls - criminals, perverts, or cultural dissidents - \\ Illustration : Wired 19942
}

In that same year, John Barlow was also represented ("Jackboots on the Infobahn", 4), who described Clipper as "last ditch attempt by the United States, the last great power from the old Industrial Era, to establish imperial control over cyberspace."

R. U. Sirius published a stand alone article ("Pomo To Go"), in 6.

In 1995, St. Jude gave a noted interview, containing the famous quote, "Girls need modems." 19

\footnotetext{
${ }^{18}$ See the ads of companies like Sense- 8 or Lapis...
${ }^{19} 2$.
} 


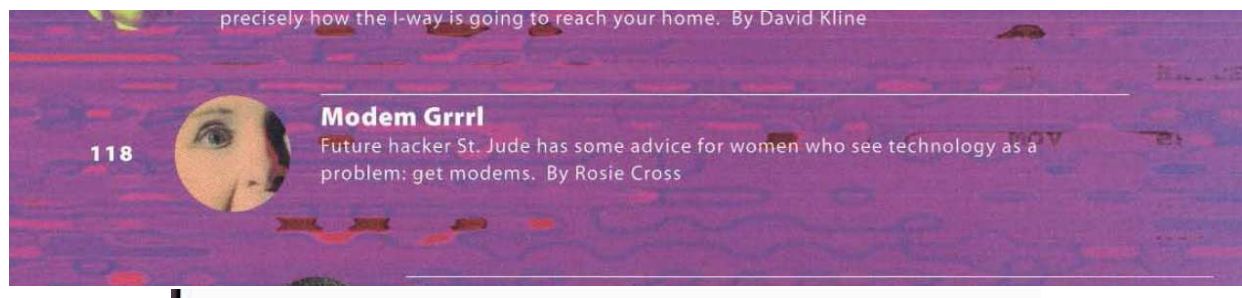

Wired: What do you think about feminism and technology?

St. Jude: I think tech will solve all our problems, personal

and scientific. Girls need modems.

Illustration : Wired 1995 2, contents and interior

Eno became one of the covers of 1995 (\#5).

In 1996 Wired called the "Fall of the EFF" on its cover.

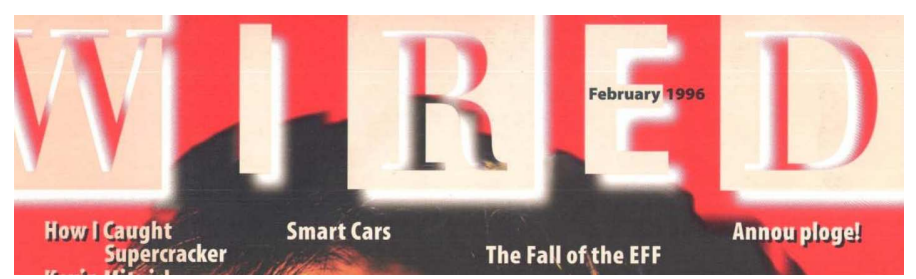

Illustration : Wired 1996 2, cover and contents

The Electronic Frontier Foundation went to Washington to "hack politics

down to its constituent parts." Then it helped pass the FBI's loathsome

Digital Telephony Bill. And discovered it was Washington that had reverse engineered the EFF, driving it into dissension, debt, disgrace - and right out of town.

Mondo's love affair with Barlow and the EFF came here to a stop if not an end.

Their critique targeted the (admitedly risible) liberal's never dying dream of "changing things from the inside", as they say, until the inside changes them invariably. Aaron Swartz belonged for much of his life - except arguably the end - to this unfortunate category. Cory Doctorow is another such figure, whose pathological interest in reformist politics would be deserving of a new inferno circle.

In 1996, still, Levy's hard hitting "Clipper chick" appeared - a play on words about a certain female cryptographer (due to cozy relationships with NSA).

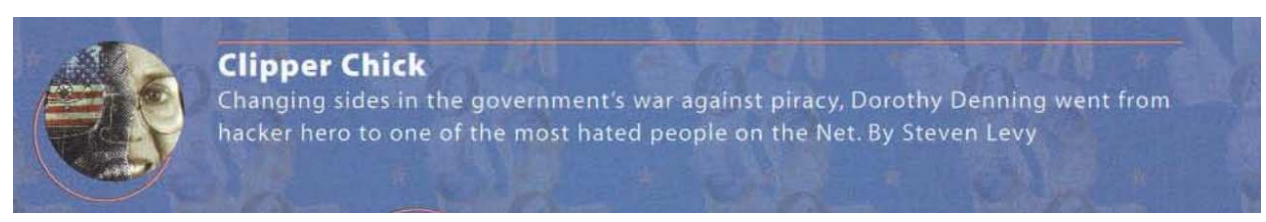

Illustration : Wired 19969 
Although "soft" by Reality Hackers standards, multiple of these articles would be probably difficult to publish today (except R.U. Sirius' forray into anti-communist cultural essays, that one not).

\section{2 the professional journalists}
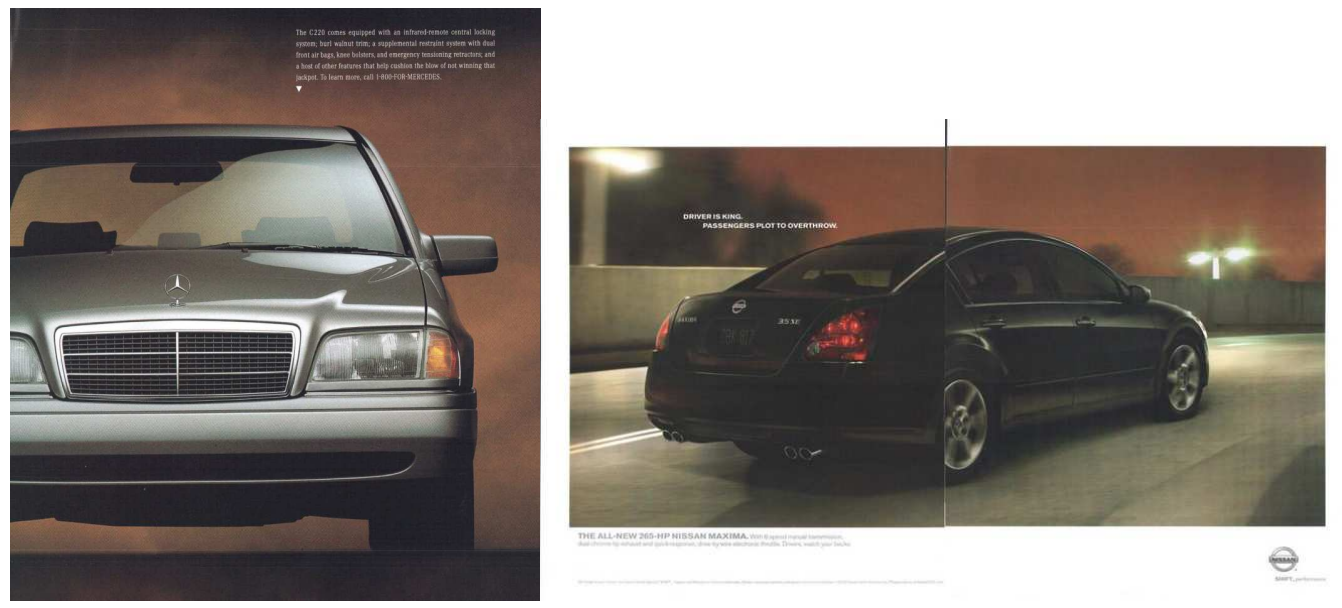

Illustration : ad examples $(1996,2003)$ Wired

The last phase past the few first years of existence of the magazine is one of rapid corporatization and turn towards the mainstream - coinciding with its sale and massive editorial change.

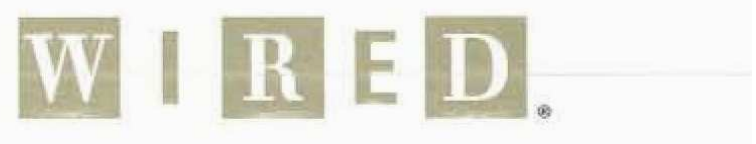

Editor in Chief: Chris Anderson

Illustration : staff (2002) Wired

Cool ads meet - sometimes indistinguishable - edgy articles, was the new formula of this magazine, culminating in the sale to Conde Nast in 1998 and the new millenium, Chris Anderson (Mr. equations) line and era.

"We decided to put the Internet-founding subculture behind us, and be more mainstream with technology. We banned Burning Man and drug culture and the letters TCP/IP,"

Anderson said. ${ }^{20}$

20"For Wired, a Revival Lacks Ads", New York Times 17/05/09. 
The mummification, the museufication of the original hackers behind Wired's formula hence could begin :

In 2003, St. Jude's death notice was published..$^{21}$

First signs of this shift were already visible in previous years (historical classifications, however useful, should not be too rigid, or be blinding) ;

this was in part. true in instances such as the interview of Steve Jobs ("the next insanely great thing" ${ }^{22}$ ) or when Wired's, now professional journalists called Ray Smith of Bell "the smartest telco CEO" 23 .

Journalists' role was not anymore to highlight the fringes of technology, it was not to shed light on what happened in the shadows of mega-corporations, it was not publishing seldom heard voices in the service of, ex gratia, democracy.

No, it would be to amplify already deafening tones, and for journalists to become the faithful stenographers of new-lords, from now on.

\section{conclusion}

During glorious live-fast-or-die existences , the publications High Frontiers, Reality Hackers and Mondo 2000 managed to do many things :

One of Mondo's achievements - in an era before diversity and inclusion politics and rhetoric - was to create an intellectual space where pioneering hackers and crackers met hip hop groups, trans. artists, outsider scientists...; thus creating a truly diverse and unique location in space and time - accessible infinitely through archives - that stands in bitter, bitter, oh so stark contrast with most journals and magazines published today.

Those courageous few who want the more sweat-inducing content of earlier years will find a way to back issues of " $H$ " and "R".

As the magazine evolved to become Mondo, its interest in and liberal attitude towards conspiracy, alternative and uncertain theories would play a bigger and bigger role (except My Dinner... would be replaced by more timely Slacker).

In its golden age (issues 1 to 11 - as now everyone knows), Mondo maintained a complicated balance between fringe roots and increased interest, content that remained truly shocking at times while not risking liberal consensus rejection (maybe it was just fun, or a joke!). ${ }^{24}$

This publication will no doubt come as a shock to all-thebest-opinions blessed liberals, found in such great masses in dominant places.

It treats alternative beliefs and theories cautiously, perhaps based on the intuition if not knowledge that some of yesterday's egregious madmen are tomor- 
row geniuses, and that today's truth is still not safe from the long, fermenting work of history. 


\title{
Introducing Mondo 2000 and its predecessors to a new audience - working research documents.
}

\author{
Camille Akmut
}

February 13, 2022

\begin{abstract}
An overview relating to staff, authors, contributors, institutions and events is provided, as well as table of contents for issues 1 to 11 of Mondo 2000, 5 and 6 of Reality Hackers, and 4 of High Frontiers; covering pre-history, beginnings all the way up to "symbolic" end of this hacker magazine which originated as a drug, science, art newspaper.
\end{abstract}

Note : references to issues of High Frontiers and Reality Hackers are preceded by the mention of $\mathrm{H}$ and $\mathrm{R}$ respectively. When nothing is specified, or cannot be derived obviously from the content, $\mathrm{M}$ is meant (standing in place for Mondo). 
R. U. Sirius / Ken Goffman

Queen Mu / Alison Kennedy

St. Jude / Jude Milhon

\section{Morgan Russell}

\section{Bart Nagel Thaddeus Now, Roger Raupp Jas. Morgan Michael Synergy \\ Heide Foley Wes Thomas Uncle St. Nunzio \\ Allan Lundell Andrew Hultkrans Gareth Branwyn Joey/Joichi Ito Timothy Leary Nick Herbert}

Gracie and Zarkov "Durk and Sandy" Rudy Rucker John Perry Barlow Robert Anton Wilson

Mark Dery Terence McKenna

\section{Jack Sarfatti Brian Eno}

Peter Lamborn Wilson / Hakim

Bey

Ram Dass

Sun Ra

Lee Felsenstein

Richard Stallman

Vernor Vinge

Abbie Hoffman

Genesis P. Orridge

Saul-Paul Sirag

Somerset Mau Mau

Sense-8
Editor-In-Chief. Becomes "Icon-at-Large" from \#11. Ken Goffman was a Publisher in Reality Hackers (R 5,6). R.U.Sirius listed on the cover of High Frontiers" "premier issue"

Credited as Domineditrix (above Editor-in-Chief in M). Alison Kennedy appeared in the first issue under "Design \& Layout", in \#2 a writer ("Grammar..."); Publisher, Proofreading, Advertising Sales in Reality Hackers (R 5,6) Publisher in H (at least 4), Domineditrix $(\ldots 3,4)$

First issue note: "Her racy tale is chronicled in the book Hackers but she prefers to maintain a mysteriously low profile." Senior Editor $(\geq$ \#5), "Cyberpranx" in 11. Column "Irresponsible Journalism" (4-8,11). Was Editor in Reality Hackers (R 6), Proofreading (R 5).

Publisher and Editor in Reality Hackers (R 5,6). In M : Associate

Editor (\#1), "European Correspondent" (3)

Art Director of Mondo

Art Director of Reality Hackers (R 5,6)

Music Editor, later also "Music \& Arts" (from M \#7)

Associate (\#1,2,4), Editor (3) then Contributing (5-8, not in 9-10)

Associate Art Director (from \#7), Deputy (6), Design Assistance (2-5)

Tech Editor (\#9-10), Editor (11), PR/Publicity (1,2,7 ..). "Hyperwebs"

Managing Editor of Reality Hackers (R 5,6)

Listed as "Future Media" in \#1.

Managing Editor (from \#5)

Street Tech Editor (from \#4, not in 9-10)

"Tokyo Correspondent" (\#3-11) [versatile, academic entrepreneur]

Contributing Editor (\#4-11...). Drug expert/leader

Column "Fringe Science" (H 4; R 6; M \#1-7,9 not 10-11). Contributing

Editor (11). Quantum Reality. Fundamental Fysiks Group

Contributing Editor (\#4-11...) (culture reviews)

D. Pearson, S. Shaw. Column (\#1-4) 'life extension(s)' 'designer foods'.. Contributing Editor (...\#9). Ed. for A User's Guide to the New Edge

Contributing Editor (\#4-5,7-11...). Grateful Dead, EFF

Column (\#1-3). SF author, futurist... (assoc. with Leary, Sirag)

Column "Guerrilla Semiotics" (\#5-7...)

Drug guru/philosopher, researcher, etc.

Fundamental Fysiks Group

Artist (generative art system, "non-musician", Another Green World, Before and After Science, Bowie's Low and other Berlin albums etc etc.) anarchist, Temporary Autonomous Zone

guru, professor (assoc. w. Leary)

Artist

One of the original hackers. Homebrew Computer Club, Community

Memory project

Free software, GNU, FSF, 'last true hacker'

Science-fiction author, A Fire Upon the Deep (1992) ('singularity')

Youth International Party, Chicago Seven

Pioneering trans. artist

Fundamental Fysiks Group

Listed on the cover of High Frontiers" "premier issue" with R.U. Sirius, resurfaces in Mondo's eigth issue

Company advertised in Mondo 2000
$\mathrm{H}, \mathrm{R}, \mathrm{M}$

H, R, M

$\mathrm{H}, \mathrm{R}, \mathrm{M}$

H, R, M

M (cred. from \#2)

$\mathrm{R}$

R, M

R. M

M (... from 2)

$\mathrm{M}$

$\mathrm{R}$

R 4, M

$\mathrm{M}$ (appears in 4)

$\mathrm{M}$ (from 2)

$\mathrm{M}($ in $\# 3)$

$\mathrm{H} 1,4 ; \mathrm{R} 5,6 ; \mathrm{M}$

H 2,4; R 5,6; M

R 6, M

R 5,6ad/ref; M $\mathrm{M}$

M $2,3 \ldots$

$\mathrm{H} 2$; $\mathrm{M}$

M (from 5)

H 1,2,4; R 5,6; M 1,10

H 1, M 8

R 6; M 4

R 6 end; M 5 end, 9

H 2

R 6

M 1, 2, see, also, Hackers part two M 1, 4, Hackers end

M 1

M 1 end quote M 3, ref 6:124, 9 M 3

H 1,4; M 


\section{Stephen Wolfram SIGGRAPH \\ HR 4079}

\section{Dr. Forshan \\ Digital \\ Underground \\ Phil Zimmermann \\ Jeff Milstead \\ Fiorella Terenzi \\ Peter Chung \\ Henry Rollins \\ Neil Young \\ KRS-One \\ Neal Stephenson \\ David Cronenberg}

\section{Lydia Lunch \\ Richard Linklater}

Iggy Pop (proprietary) Mathematica software, known to students

Important computer graphics conference (one of the ACM S.I.G.s)

National Drug and Crime Emergency Act - "prisoners may be housed in tents and other temporary facilities", "prisoners shall work absent medical certification of 100 percent disability" congress.gov

$80 \$$ a month, $19 \%$ interest breasts

Hip-hop group (associated with Tupac)

Creator of PGP [encryption for the masses], hailed as hero by the magazine

M 4:20 footnote

Astrophysicist

Animator : Aeon Flux, The Animatrix...

Black Flag

Went from touching songs, to unrecognizable hippies-and-queers hating

Reaganite, to liberal.

"Hip means to know", Hop means to move

Snow Crash (1992)

Scanners, Videodrome... as well as lesser known movies on

transgenderism, crossdressing and homosexuality in the Chinese

tradition ("Cut sleeve").

artist (associated, a.o., with Sonic Youth)

Slacker (1990) [b.], Dazed and Confused (1993)... Themes : youth, underground, alternative beliefs - in common with the magazine's

The Stooges ("I Wanna Be Your Dog"), dislikes clothes
R 6 ref, M 3

M 3...

M 3

M 3:100

M 4

M 5,9,10(v 1.0,2)

M 5 cover and interview

M 6

M 6

M 6

M 7

M 7 review

M 8

M 9

M 9

M 11

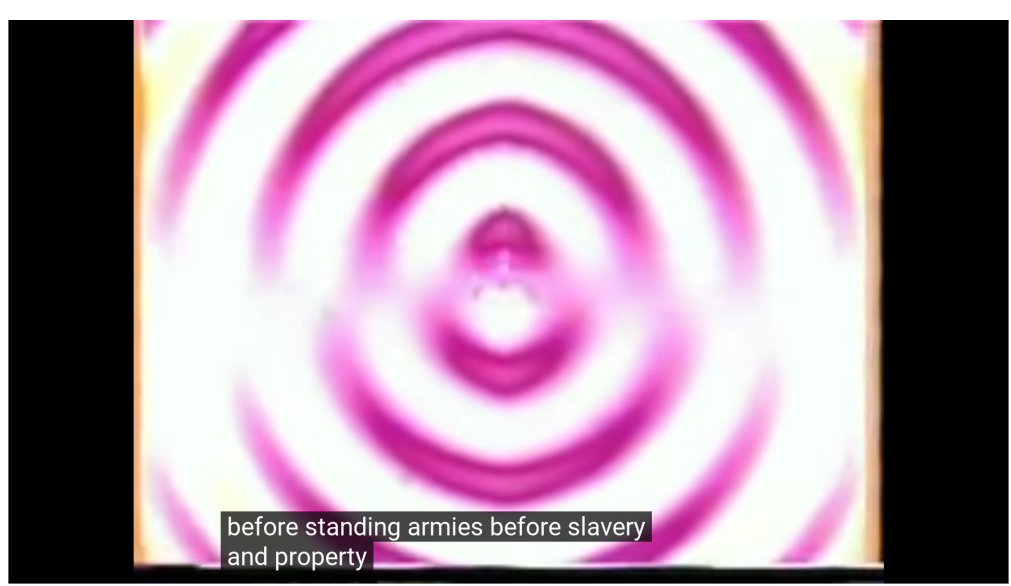

Illustration : Alien Dreamtime

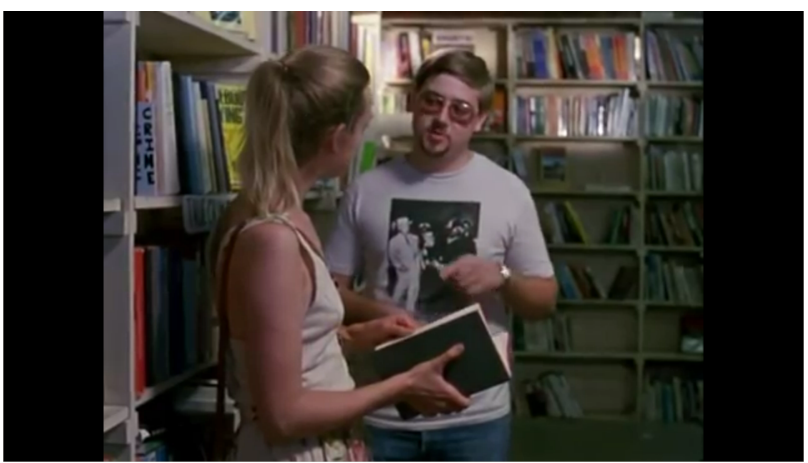

Illustration : 'real crimes' afficionado segment in Slacker

(a.k.a. hey, remember, we had an anthropology class together...)

- But, then, of course, there's my real favorite one right here. Which you really should snap up 